\title{
EPIDEMIOLOGIA DAS LEISHMANIOSES NO SUL DO ESTADO DE MINAS GERAIS, BRASIL: ASPECTOS REFERENTES À TRANSMISSÃO VETORIAL (DIPTERA, PSYCHODIDAE, PHLEBOTOMINAE)
}

\section{CARLOS FREDERICO LOIOLA}

Tese de Doutorado apresentada ao Departamento de Epidemiologia da Faculdade de Saúde Pública da Universidade de São Paulo para a obtenção do título de "Doutor em Saúde Pública".

Área de Concentração: Epidemiologia

Orientadora: Profa. Dra. Eunice Aparecida Bianchi Galati

São Paulo

2003

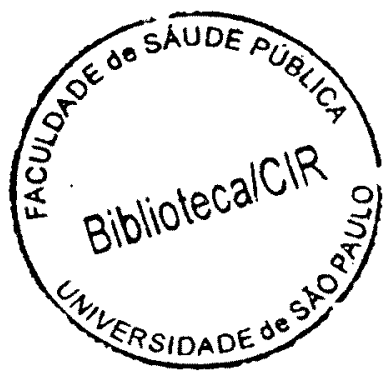


Autorizo, exclusivamente para fins acadêmicos e científicos, a reprodução total ou parcial destatese, por processos fotocopiadgres.

Assinatura:

Data: $10 / 10 \% 2003$ 
Minas não é palavra montanhosa É palavra abissal. Minas é dentro e fundo. As montanhas escondem o que é Minas. No alto mais celeste, subterrânea.

É galeria vertical varando o ferro Para chegar onde ninguém sabe onde.

Ninguém sabe Minas A pedra O buriti A carranca $O$ nevoeiro O raio Selam a verdade primeira, sepultada em eras geológicas de sonho.

Só os mineiros sabem. E não dizem nem a si mesmos o irrevelável segredo chamado Minas

Carlos Drummond de Andrade 
Dedicatória

Aos meus queridos e amados,

Carlos e Lúcia,

Pai e Mãe.

Sempre presentes de um modo muito especial. Incentivando, acreditando, apoiando, zelando e orando. 
Dedicatória especial

À Valéria e ao Felipe.

Minhas pedras preciosas nestas Minas Gerais de tantos segredos e maravilhas. Pelo carinho, amor, segurança, cumplicidade, companheirismo, apoio e confiança. Pelas ausências e pelo compromisso com a nossa Felicidade. 
AGRADECIMENTOS 
À professora Dra. Eunice Galati, minha primeira orientadora de verdade, pela prestimosa orientação, pela confiança, credibilidade, pelo grande apoio e pelo exemplo do que é ser um mestre do saber, com humildade, sabedoria e riqueza.

Aos professores Dr. Delsio Natal e Dr. José Maria Soares Barata, pelo apoio, sugestões e amizade.

Ao professor Dr. Almério de Castro Gomes pelas sugestões e incentivo, como mestre e como chefe do Departamento de Epidemiologia da FSP/USP.

Aos amigos e colegas Paulo e Waltinho, pelos agradáveis momentos de descontrações e pelo grande apoio durante a época dos créditos.

À amiga Ana Maria, por sua presteza e carinho e por nossos momentos de coleguismo durante os créditos.

À Rute, pelos momentos de contribuições, sugestões e descontrações no laboratório.

À Edna pelo apoio no laboratório, na orientação prática de montagens e clarificação dos insetos.

A todos os funcionários do Departamento de Epidemiologia da FSP/USP, que contribuíram, de alguma maneira, para nossa estada em São Paulo, em vários momentos nestes quatro anos.

Aos funcionários das secretarias de Pós-Graduação e de apoio acadêmico da FSP/USP, nas pessoas da Ângela e da Cidinha, pelas orientações e encaminhamentos.

À Universidade José do Rosário Vellano - UNIFENAS, nas pessoas do professor Hudson Bianchini e da professora Marlene Godoy, que desde o inicio nos apoiaram e acreditaram na realização deste estudo. 
Aos colegas e amigos da UNIFENAS, que compartilham desta conquista e desta oportunidade de ensinar e aprender ao mesmo tempo.

A Secretaria Estadual de Saúde de Minas Gerais, na pessoa da prestativa Médica Veterinária Simone, responsável pelo controle das Leishmanioses no Estado, pelo valioso apoio no fornecimento dos dados de notificação de casos de LTA e LVA em Minas Gerais.

À Companhia Energética de Minas Gerais, através do seu departamento de climatologia, pelo fornecimento dos dados climatológicos utilizadas na análise dos resultados apresentados neste estudo.

Aos meus queridos alunos, amigos e companheiros, Delano, Eduardo, João (Mãozinha I), Marcony, Melissa, Werton (Mãozinha II), por suas abnegações, disponibilidades e responsabilidades, nos trabalhos de campo e no laboratório, sem os quais este estudo não poderia ter sido concluído, pois "a maior alegria de um mestre é ser superado por seus discípulos".

A minha querida e amada família, Pai, Mãe, Dani, Leo, Cida, Moara, Taninha, Fernandinho, Vaninha, Adriano, Débora e Marina, por todo o apoio, incentivo e pela confiança.

Aos meus queridos Valdevino, Neli, Vanderleia, Márcio, Nádia, Hilário e Gabriel, pelo imensurável apoio familiar e pela compreensão nos momentos de ausências e angústias.

A todos que de alguma forma contribuiram para que este trabalho pudesse ser concretizado.

A Deus, que é a luz no caminho e o perdão na escuridão. 
RESUMO 
Loiola CF. EPIDEMIOLOGIA DAS LEISHMANIOSES NO SUL DO ESTADO DE MINAS GERAIS, BRASIL: ASPECTOS REFERENTES À TRANSMISSÃO VETORIAL (DIPTERA, PSYCHODIDAE, PHLEBOTOMINAE). São Paulo, 2003. [Tese de Doutorado - Faculdade de Saúde Pública da Universidade de São Paulo].

O conhecimento da fauna flebotomínica é um importância fundamental para a compreensão da epidemiologia das Leishmanioses, pois, entre os fatores determinantes dessas zoonoses, encontra-se a interação deste grupo com os seus agentes etiológicos, com o ambiente e com os reservatórios silvestres e domésticos. Com o objetivo de se identificar a fauna destes dipteros hematófagos no sul do Estado de Minas Gerais, selecionou-se quatro municipios (Caldas, Conceição da Aparecida, Jacutinga e Machado) com incidência conhecida e posicionados em diferentes pontos em relação à Serra da Mantiqueira. Nestes foram realizadas as pesquisas entomológicas, que objetivaram, dentre outros, determinar a presença das espécies, frente aos casos humanos das enfermidades, com exceção do município de Caldas, onde não foi notificado nenhum caso de Leishmaniose, até a presente data. Outros objetivos foram relacionados ao estudo da ecologia das populações flebotomínicas amostradas e tentativa de relacionar aspectos comportamentais da mesma com os fatores climáticos e áreas de ocorrência da leishmaniose tegumentar. A pesquisa foi realizada em 18 meses, com capturas mensais nos quatro municípios, em ambiente domiciliar e extradomiciliar com armadilhas automáticas luminosas tipo $\mathrm{CDC}$ e a armadilha de Shannon. Como resultado foi capturado um total de 1.949 flebotomíneos, distribuídos em vinte espécies 
sendo elas: Nyssomyia whitmani; Nyssomyia intermedia; Nyssomyia neivai; Pintomyia monticola; Pintomyia fischeri, Pintomyia bianchigalatiae; Pintomyia misionensis; Psathyromyia brasiliensis; Psathyromyia aragaoi; Migonemyia migonei; Evandromyia lenti; Evandromyia sallesi; Evandromyia termitophila; Psychodopygus Iloydi; Psychodopygus davisi; Lutzomyia longipalpis; Brumptomyia brumpti; Brumptomyia cardosoi; Brumptomyia nitzulescui; e Brumptomyia sp. Além das pesquisas entomológicas foi realizada uma análise do Coeficiente de Incidência Acumulada de 128 municípios pertencentes aos Regionais de Saúde, componentes da região Sul do Estado de Minas Gerais. Dentre as espécies capturadas destaca-se a presença, pela primeira vez na região, da Lutzomyia longipalpis. Outro fato é o encontro em simpatria, das espécies $N y$. intermedia e $N y$. neivai. Os resultados das capturas em Caldas foram negativos, corroborando com a inexistência de casos de leishmanioses neste municipio. Possivelmente, a ausência de flebotomíneos em Caldas esteja relacionada ao solo vulcânico da área onde se insere o município, levando a interferências no desenvolvimento das formas imaturas. Por fim, este estudo possibilitou a caracterização da distribuição das espécies e de vários outros aspectos ecológicos da fauna na região, bem como de seus possiveis papéis como vetores no sul de Minas, frente aos Coeficientes de Incidência obtidos. 
SUMMARY 
Loiola CF. EPIDEMIOLOGY OF THE LEISHMANIASES IN THE REGION OF

MINAS GERAIS STATE, BRAZIL: VECTORIAL ASPECTS OF TRANSMISSION (DIPTERA, PSYCHODIDAE, PHLEBOTOMINAE) São Paulo, 2003 [Tese de Doutorado - Faculdade de Saúde Pública da Universidade de São Paulo].

knowledge of the sand fly fauna is one of the main prerequisites for the understanding of the epidemiology of the Leishmaniases, since, among the determinants of these zoonoses are the interaction of this group of insects with the Leishmania, with the environment and with wild and domestic reservoirs. The may objectives were to identify the phlebotomine fauna and its relation to the occurrence of human cases of leishmaniases in the Southern region of Minas Gerais State, four counties: Jacutinga, Conceição da Aparecida, and Machado, all with known incidence of cutaneous leishmaniasis and Caldas, where no case of leishmaniasis has so far been notified, were sampled. Jacutinga county is located to the south and Conceição da Aparecida and Machado to the north of the Mantiqueira mountain while Caldas is on the top of the range. Monthly captures were made during 18 months, with CDC light traps and the Shannon traps. A total of 1,949 sand flies was captured, belonging to 20 species: Nyssomyia whitmani; Nyssomyia intermedia; Nyssomyia neivai; Pintomyia monticola; Pintomyia fischeri; Pintomyia bianchigalatiae; Pintomyia misionensis; Psathyromyia brasiliensis; Psathyromyia aragaoi; Migonemyia migonei; Evandromyia lenti; Evandromyia sallesi; Evandromyia termitophila; Psychodopygus Iloydi; Psychodopygus davisi; Lutzomyia longipalpis; Brumptomyia brumpti; Brumptomyia cardosoi; Brumptomyia nitzulescui; e 
Brumptomyia sp. Besides the entomological studies the Accumulated Incidence Coefficient of cutaneous leishmaniasis in the 128 cities included in the administrative health district of the southn region of the State of Minas Gerais was analysed. Lutzomyia longipalpis was captured in the region for the first time and the occurrence in sympatry of $\mathrm{Ny}$. intermedia and $\mathrm{Ny}$. neivai. is recorded. No sandflies were captured in Caldas. This results is in keeping with the lack of any record of leishmaniasis in the county. The absence of phlebotomines in Caldas is probably due to the volcanic soil of the area in which this county is situated, which may hinder the development of the their immature stages. The characterisation of the distribution of the species and several other ecological aspects of the sand fly fauna of the region was made, and suspicions raised as to possible vectors of Leishmania in the South of Minas Gerais, based on the recorded incidence of the disease. 
ÍNDICE 
$\begin{array}{ll}\text { 1. INTRODUÇÃO } & 01\end{array}$

1.1. Os flebotomíneos 02

1.2. As Leishmanioses nas Américas 06

1.2.1. Etiologia 06

1.2.2. A Leishmaniose Visceral Americana (LVA) no Brasil 07

1.2.3. A Leishmaniose Tegumentar Americana (LTA)

no Brasil $\quad 09$

1.2.4. As Leishmanioses em Minas Gerais $\quad 11$

1.3. Os Flebotomíneos e as Leishmanioses 13

$\begin{array}{ll}\text { 2. JUSTIFICATIVA } & 14\end{array}$

3. OBJETIVOS 17

3.1. OBJETIVO GERAL 18

3.2. OBJETIVOS ESPECÍFICOS 18

4. MATERIAL E MÉTODOS 19

4.1. Áreas de estudo 20

4.2. Coeficiente de Incidência Média 28

4.3. Dados climatológicos 29

4.4. Inquérito entomológico 29

4.4.1. Técnica de capturas e procedimentos para a identificação $\quad 31$

4.4.2. Cálculo da diversidade de espécies 33

4.4.3. Cálculo do indice de abundância de espécies 34 
4.4.4. Cálculo do Índice de Similaridade entre as localidades pesquisadas

4.4.5. Cálculo da Média de Williams

4.4.5.1. Avaliação do periodo de atividade, ou freqüência horária das espécies

4.4.6. Análise da variação sazonal das espécies

5. RESULTADOS

5.1. Coeficiente de Incidência Acumulada nos Regionais de Saúde da Região Sul de Minas Gerais

5.2. Composição das espécies capturadas nos municípios pesquisados

5.3. Composição das espécies capturadas, por armadilhas e por sexo

5.4. Composição das espécies capturadas através da armadilha automática luminosa, tipo CDC, por ecótopos e por sexo 50

5.5. Distribuição sazonal de flebotomíneos capturados e os dados climatológicos

5.6. Freqüência horária noturna

5.7. Índice de abundância de espécies 66

5.8. IÍndice de Similaridade entre os ecótopos das localidades pesquisadas 69

5.9. Índice de Diversidade das espécies capturadas 
6. DISCUSSÃO

7. CONCLUSÕES

9. ANEXOS

ANEXO 01 - Fotos de satélite localizando a sede municipal de Jacutinga

ANEXO 02 - Fotos de satélite localizando a sede municipal de Machado

ANEXO 03 - Fotos de satélite localizando a sede municipal de Conceição da Aparecida

ANEXO 04 - Fotos de satélite localizando a sede municipal de Caldas

ANEXO 05 - Fotos de satélite localizando a Serra da Mantiqueira

ANEXO 06 - Fotos da armadilha automática luminosa tipo CDC 99 ANEXO 07 - Fotos da armadilha Shannon 
1. INTRODUÇÃO 
As leishmanioses são parasitoses que em suas etiologias participam várias espécies do gênero Leishmania, cujo parasitismo pode levar a manifestaçōes clínicas nas formas visceral, tegumentar e mucocutânea em hospedeiros de diversos grupos de mamíferos, sendo transmitidas por flebotomíneos, dípteros da família Psychodidae.

Essas zoonoses estão amplamente difundidas pelos continentes asiático, africano, europeu e americano, com 350 milhões de pessoas vivendo em áreas de risco e 12 milhões de infectados (WHO 1990). A incidência das leishmanioses no mundo é estimada em $\mathbf{4 0 0}$ mil casos/ano, dos quais, 300 mil referem-se à Leishmaniose Visceral (ASHFORD et al. 1992).

\subsection{Os Flebotomíneos}

Os flebotomíneos constituem um grupo de insetos de origem antiga, com registros fósseis datando de cerca de 120 milhões de anos (HENNIG, 1972). Estão distribuídos por todos os continentes, sendo descritas no mundo aproximadamente 800 espécies, das quais, 470 ocorrem nas Américas e metade delas no Brasil (GALATI 2003). A distribuição dos flebotomineos nas Américas se estende desde o sul do Canadá até o sudeste da Argentina (MARTINS e MORALES-FARIAS 1972; MUZÓN et al. 2002). Algumas espécies apresentam ampla distribuição geográfica, outras são mais restritas a uma região, com distribuição local e até mesmo focal (REBÊLO et al. 1996).

No Brasil, os flebotomíneos ocorrem em todos os Estados (MARTINS et al. 1978; YOUNG e DUNCAN 1994). Sendo popularmente denominados como asa branca, birigui, cangalhinha, flebótomo (ou fleboti), mosquito-palha e 
tatuquira (FORATTINI 1973). Essa variedade de nomes populares mostra como um leigo pode distinguí-los de outros insetos hematófagos.

As suas formas imaturas desenvolvem-se em solo úmido, ao abrigo da luz direta, rico em matéria orgânica, encontrado entre raízes expostas, em baixo de folhas caidas e de pedras, em gretas de rochas, tocas de animais e no ambiente antrópico, em chiqueiro, galinheiro ou outros ecótopos em que as condições adequadas se fizerem presentes (FORATTINI 1973).

Ambos os sexos necessitam de açúcares em sua dieta. Embora existam relatos de encontros de machos com sangue em seu tubo digestivo (GONTIJO et al. 1987; SILVA e GRÜNEWALD 1999) apenas as fêmeas são consideradas hematófagas, picando um largo espectro de animais representados por mamíferos, aves e também animais de sangue frio (TESH et al. 1972; NGUMBI et al. 1992; MORRISON et al. 1993; OGOSUKU et al. 1994; COLMENARES et al. 1995)

A atividade hematofágica de maneira predominante é noturna, mas também podem ocorrer durante o dia (GOMES et al. 1989a; GALATI et al. 1999a). As formas aladas abrigam-se nos mesmos locais de criadouros ou em tronco de árvores e folhas de arbustos ou entre o folhedo caído no chão. Ambos os sexos tendem a não se afastarem muito dos seus criadouros ou locais de abrigos, embora possam ser capturados até cerca de $1 \mathrm{Km}$ do ponto de soltura, com a maioria não indo além dos 250 m (MORRISON et al. 1993).

Entre os flebotomíneos americanos, cerca de 60 espécies (13\%), podem sugar sangue do homem ou ainda estarem associadas às condições ambientais que o homem vem criando na sua busca pela sobrevivência e pela produtividade (YOUNG e DUNCAN 1994). Dentre eles são encontradas as 
espécies vetoras de Leishmania, causadoras de Leishmaniose Tegumentar Americana (LTA) e Leishmaniose Visceral Americana (LVA).

Os flebotomíneos apresentam importância médica, não só pelo fato de atuarem como vetores de arboviroses, bartonelose e das leishmanioses, como também por serem incluídos como insetos importunos, devido à sua picada dolorida, com freqüentes reaçōes alérgicas.

Também foram isolados do tubo digestivo de flebotomíneos, tripanosomatídeos de importância para o homem, ainda por esclarecer, pertencentes aos subgêneros Herpetosoma e Megatrypanum (MILES et al. 1983; NAIFF et al. 1989).

Entre os parâmetros que norteiam a incriminação de uma espécie como vetora de determinada parasitose, além da distribuição geográfica coincidente com a da doença e da competência vetorial, são fatores relevantes, o seu grau de relacionamento com os reservatórios e/ou homem, densidade e taxa de infecção natural pelo parasito. Em relação a esta, entre os flebotomíneos, a infecção por flagelados, em áreas endêmicas de leishmaniose tegumentar, apresenta-se entre $0,01 \%$ e $0,2 \%$ (BARRETTO 1943; CASANOVA et al. 1995, GALATI et al. 1996).

As infecções concomitantes produzidas por bactérias, fungos e protozoários não flagelados, no tubo digestivo dos flebotomíneos, podem tanto reduzir a população destes insetos quanto inibir o desenvolvimento de Leishmania. Desta forma, a presença destes microorganismos podem influenciar a suscetibilidade de flebotomíneos frente às infecções por Leishmania e transmissão dos flagelados, em uma dada região (KILLICKKENDRICK 1979). 
O conhecimento da diversidade de espécies de flebotomíneos e sua abundância relativa fazem parte dos itens necessários para a compreensão da história natural dos parasitos transmitidos por estes insetos (FELICIANGELI 1987). Além disso, são importantes também na determinação dos níveis de antropofilia e zoofilia das espécies e sua distribuição ecológica, principalmente nas áreas endêmicas para leishmanioses.

MEMMOTT (1991), em sua pesquisa sobre a distribuição e abundância de flebotomineos em uma floresta úmida na Costa Rica, também afirma que são importantes quatro aspectos nos estudos sobre fauna flebotomínica: determinação da fauna existente, o efeito da vegetação na distribuição das espécies, a distribuição vertical de cada uma das espécies em um determinado ambiente e a distribuição das espécies em seus abrigos diurnos.

Pouco se conhece sobre a distribuição ecológica das espécies de flebotomíneos, uma vez que os mesmos se distribuem de acordo com seu local de abrigo, de maneira bem focal (FORATTINI 1973). Recentemente novos estudos tentam compreender melhor esta distribuição das espécies, principalmente daquelas de importância na transmissão de Leishmania para o homem, tal como o estudo de CASANOVA (2001).

Segundo KILLICK-KENDRICK (1990), dentre os sete critérios para incriminar os potenciais vetores de Leishmania, é fundamental o encontro de promastigotas no trato digestivo dos exemplares capturados. Além disso, sua densidade populacional também tem papel importante nesta definição, principalmente associado a este primeiro fato.

Dos flebotomíneos conhecidos, apenas 81 espécies, $10 \%$ do total, têm sido implicadas como vetoras de leishmanioses (CIPA GROUP, 1999). Para 19 
destas, houve comprovação de tal capacidade, 11 no Velho Mundo, pertencentes ao gênero Phlebotomus e oito ao gênero Lutzomyia s.I., no Novo Mundo (KILLICK-KENDRICK 1990).

Um aspecto importante refere-se ao fato de um grande número de autores relatarem a possibilidade de mudanças no quadro epidemiológico das leishmanioses nas Regiões Sudeste e Sul do Brasil e de alguma forma, indicam possiveis interferências ambientais alterando o comportamento de algumas espécies de vetores, ou vetores em potencial, devido principalmente às alterações antrópicas que o meio ambiente tem sofrido nestas áreas (FORATTINI et al. 1976; BARROS et al. 1985; COUTINHO et al. 1985; FALQUETO et al. 1986; GOMES 1986; GOMES et al. 1989b; GOMES 1992; GOMES 1994; AGUILLAR et al. 1987; TEODORO et al. 1993; PASSOS et al. 1993; SOUZA et al. 1995).

\subsection{As leishmanioses nas Américas}

\subsubsection{Etiologia}

Nas Américas, atuam como agente etiológico na forma visceral a Leishmania (Leishmania) chagasi Cunha \& Chagas, 1937 e nas formas dermatotrópicas humanas, pelo menos, 11 espécies. No Brasil, estas compreendem sete: Leishmania (L) amazonensis Lainson \& Shaw, 1972, de ocorrência na região amazônica, nordeste e sul do país; L. (Viannia) guyanensis Floch, 1954; L. (V.) lainsoni Silveira, Shaw, Braga \& Ishikawa, 1987; L. (V.) naiffi Lainson \& Shaw, 1989 e L. (V.) shawi Lainson, Braga, 
Souza, Povoa \& Ishikawa, 1989, L. (V.) lindenbergi Silveira, Ishikawa, SOUZA \& Lainson, 2002 as cinco, encontradas apenas na regiāo amazônica e Leishmania (V.) braziliensis Vianna, 1911, com a mais ampla distribuição no Brasil (DIMIER-DAVID et al. 1993, SILVEIRA et al. 2002).

\subsubsection{Leishmaniose Visceral Americana (LVA) no Brasil}

A infecção pela $L$. (L.) chagasi é relativamente freqüente entre as pessoas que vivem em áreas endêmicas, porém as manifestações clínicas clássicas da LVA ocorrem, principalmente, em crianças desnutridas ou em adultos imunodeprimidos (BADARÓ et al. 1986). Em áreas brasileiras, sobretudo no Nordeste, representa importante problema de saúde pública face à gravidade dos casos e incidência em caráter esporádico ou endêmicoepidêmica, atingindo predominantemente as faixas etárias abaixo dos 10 anos de idade, com $60 \%$ dos casos em menores de 4 anos (GOMES et al. 1996).

Embora canideos silvestres tenham sido encontrados infectados pela $L$. (L.) chagasi (DEANE e DEANE 1955, LAINSON e SHAW 1971, MELLO et al. 1988; TOLEZANO et al. 1999), bem como didelfideos (SHERLOCK et al. 1984; CORREDOR et al. 1989), considera-se que os principais reservatórios da LVA são os cães domésticos (LAINSON e SHAW 1987).

O flebotomíneo Lutzomyia longipalpis tem sido incriminado como vetor em todas as áreas de ocorrência da doença (LAINSON e SHAW 1987), com exceção, das áreas hiperendêmicas de Corumbá e Ladário, em Mato Grosso do Sul, onde não foi capturado e evidências epidemiológicas apontaram para duas outras: Lu. forattinii Galati, Rego, Nunes \& Teruya, 1985 e Lu. cruzi 
Mangabeira 1938 (GALATI et al. 1997). Para a última, observou-se a infecção natural por Le. (Le.) chagasi numa taxa de $0,39 \%$ dentre 3.575 espécimes examinados (SANTOS et al. 1998).

A Leishmaniose Visceral, cuja incidência dobrou entre o início e final da década de 90 é uma doença em franca expansão no país, atingindo praticamente todas as regiões do Brasil e com alto potencial de urbanização (CENEPI/FUNASA 1996).

Contribuem para este quadro, a adaptação de seu agente etiológico, a Leishmania chagasi e de sua principal espécie vetora Lutzomyia longipalpis, às degradações ambientais com ação antrópica e infra-estruturas sanitárias deficientes. Percebendo-se um aumento na urbanização da Leishmaniose Visceral (MARZOCHI \& MARZOCHI 1997). Aliás, DEANE \& DEANE (1955) já alertavam para este problema.

Em seus aspectos eco-epidemiológicos, existem várias lacunas do conhecimento que necessitam de esclarecimentos, tais como: qual seria o reservatório primário de L. chagasi nas Américas? (MOMEM et al. 1987, GRIMALDI-JÚNIOR. et al. 1989) Qual a real lista de mamiferos hospedeiros (homem, cães, canideos silvestres, marsupiais e roedores) no ciclo da LVA? Além da Lu. longipalpis existem outras espécies de flebotomíneos com capacidade vetorial comprovada? Onde se encontram os criadouros naturais dos flebotomíneos vetores? (SHERLOCK, 1996). Para a definição destes fatores e seu inter-relacionamento são necessários novos estudos ecoepidemiológicos em todas as regiões onde ocorre a LVA. 


\subsubsection{Leishmaniose Tegumentar Americana (LTA) no Brasil}

A Leishmaniose Tegumentar Americana representa importante problema de saúde pública, em vista de sua ampla distribuição, prevalência e gravidade dos casos, decorrente da destruição ou mutilação de mucosas ou lesões cutâneas deformantes, que acarretam fenômenos psicossociais e estigmatizantes aos pacientes (BARRAL et al. 1991; COSTA et al. 1987). Acrescem-se as dificuldades no diagnóstico, tratamento e controle, dada a complexidade de seus quadros epidemiológicos.

Dentre as espécies de Leishmania que atuam na etiologia da LTA que ocorrem no Brasil, a L. (V.) braziliensis é a que apresenta maior complexidade em sua epidemiologia. São várias as espécies vetoras envolvidas, bem como os reservatórios silvestres e domésticos. A infecção também tem sido detectada em cães e eqüídeos (FALQUETO et al.1986; AGUILAR et al. 1987b; PIRMEZ et al. 1988; MARZOCHI 1992; YOSHIDA et al. 1990).

A modalidade clássica da transmissão é a silvestre, na qual o homem adquire a infecção ao adentrar seu foco natural, onde interagem seus reservatórios naturais e vetores (PESSÔA e BARRETTO 1948; LAINSON e SHAW: 1987). Nesta circunstância, a doença atinge predominantemente o sexo masculino e em faixa etária produtiva. Manifesta-se na forma endêmica em quase todos os estados brasileiros, ocasionalmente, na forma de surtos epidêmicos (JONES et al. 1987; GOMES 1992). No entanto, em regiōes do pais com maior influência antrópica, sobretudo no Sudeste e no Nordeste, a $L$. braziliensis encontra-se adaptada a ecossistemas alterados e a sua 
transmissão vem ocorrendo em áreas há muito colonizadas (GOMES 1992; MARZOCHI 1992).

A LTA é uma doença com grande distribuição no território brasileiro, de transmissão caracterizada como essencialmente focal; variando sua dinâmica entre os locais de ocorrência em relação às variáveis relacionadas aos parasitos, aos seus respectivos vetores, aos ecossistemas e aos processos sociais de produção e ocupação do solo (CENEPI/FUNASA 2002).

O número de casos de LTA, no período de 1970 a 2001, variou de 3.000 a 37.000. Na década de 90, houve um pequeno aumento de casos, mas uma grande variação entre os anos, destacando-se o ano de 1999 quando as variáveis disponiveis para análise no nível nacional eram somente casos por Unidade Federada (UF) (CENEPI/FUNASA 2002). 


\subsubsection{As Leishmanioses em Minas Gerais}

No periodo compreendido entre os anos de 1988 a 2002, 25.790 casos de LTA, dentre todas suas formas clínicas comuns na Região Sudeste, foram notificados em Minas Gerais pela Secretaria Estadual de Saúde de Minas Gerais - SES/MG.

Destacando-se o ano de 1999, no Estado de Minas Gerais, foram 400 os municípios com registros de casos de LTA e 47 de LVA. Estes dados equivalem ao dobro do ano anterior, o que demonstra a expansão dessas parasitoses (SES/MG 2003).

No período de 1994 a 1999, em 32 municípios, dos 36 da região metropolitana de Belo Horizonte, foram notificados casos de LTA (SES/MG 2003). A instalação e epidemia da LVA em Montes Claros (região norte) e Belo Horizonte (Capital), nesta com notificação de 168 casos humanos autóctones, entre 1994 e 1997, já havia sido prevista desde os estudos de PASSOS et al. 1993, que indicaram fatores de risco da transmissão no município de Sabará, região metropolitana de Belo Horizonte.

Na cidade de Belo Horizonte, no ano 2001, foram notificados 57 casos de LV e em 2002, 71 casos, com oito óbitos. Recentemente, no ano de 2002, foi notificado o primeiro caso de óbito, por Leishmaniose Visceral, autóctone no sul de Minas, na cidade de Cabo Verde (SES/MG 2003).

O Sul de Minas Gerais não é considerada uma área endêmica para as leishmanioses, mas percebe-se, nos dados de Coeficiente de Incidência Acumulada a serem apresentados neste estudo, que há uma tendência natural 
de acompanhamento da curva de incidência para o Estado, nos últimos anos, como mostram as figuras 01 e 02

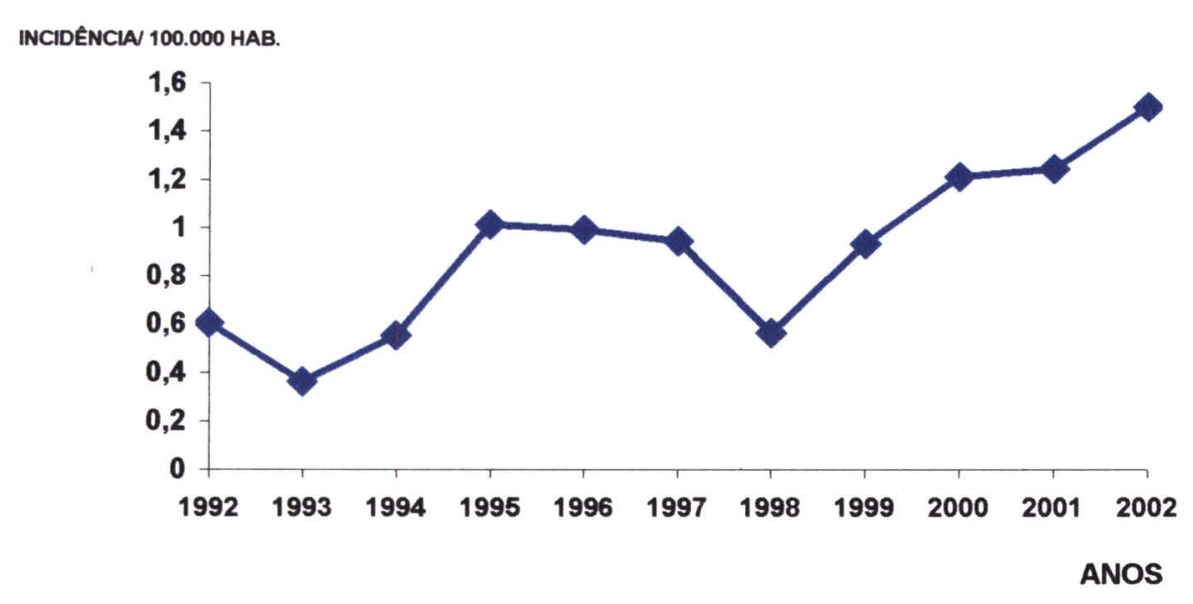

FONTE: SES/MG 2003

Figura 01 - Incidência da Leishmaniose Visceral em Minas Gerais, de 1992 a 2002

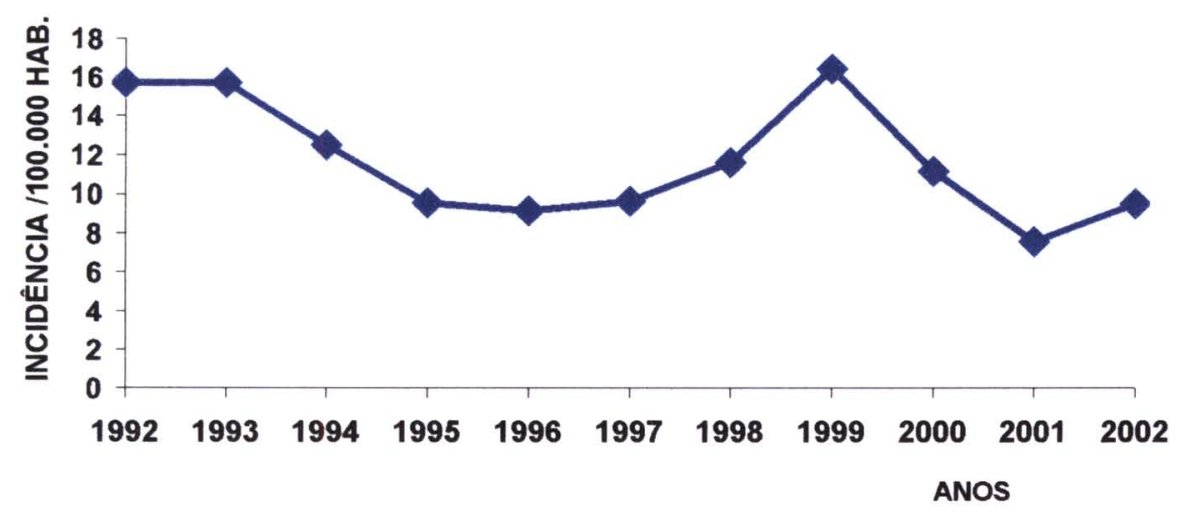

FONTE: SES/MG 2003

Figura 02 - Incidência da Leishmaniose Tegumentar em Minas Gerais, de 1992 a 2002. 


\subsection{Os Flebotomíneos e as leishmanioses}

Estudos relacionando a incidência de LTA com a presença de reconhecidos vetores, obtidos em inquéritos entomológicos de locais prováveis da infecção, revelaram a sobreposição vetor/doença concordante em $97,1 \%$ dos municípios do Estado de São Paulo com transmissão; correlação esta que aponta para um bom indicador da autoctonia dos casos. Este mesmo estudo ainda conclui que os monitoramentos entomológicos, em áreas de risco, devem ser realizados a fim de obter-se indicadores das atividades de controle. Propondo ainda que para avançar na proposta de vigilância vetorial deve-se estudar a densidade, a infecção natural e o hábito alimentar dos flebotomíneos (NEVES 1999). 
2. JUSTIFICATIVA 
Face à expansão das leishmanioses em Minas Gerais e mais recentemente para a região sul do Estado, aliada a pouca informação existente sobre os possiveis vetores na área, são necessários estudos ecológicos sobre estes dípteros que possam contribuir para a elucidação da autoctonia dos casos, assim como contribuir com medidas de vigilância vetorial.

A incidência da doença tem apresentado intensa variação a cada ano nas mesmas localidades e municípios de áreas endêmicas, dificultando a utilização dos métodos tradicionais de estratificação territorial. Neste sentido, o Centro Nacional de Epidemiologia em parceria com o Departamento de Endemias Samuel Pessoa - ENSP/FIOCRUZ, elaboraram uma proposta de vigilância e monitoramento da Leishmaniose Tegumentar Americana no Brasil, integrando diferentes escalas de análise, tais como as variáveis individuais e sócio-ambientais, necessárias para a descrição das características epidemiológicas dos casos e dos espaços críticos de produção desta endemia visando contribuir com as ações de controle e definição de prioridades.

Então foi apresentado um novo modelo de monitoramento e vigilância da LTA no Brasil, discutindo aspectos relacionados à vigilância epidemiológica e entomológica, diagnóstico laboratorial, tratamento com ênfase nas reações adversas ao Antimoniato de Meglumina, Sistemas de Informações (SIES e SINAN), ações de controle e o processo de descentralização da LTA.

Foram apresentados os principais vetores responsáveis pela transmissão da LTA no Brasil sendo muito discutido a importância do serviço de entomologia no controle da Leishmaniose Tegumentar, principalmente nas áreas reconhecidas com transmissão peri ou intra-domiciliar. Atualmente no Brasil, as ações de controle voltadas para os flebotomíneos, são realizadas 
sem conhecimento prévio da presença e/ou do comportamento do vetor nas áreas com transmissão da doença, sendo indicada a utilização de inseticidas, muitas vezes indiscriminadamente. Neste sentido, após grandes discussões, foi proposto que o CENEPI dê o suporte necessário aos Estados na área de entomologia, ficando evidente que há necessidade de uma estruturação e organização do mesmo, para que as ações de vigilância possam ser realizadas de forma efetiva.

Foi proposto pelo grupo, que o Centro Nacional de Epidemiologia, junto às áreas técnicas responsáveis, priorizasse para o ano de 2003, as atividades abaixo, para que as mesmas possam subsidiar os Estados na organização do serviço entomológico voltado para o controle de flebotomíneos:

- Definição de Serviços de Referências Regionais na área de entomologia voltadas aos flebotomíneos, para que possam dar suporte às SES na organização de serviços e assessoria técnica;

- Suporte às Secretarias Estaduais de Saúde para a capacitação de recursos humanos para trabalhar com flebotomíneos.

Perante estas considerações de grande importância, maiores são as justificativas para a realização desta pesquisa entomológica, modulada pelas informações epidemiológicas obtidas junto a Secretaria Estadual de Saúde de Minas Gerais. 
3. OBJETIVOS 


\subsection{OBJETIVO GERAL}

Estudar a fauna flebotomínea (Diptera, Psychodidae, Phlebotominae) no sul do Estado de Minas Gerais e seus aspectos comportamentais, com vistas à caracterização dos possiveis fatores vetoriais relacionados à transmissão das Leishmanioses Tegumentar e Visceral.

\subsection{OBJETIVOS ESPECÍFICOS}

1)- Identificar as áreas ou locais de transmissão das leishmanioses, a partir de casos autóctones, em quatro municipios da região do sul de Minas Gerais, situados em posições diferentes em relação a Serra da Mantiqueira.

2)- Avaliar epidemiologicamente, através do Coeficiente de Incidência Acumulada, os municipios dos regionais de saúde que compõem o sul de Minas Gerais.

3)- Identificar as espécies de flebotomíneos presentes em áreas ou localidades dos municípios estudados.

4)- Caracterizar a distribuição sazonal das principais espécies de flebotomineos capturados nas áreas de estudo.

5)- Definir a freqüência horária das principais espécies de flebotomíneos encontradas nas localidades pesquisadas.

6)- Comparar os índices de diversidade e similaridade da fauna flebotomínica, nos municipios pesquisados. 
4. MATERIAL E MÉTODOS 


\section{1. Áreas de Estudo}

O Estado de Minas Gerais se divide em 853 municípios, com população estimada de 16.672.613 habitantes (IBGE 2003). Hoje, a Secretaria de Estado da Saúde é a Instituição responsável pela notificação, tratamento, controle e avaliação das principais endemias, inclusive das leishmanioses. Sendo assim, para melhor gerenciar este trabalho ela se divide, administrativamente, em 25 Regionais.

As áreas estudadas pertencem aos regionais de saúde de Alfenas, Pouso Alegre e Varginha, situados ao sul e sudoeste do Estado, fazendo limite com o Estado de São Paulo.

Dentre os 128 municipios destas regionais, foram selecionados quatro para o estudo:

- Caldas (13.047 hab.),

- Conceição da Aparecida (18.482 hab.)

- Jacutinga (16.124 hab.) e

- $\quad$ Machado (32.123 hab.) (IBGE, 2003).

Para a escolha desses municípios levou-se em consideração a localização em referência a Serra da Mantiqueira (figura 03) e as taxas de incidência média nos municipios investigados, no período compreendido entre os anos de 1985 a 1999, quando da elaboração do projeto desta pesquisa.

Quanto à localização em relação a Serra, foram escolhidos dois municípios no lado norte (Conceição da Aparecida e Machado), outro no lado sul (Jacutinga) e um sobre a Serra (Caldas). As localidades trabalhadas, com exceção no município de Jacutinga, foram em áreas rurais, 


\title{
Minas Gerais
}

\author{
Belo Horizonte \\ Caldas \\ $\bigcirc$ Jacutinga \\ Conceição da Aparecida \\ Machado \\ Serra da Mantiqueira
}
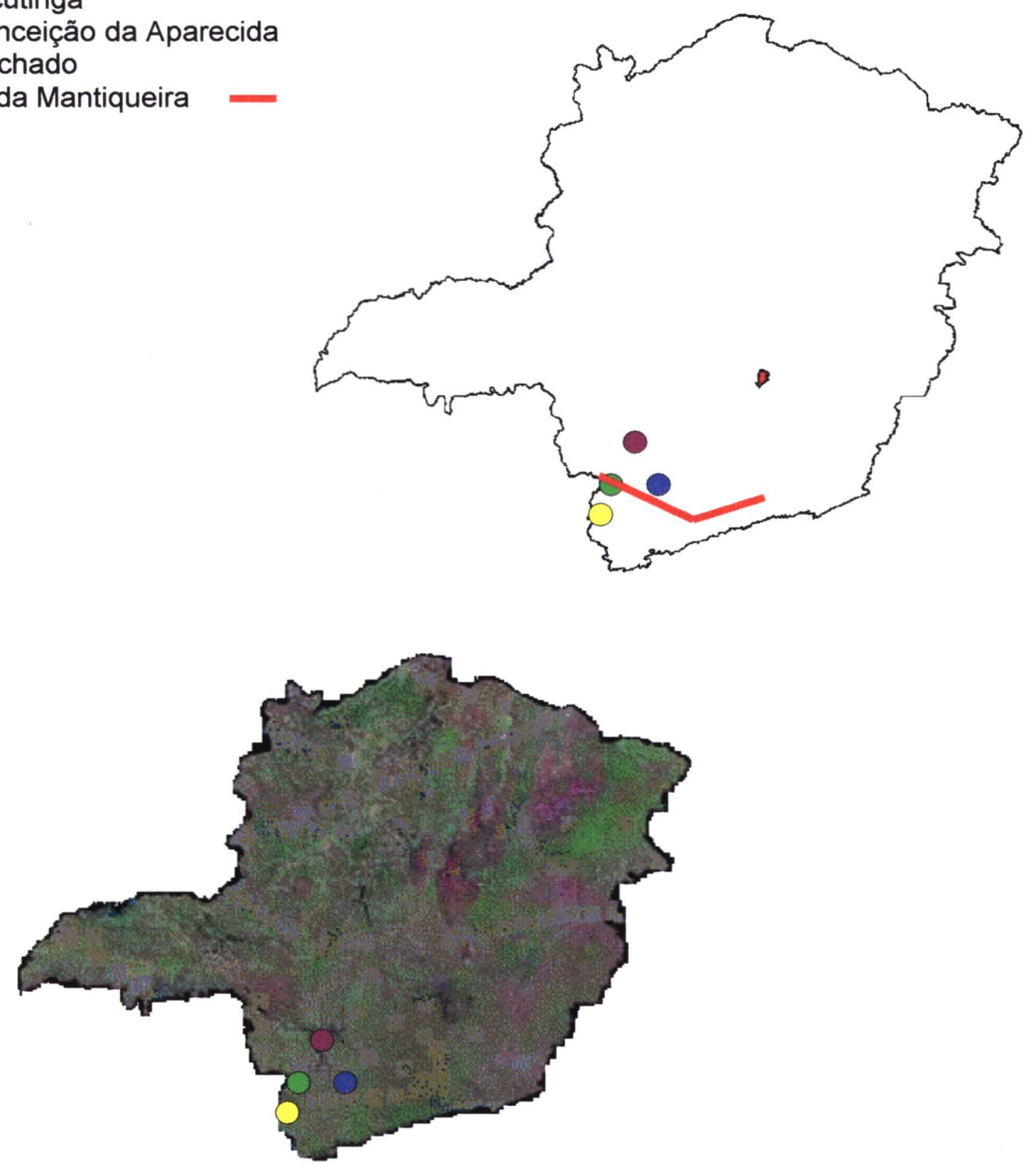

Fonte:Embrapa monitoramento por satélite 2000-2003

Figura 03 - Mapa do Estado de Minas Gerais apresentando os municípios onde foram realizados os estudos de incidência e a pesquisa entomológica, relacionados com a disposição da Serra da Mantiqueira 
fazendas e/ou sítios, com atividades agropecuárias de alguma natureza. Em Jacutinga, a maioria dos casos relatados, apesar de poucos, ocorreram em pacientes de área urbana. Sendo assim, procurou-se investigar a presença de flebotomíneos nas proximidades do domicilio de um destes casos (figura 04) e em locais estratégicos na área urbana (figura 05).

O município de Caldas, pertencente ao regional de saúde de Pouso Alegre, está localizado sob as coordenadas $46^{\circ} 17^{\prime} \mathrm{W} / 21^{\circ} 48^{\prime} \mathrm{S}$ e a uma altitude de 1.313 metros, sobre a Serra da Mantiqueira (figura 03 e anexo 04). Neste municipio o solo apresenta características vulcânicas, pois o mesmo se encontra dentro do chamado Planalto de Poços de Caldas, ou seja, dentro da cratera do vulcão (anexo 04). A região se destaca pela atividade extrativista de minerais radioativos como o Urânio, principalmente. Os trabalhos foram realizados em dois sítios vizinhos, os quais apresentavam atividades agrícolas rotativas, com lavouras de milho, cana e feijão. Além de uma granja de suínos com grande potencial pecuáriarista (figura 06).

Conceição da Aparecida, município pertencente ao regional de saúde de Alfenas, está localizado a $70 \mathrm{Km}$ de Alfenas, sob as coordenadas $46^{\circ} 13^{\prime} \mathrm{W} / 21^{\circ} 06^{\prime}$ S, a uma altitude de 966 metros, ao norte da Serra da Mantiqueira (anexo 03). A localidade estudada foi uma fazenda de café (figura 07) na divisa com o municipio de Carmo do Rio Claro, municipio este que fica às margens do reservatório de Hidrelétrica de Furnas. Nesta fazenda de café, também com atividades leiteiras e pequenas lavouras e pomares de subsistência, foi identificado o primeiro caso de Leishmaniose Tegumentar acompanhando durante a pesquisa (figura 08). Trata-se do caso índice para o 
estudo na localidade, sendo o paciente R.J.J. de 34 anos, diagnosticado, tratado e curado (figura 09).

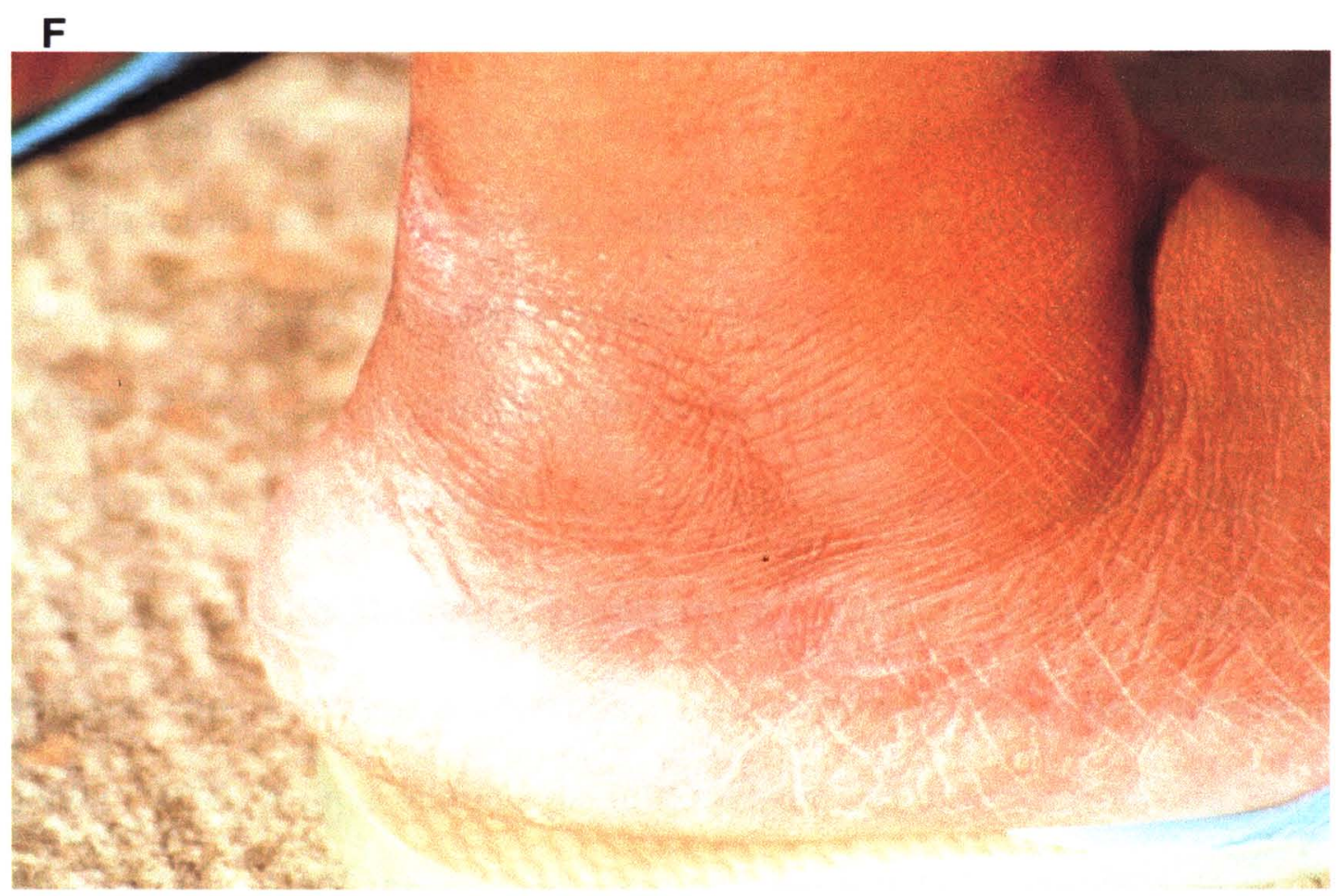

Autor: Carlos Frederico Loiola

Figura 04 - Lesão cicatrizada da paciente A.S., em Jacutinga/MG.

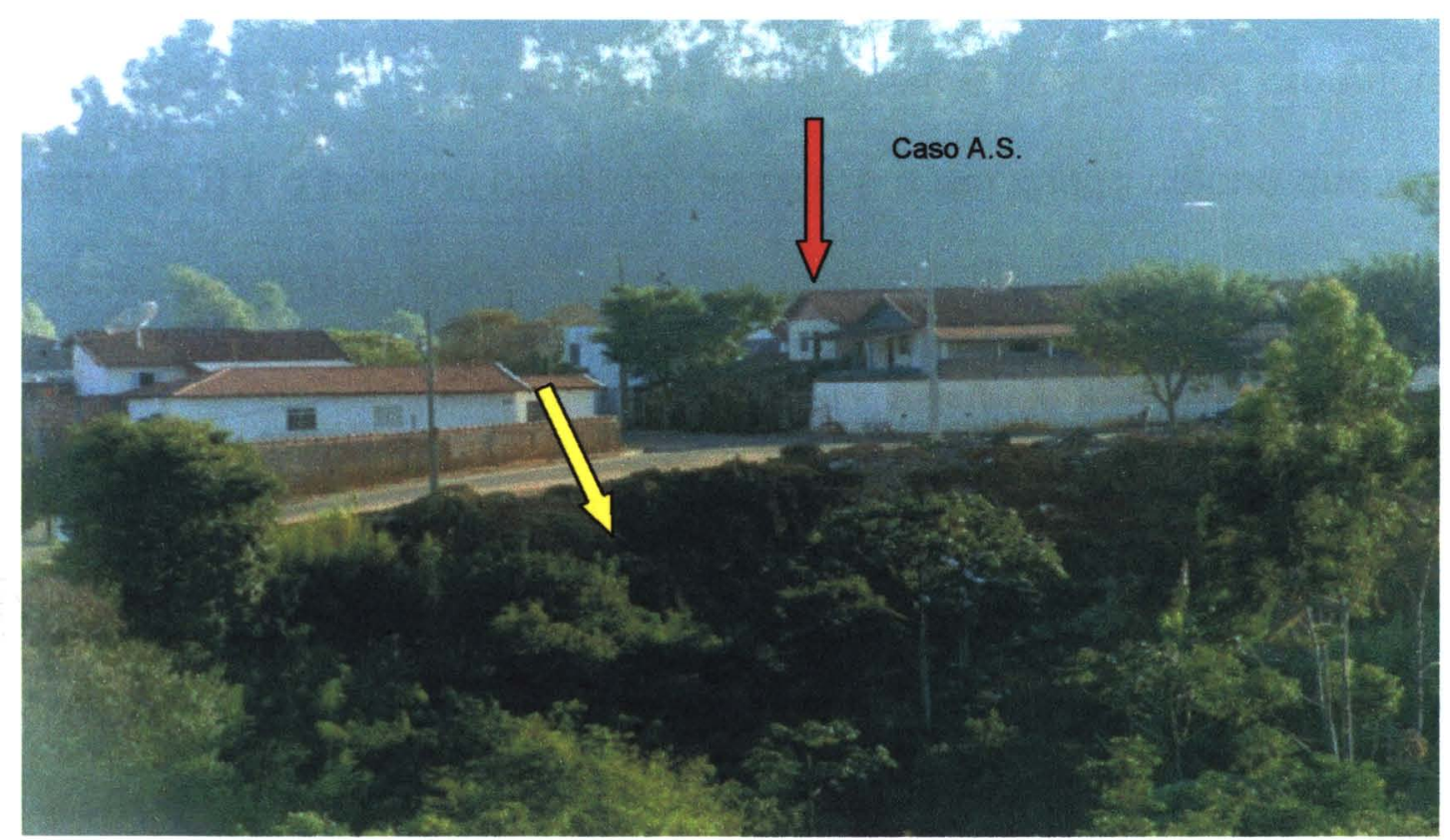

Autor: Carlos Frederico Loiola

Figura 05 - Vista do bairro trabalhado em Jacutinga/MG, com a mata residual onde foram realizadas as capturas (seta). 
O município de Jacutinga, distante $180 \mathrm{Km}$ de Alfenas, apresentou o segundo maior Coeficiente de Incidência Acumulada do regional de saúde de Pouso Alegre. Está localizado sob as coordenadas $46^{\circ} 36^{\prime} \mathrm{W} / 22^{\circ} 16^{\prime} \mathrm{S}$, em uma altitude de 858 metros, ao sul da Serra da Mantiqueira (anexo 01). A área pesquisada foi no perimetro urbano, associado ao caso da senhora A.S., de 57 anos de idade (figura 04). Jacutinga se destaca pela atividade da indústria têxtil, responsável por um grande número de malharias que, juntamente com as atividades agropecuárias, geram $100 \%$ de mão de obra para a população.

O município de Machado, localizado a $40 \mathrm{Km}$ de Alfenas e pertencente ao regional de saúde de Alfenas, encontrada-se sob as coordenadas $45^{\circ} 56^{\prime} \mathrm{W} / 21^{\circ} 40^{\prime}$ S, a uma altitude de 959 metros, estando ao norte da Serra da Mantiqueira (anexo 02). Apresenta uma das maiores lavouras de café do Brasil e do Mundo, sendo este o seu principal produto agrícola. Mas também é um município com grande produção de gado leiteiro e de corte na região do sul de Minas. A fazenda na qual foi realizada a pesquisa é uma grande produtora de café (figura 10) e o caso ali notificado se refere a um antigo colono que residia em uma das casas da colônia.

A vegetação nos municipios estudados é bastante semelhante, tratandose, em todos eles, de áreas de transição entre as tipologias vegetacionais do Cerrado e a Mata Atlântica. Entretanto, deve-se ressaltar que a vegetação nativa se encontra completamente alterada. Especificamente nas localidades estudadas, onde as atividades antrópicas, como a agropecuária, a indústria, hidrelétrica e a extração mineral, descaracterizaram completamente os ambientes naturais. As matas existentes podem ser consideradas resíduos de uma vegetação secundária, pobre em abundância e diversidade populacionais. 


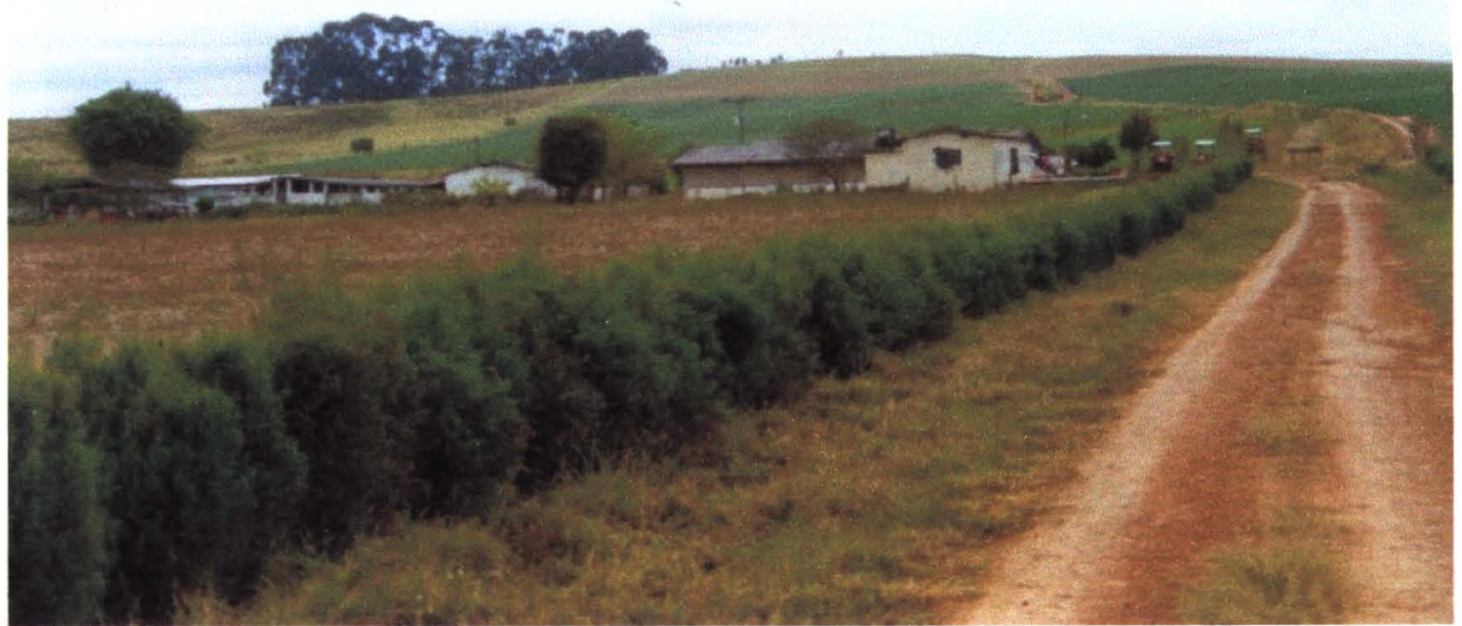

Autor: Carlos Frederico Loiola

Figura 06 - Vista da granja de suínos no local de capturas em Caldas/MG.

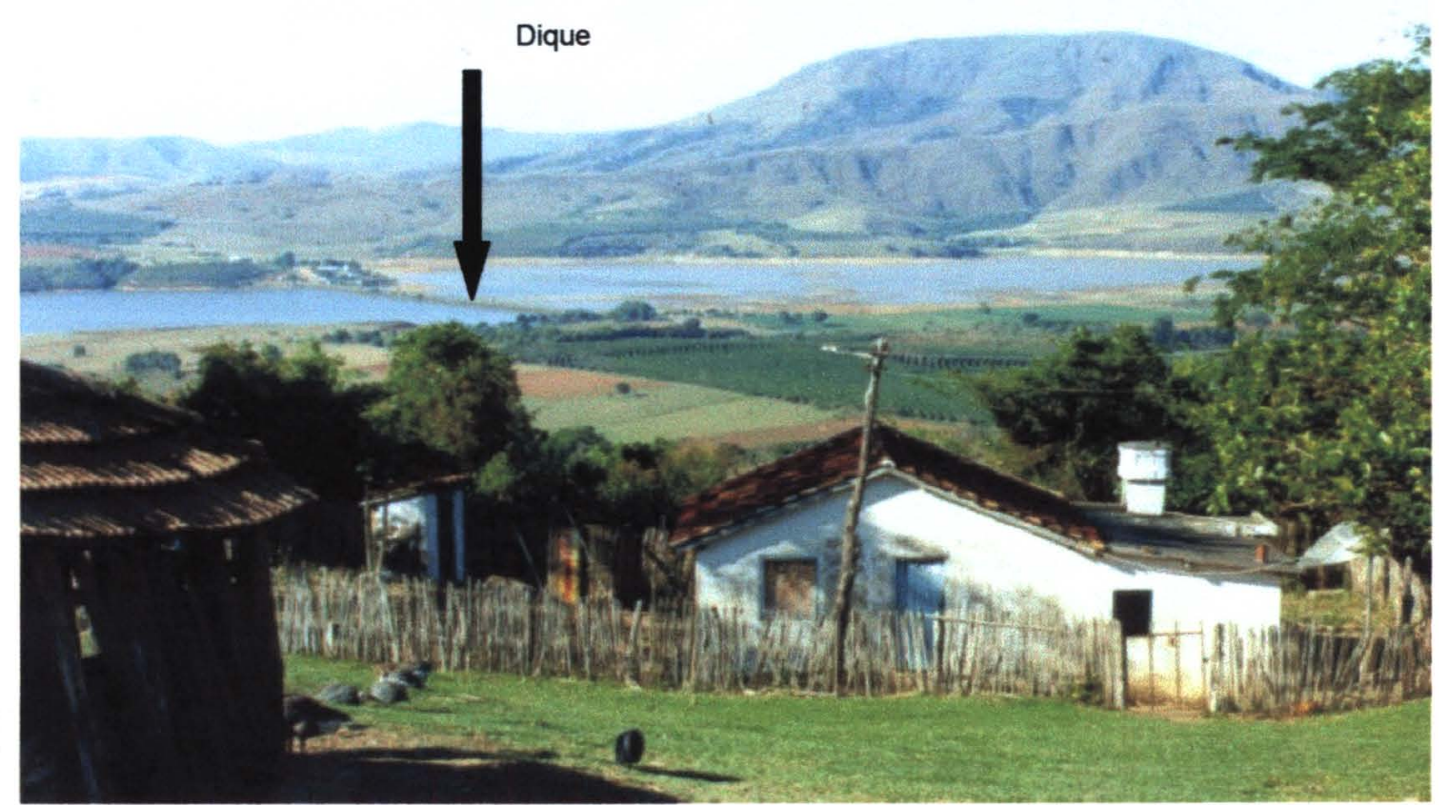

Autor: Carlos Frederico Loiola

Figura 07 - Vista da fazenda em Conceição da Aparecida/MG, onde foram realizadas as capturas e do reservatório de Furnas, mostrando a estrada em direção à Carmo do Rio Claro, sobre o dique. 


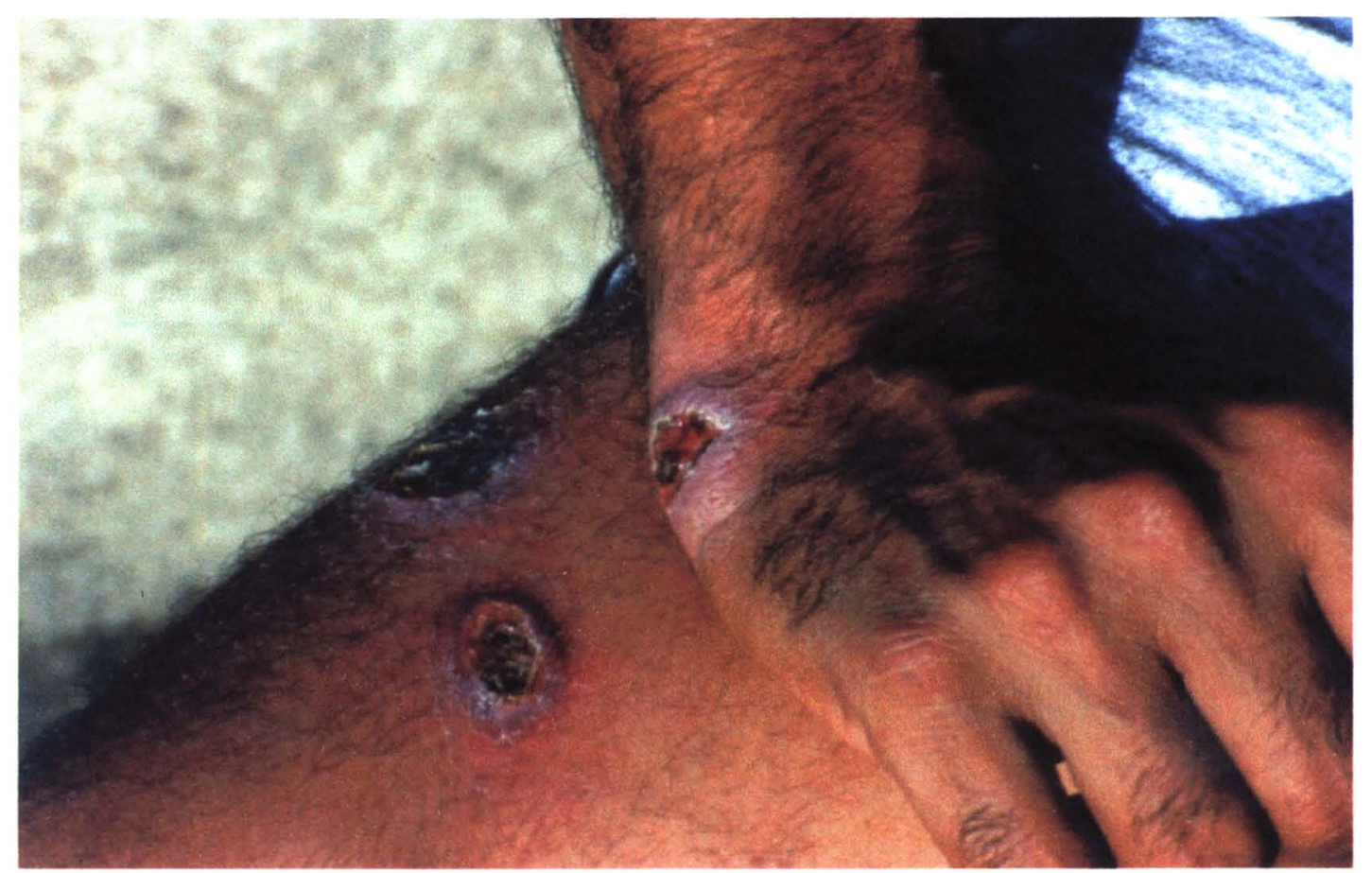

Autor: Carlos Frederico Loiola

Figura 08- Paciente R.J.J., de 34 anos, antes do tratamento. Caso notificado na localidade estudada em Conceição da Aparecida/MG.

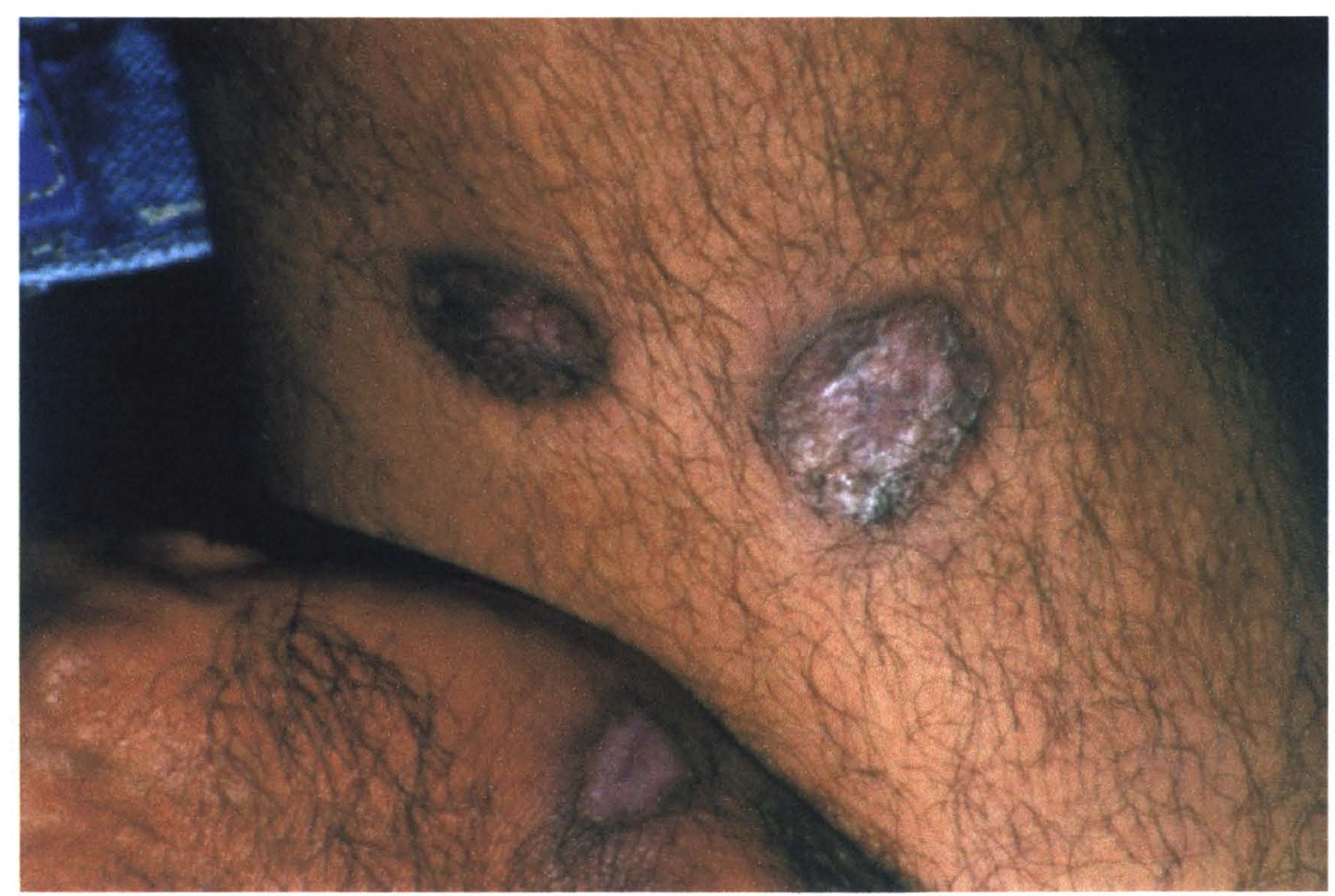

Autor: Carlos Frederico Loiola

Figura 09- Paciente R.J.J., depois do tratamento. Em Conceição da Aparecida/MG 


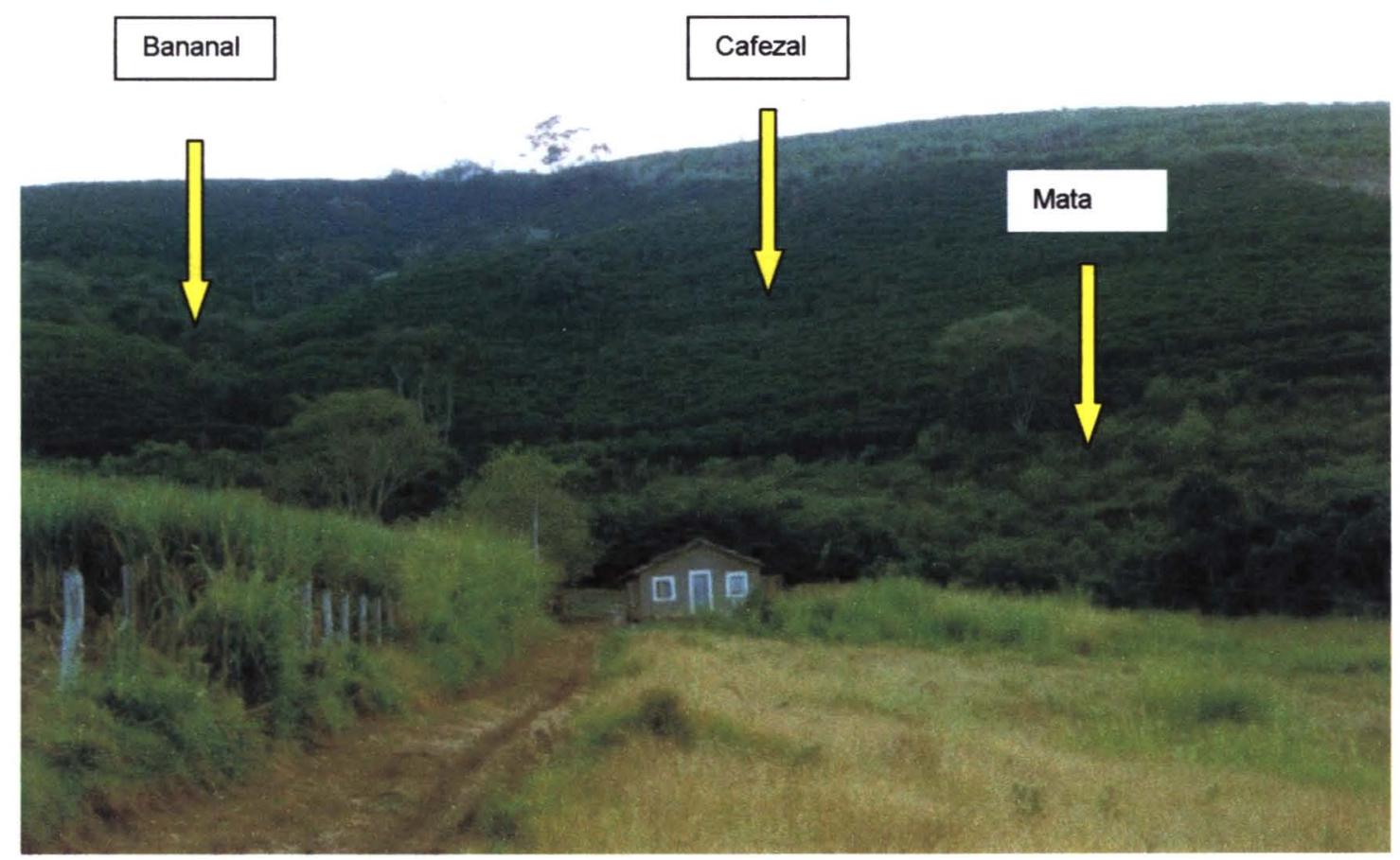

Autor: Carlos Frederico Loiola

Figura 10 - Vista da casa de colono, em uma fazenda de café de Machado/MG onde foram realizadas as capturas de flebotomíneos, mostrando a relação da casa, com a lavoura e com a mata. 


\subsection{Coeficiente de Incidência Média}

As informações obtidas junto à Secretaria de Estado da Saúde de Minas Gerais, referentes aos casos de leishmanioses notificados, foram utilizadas para o cálculo do nível de incidência das leishmanioses de todos os municípios presentes nos três regionais de saúde que compõem o sul do Estado, especialmente aqueles estudados. Para a Leishmaniose Tegumentar, as notificações iniciaram-se a partir de 1985 e para a visceral, a partir de 1996 . O Coeficiente de Incidência foi calculado segundo Szklo 1993, de acordo com a fórmula a seguir:

$$
C I=\frac{\left(\frac{n}{\frac{P 1+P 2}{2}}\right)}{A} \times 100.000
$$

Onde:

$\mathrm{Cl}=$ Coeficiente de Incidência

$\mathrm{n}=$ número de casos no periodo

P1 = População inicial

P2 = População final

$A=$ número de anos do período de estudo 


\subsection{Dados climatológicos}

As médias de precipitações mensais em $\mathrm{mm}$ e as médias mensais de temperaturas máximas e mínimas em ${ }^{\circ} \mathrm{C}$, utilizadas nesta pesquisa, foram obtidas a partir de dados fornecidos por duas estações meteorológicas da Companhia Energética de Minas Gerais - CEMIG, uma em Passos e outra em Botelhos, sendo estas estações as mais próximas dos municípios trabalhados, não ultrapassando um raio de $50 \mathrm{~km}$ de distância. Os dados obtidos na estação de Passos serviram de referência para o município de Conceição da Aparecida e os demais foram referendados pela estação de Botelhos.

\subsection{Inquérito Entomológico:}

$O$ inquérito entomológico foi realizado nas quatro localidades já mencionadas. Em três delas, Jacutinga, Machado e Conceição da Aparecida, com notificação de pelo menos um caso humano de Leishmaniose Tegumentar, e a quarta localidade, Caldas, sem notificação de casos desta doença. A título de esclarecimento, nos últimos dez anos somente foram notificados dois casos autóctones de Leishmaniose Visceral no sul de Minas Gerais, um em Alfenas e, mais recentemente, um em Cabo Verde. Sendo que, este último evoluiu para óbito (SES/MG 2003).

Estabelecidas as localidades, as capturas de insetos foram realizados nos ambientes domiciliares, peri-domiciliares e silvestres das Unidades Domiciliares (UDs), quando na área rural. Em Jacutinga, por se tratar de uma área urbana, não havia anexos no peri-domicílio como nas propriedades rurais, 
mas existiam áreas verdes, como o bosque dos aposentados e os jardins de um determinado hotel na cidade. Nas proximidades do domicílio pesquisado existia uma pequena mata residual que estava sendo retirada para loteamento urbano (figura 11). Entende-se por UDs, nas localidades de área rural, aquelas onde se encontra um domicílio ativo, ou seja ambiente humano (com moradores e animais domésticos), um peri-domicílio com galinheiro, chiqueiro, pomar.

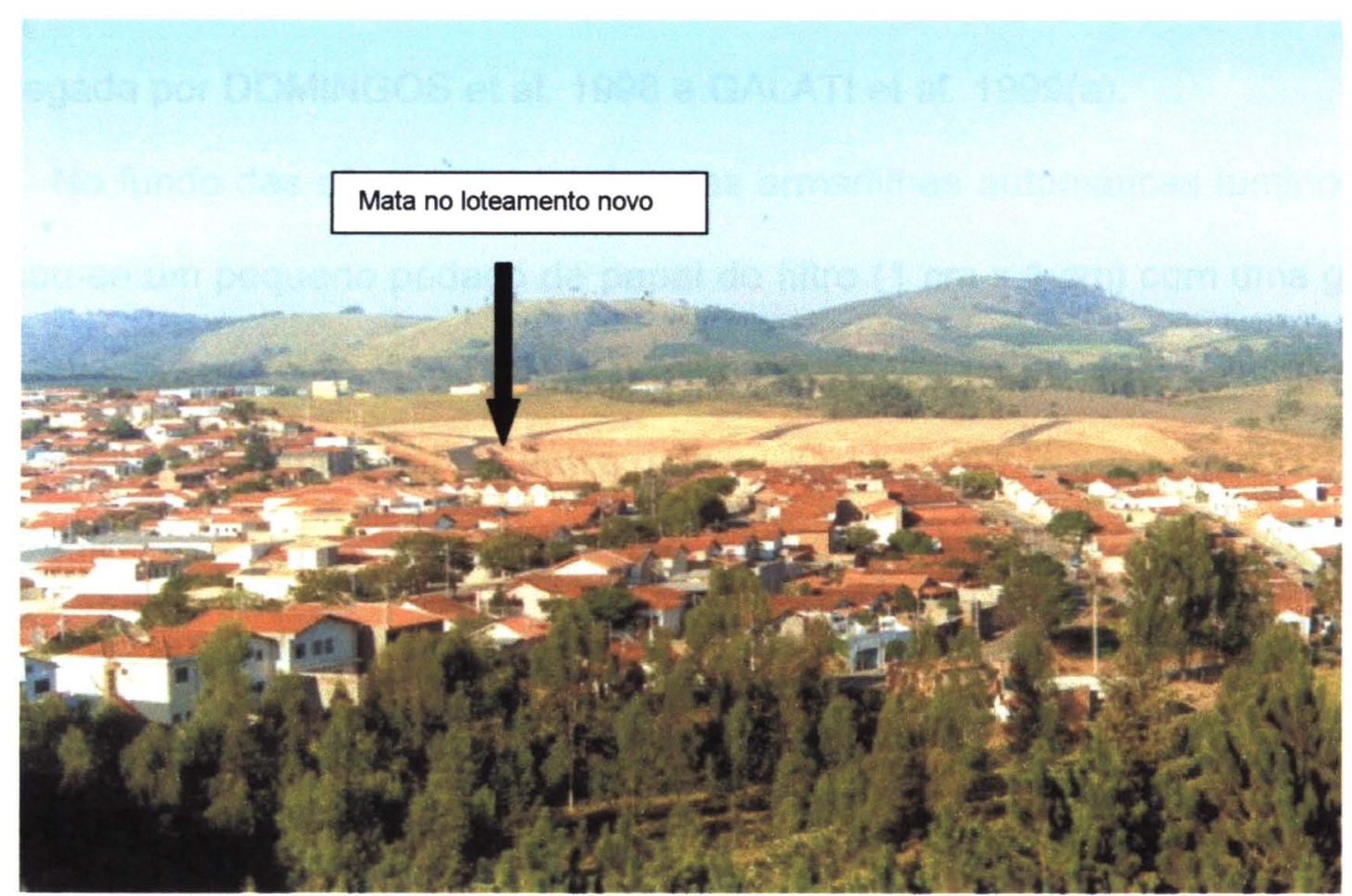

Autor: Carlos Frederico Loiola

Figura 11- Vista do loteamento urbano, no município de Jacutinga, com a mata residual onde foram realizadas as capturas de flebotomíneos (seta). 


\subsubsection{Técnica de capturas e procedimentos para a identificação das espécies.}

As capturas foram realizadas durante 18 meses consecutivos das $18 \mathrm{~h}$ às 6h, obedecendo-se os horários de crepúsculos vespertino e matutino, com periodicidade mensal, durante três dias consecutivos em Machado e Conceição da Aparecida e dois dias em Jacutinga e Caldas, com as armadilhas automáticas luminosas, tipo CDC, (NATAL et al. 1991) (Anexo 06) e em armadilha de Shannon (SHANNON 1939) (Anexo 07), segundo a metodologia empregada por DOMINGOS et al. 1998 e GALATI et al. 1999(a).

No fundo das câmaras coletoras das armadilhas automáticas luminosas colocou-se um pequeno pedaço de papel de filtro $(1 \mathrm{~cm} \times 1 \mathrm{~cm})$ com uma gota do inseticida piretróide, que matava instantaneamente os insetos. O inseticida era aplicado nos papéis um dia antes da captura.

Em cada uma das localidades selecionadas, foram instaladas as armadilhas automáticas luminosas em diversos ecótopos, sem que nenhuma armadilha pudesse interferir na outra.

Deste modo, os ecótopos amostrados em cada localidade foram:

Machado: $\quad 02$ no domicílio;

03 na lavoura de café

02 na mata ciliar;

01 no galinheiro;

01 na amoreira

Totalizando 09 armadilhas 
Jacutinga: $\quad 03$ no domicilio;

03 na mata urbana;

01 no bosque dos aposentados;

01 na área verde do hotel

Totalizando 08 armadilhas

Conceição da Aparecida: - 02 no domicílio;

02 na mata;

01 no galinheiro;

03 na lavoura de café e banana

01 no lago;

01 na goiabeira

Totalizando 10 armadilhas

Caldas: $\quad 02$ no domicilio;

01 no chiqueiro

01 no galinheiro;

01 na lavoura de milho;

02 na mata ciliar;

01 no galpão da lavoura.

Totalizando 08 armadilhas

A armadilha de Shannon foi instalada sempre no peri-domicilio de cada localidade, durante duas horas a partir do crepúsculo vespertino, durante dois dias consecutivos. Uma vez por mês, em cada localidade estudada, foi realizada a captura durante toda a noite com esta armadilha, durante doze 
horas, envolvendo os crepúsculos vespertino e matutino, objetivando estudos de freqüência horária noturna das espécies capturadas.

Os espécimes capturados foram transportados para o Laboratório de Doenças Parasitárias e Saúde Pública da Universidade José do Rosário Vellano - UNIFENAS, em Alfenas/MG para triagem, clarificação, montagem em lâmina e lamínula, segundo GALATI (2002 e 2003).

Ressalta-se ainda que, para a listagem das espécies capturadas, neste estudo foram seguidas as orientações da Comissão Internacional em Nomeclatura Zoológica, de 1999, onde no seu capítulo 7, página 31, são listados os critérios para abreviações dos nomes de espécies.

\subsubsection{Cálculo do índice de diversidade de espécies (MARGALEF} 1949, citado por SERVICE 1993).

O cálculo do índice de diversidade das espécies foi proposto por Margalef, como uma definição de medida da composição de espécies de um determinado ambiente, de uma localidade ou de um município, em termos quantitativos e de abundância relativa destas espécies. Esta análise de diversidade de espécies deve levar em consideração a riqueza de espécies e a eqüitabilidade na repartição dos indivíduos entre as espécies (SERVICE 1993).

Para este cálculo utilizou-se a seguinte fórmula:

$$
D=\frac{(S-1)}{\log _{\mathrm{c}} N}
$$


$\mathbf{S}=$ número de espécies

$\mathbf{N}=$ número de indivíduos

4.4.3. Cálculo do índice de abundância de espécies (ROBERTS \& HSI 1979)

O índice de abundância das espécies é calculado sobre os dados referentes a capturas em ambientes diferentes, com a mesma metodologia de captura e estima a abundância das espécies capturadas em diferentes ecótopos ou em uma seqüência temporal.

Para o cálculo deste indice, os autores definiram a seguinte fórmula:

$$
I A E=\frac{a+R j}{K}
$$

IAE = Índice de Abundância de Espécies

$a=$ número de ausências da espécie nos ecótopos ou horários pesquisados multiplicado por c

$c=$ considerando todos os pontos ou horários de capturas deve-se fazer um "ranking" das espécies e o maior valor obtido para as posições de todas as espécies deve ser acrescido de +1

$\mathbf{R j}$ = somatório das posições da espécie avaliada em cada ecótopos ou horário de atividade

$\mathbf{K}=$ número de ecótopos amostrados 
Para converter os valores do IAE em uma escala de zero a um, deve-se usar outro índice, chamado pelos autores, de Índice de Abundância de Espécies Padronizado. Deste modo, as análises poderão ser realizadas considerando-se os valores mais próximos de 1 para as espécies mais abundantes e os valores mais próximos de 0 referem-se às espécies menos abundantes. A fórmula para o cálculo do IAEP é:

$$
I A E P=\frac{c-I A E}{c-1}
$$

4.4.4. Cálculo do Índice de Similaridade entre as localidades pesquisadas

O cálculo de similaridade entre os ambientes é uma análise quantitativa sobre o número de espécies capturadas em cada ambiente ou localidade, onde o índice encontrado deve estar entre os valores zero e 1, indicando maior ou menor grau de similaridade entre dois ambientes, ou amostras comparados. Sendo assim, o valor máximo a ser atingido por este índice é 1 , o que significa identidade de faunas e menor valor é zero, o que significa que não existe comunhão de faunas entre os ambientes comparados. Para tal utiliza-se o Índice de Sorensen (SORENSEN 1948, MAGURRAN 1988; SERVICE 1993) dado pela seguinte fórmula:

$$
S=\frac{2 J}{(a+b)}
$$


$S=$ İndice de Sorensen

$\mathrm{J}=$ número de espécies comuns aos dois ambientes comparados

$a=$ número de espécies em a

$b=$ número de espécies em $b$

\subsubsection{Cálculo da Média de Williams (HADOW 1954 e 1960)}

A média de Williams é na verdade uma média geométrica modificada, portanto trata-se de uma medida de tendência central, onde a freqüência das espécies é tão importante quanto o próprio número respectivo de indivíduos capturados. Para tal, a fórmula utilizada para o cálculo desta média é:

$$
\bar{X} w=\left[\operatorname{antilog}\left(\frac{\sum \log (n+1)}{N}\right)\right]-1
$$

$\mathrm{n}$ = número de espécimes da espécie estudada

$N=$ número de espécimes de todas as espécies capturadas

4.4.5.1. Avaliação do período de atividade noturna, ou freqüência horária das espécies

Com o cálculo da Média de Williams em doze meses de capturas, pode-se apresentar a distribuição das espécies de Flebotomíneos capturados na armadilha de Shannon, durante doze horas de atividades, entre o crepúsculo vespertino e matutino. 
Esta distribuição foi computada a cada hora das doze horas de capturas, analisando-se assim o ritmo horário das espécies através deste método de capturas.

\subsubsection{Análise da variação sazonal das espécies}

Com a distribuição das espécies ao longo de doze meses de estudo, pode-se demonstrar a sazonalidade das espécies capturadas nas localidades, comparando-se ainda com os gráficos das médias das temperaturas e da pluviosidade no mesmo ano. 
5. RESULTADOS 


\subsection{Coeficiente de Incidência Média por 100.000 habitantes nos Regionais de Saúde do Sul de Minas Gerais}

Nas tabelas 01 e figuras 12 e 13 são apresentados os Coeficientes de Incidência por 100.000 habitantes, para os municipios dos três regionais da Secretaria Estadual de Saúde de Minas Gerais: Alfenas, Pouso Alegre e Varginha, nos quais foram notificados casos de LTA. Estes Coeficientes foram calculados mediante as notificações de LTA desde 1985 até 2002, ou seja, em um período de 17 anos. Ressalta-se que devido à ausência de casos autóctones de LVA não foram possiveis os cálculos de incidência para esta parasitose. Entretanto, é importante a informação da Secretaria Estadual de Saúde, de que no ano de 2002 foi notificado um óbito por LVA de uma paciente de 22 anos de idade, no município de Cabo Verde, pertencente ao regional de saúde de Alfenas.

No regional de Pouso Alegre, composto de 52 municípios, encontram-se os municípios de Caldas e Jacutinga, este último com Coeficiente de 6,80/100.000 hab. Na figura 12 estão representados os 27 municípios com notificações de casos de LTA. Na figura 13 estão representados os 26 municípios do regional de Alfenas com notificações de LTA. Dentre estes estão os municípios de Conceição da Aparecida e Machado, com Coeficientes de Incidência de 20,08/100.000 hab. e 17,99/100.000 hab., respectivamente, nos quais foram realizadas as pesquisas entomológicas.

A tabela 01 apresenta os 35 municipios com notificações para LTA, de um total de 50, pertencentes ao regional de saúde de Varginha. Entretanto deste 
regional, por motivos operacionais, não foi escolhido nenhum município para a investigação entomológica.

Tabela 01 - Coeficiente de Incidência Média de LTA por 100.000 habitantes, nos municipios do Regional de Saúde de Varginha/MG, de 1985 a 2002.

\begin{tabular}{|c|c|}
\hline MUNICIPIO & Cl/100.000 hab. \\
\hline 1 Boa Esperança & 13,54 \\
\hline 2 Cambuquira & 0,52 \\
\hline 3 Carmo de Minas & 1,86 \\
\hline 4 Caxambu & 0,3 \\
\hline 5 Conceiç. Do Rio Verde & 37,35 \\
\hline 6 Coqueiral & 6,83 \\
\hline 7 Cordislåndia & 0,2 \\
\hline 8 Cruzilia & 0,5 \\
\hline 9 Elói Mendes & 5,27 \\
\hline 10 ljaci & 5,47 \\
\hline 11 llicinea & 5,32 \\
\hline 12 Ingai & 2,48 \\
\hline 13 Itamonte & 0,58 \\
\hline 14 Itumirim & 2,09 \\
\hline 15 Jesuânia & 1,36 \\
\hline 16 Lambari & 1,49 \\
\hline 17 Lavras & 2,06 \\
\hline 18 Luminárias & 2,3 \\
\hline 19 Monsenhor Paulo. & 2,69 \\
\hline 20 Nepomuceno & 8,45 \\
\hline 21 Olimpio Noronha & 2,91 \\
\hline 22 Passa Quatro & 0,45 \\
\hline 23 Perdōes & 1,83 \\
\hline 24 Pouso Alto & 2,03 \\
\hline 25 Ribeirăo Vermelho & 19,07 \\
\hline 26 Santana da Vargem & 7,94 \\
\hline 27 S. Gonçalo do Sapucaí & 0,91 \\
\hline 28 São Lourenço & 3,49 \\
\hline 29 Săo Seb. Do Rio Verde & 6,71 \\
\hline 30 São Tomé das Letras & 4,25 \\
\hline 31 Soledade de Minas & 11,19 \\
\hline 32 Três Corações & 3,11 \\
\hline 33 Três Pontas & 3,36 \\
\hline 34 Turvolândia & 3,18 \\
\hline 35 Varginha & 1,47 \\
\hline
\end{tabular}




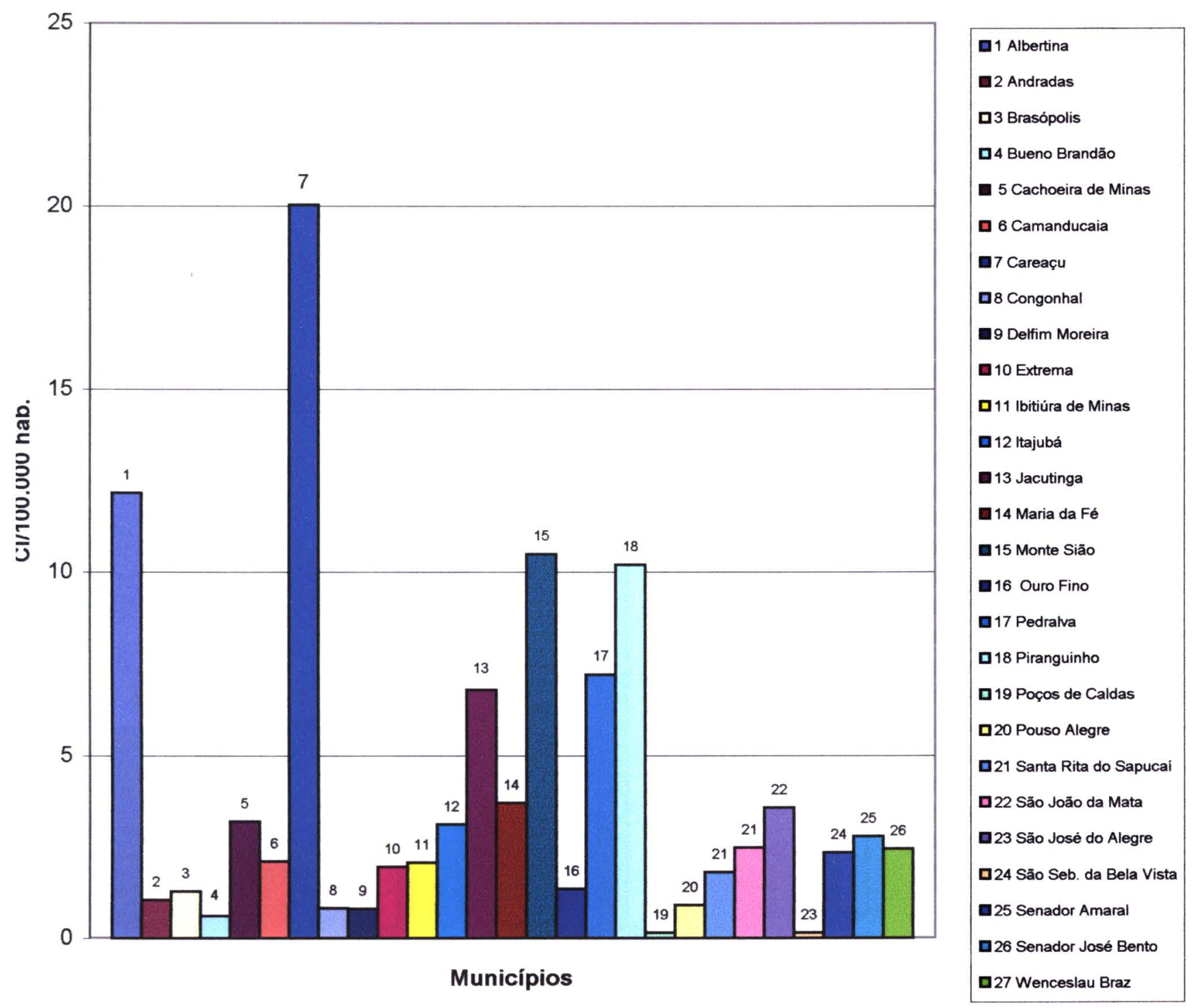

Figura 12 - Coeficientes de Incidência Média por 100.000 hab. para LTA, nos municípios do Regional de Saúde de Pouso Alegre/MG, no período de 1985 a 2002. 
Cl/100.000 hab.

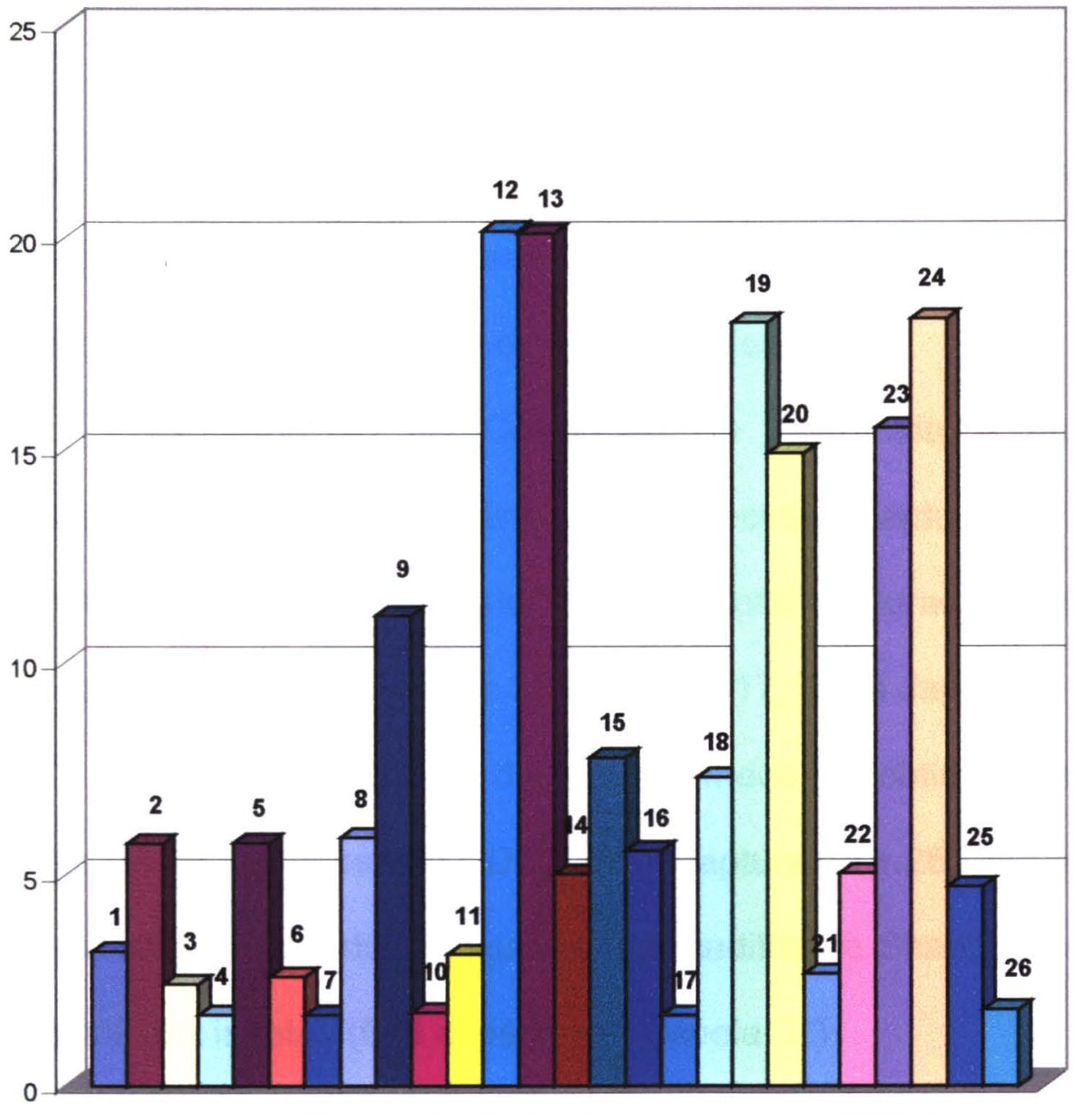

Municipios
口1 Alfenas

口2 Alterosa

口3 Arceburgo

प4 Areado

$\square 5$ Bandeira do Sul

口6 Botelhos

-7 Cabo Verde

$\square 8$ Campestre

a Campos Gerais

10 Campo do Meio

口11 Carmo do Rio Claro

口12 Carvalhopolis

13 Conc. da Aparecida

14 Divisa Nova

口15 Fama

घ16 Guaranésia

$\square 17$ Guaxupé

口18 Juruaia

口19 Machado

口20 Monte Belo

口21 Muzambinho

प22 Nova Rezende

口23 Paraguaçu

口24 Poço Fundo

口25 São Pedro da União

口26 Serrania

Figura 13 - Coeficientes de Incidência Média por 100.000 hab. para LTA, nos municípios do Regional de Saúde de Alfenas/MG, no período de 1985 a 2002. 


\section{2. - Composição das espécies capturadas nos municípios} pesquisados.

Durante os 18 meses de estudos foram capturados 1.949 flebotomíneos em localidades dos municipios de Conceição da Aparecida, Jacutinga e Machado (Tabela 02). Ressalta-se que no municipio de Caldas nenhum inseto foi capturado durante o período da pesquisa.

No município de Conceição da Aparecida a fauna flebotomínica apresentou a maior freqüência de espécimes capturados, com um total de 1.444 insetos, representando $74,1 \%$ do total capturado em todo o estudo. Em Machado, foram capturados 333 insetos $(17,1 \%)$ e Jacutinga com $172(8,8 \%)$.

A maior freqüência de flebotomineos foi obtida com que a armadilha automática luminosa tipo CDC, com a captura de 1.260 , ou seja, $64,6 \%$ do total de insetos capturados. Enquanto a armadilha de Shannon capturou os demais $35,4 \%$ dos insetos (689 espécimes) (tabela 02).

$\mathrm{Na}$ tabela 03 são apresentadas as 20 espécies de Flebotomíneos capturadas nos municípios pesquisados. Sendo elas: Nyssomyia whitmani (Antunes \& Coutinho 1939); Nyssomyia intermedia (Lutz \& Neiva 1912); Nyssomyia neivai (Pinto 1926); Pintomyia monticola (Costa Lima 1932); Pintomyia fischeri (Pinto 1926); Pintomyia bianchigalatiae (Andrade-Filho, Aguiar, Dias \& Falcão 1999); Pintomyia misionensis (Castro 1959); Psathyromyia brasiliensis (Costa Lima 1932); Psathyromyia aragaoi (Costa Lima 1932); Migonemyia migonei (França 1920); Evandromyia lenti (Mangabeira 1938); Evandromyia sallesi (Galvão e Coutinho 1939); 
Evandromyia termitophila (Martins, Falcão \& Silva 1964); Psychodopygus lloydi (Antunes 1937); Psychodopygus davisi (Root 1934); Lutzomyia longipalpis (Lutz \& Neiva 1912); Brumptomyia brumpti (Larrouse 1920); Brumptomyia cardosoi (Barreto \& Coutinho 1941); Brumptomyia nitzulescui (Costa Lima 1932); e Brumptomyia sp.

Quanto a estes resultados, destaca-se a grande diversidade de espécies encontradas e deve-se ressaltar ainda, dentre outros aspectos, primeiramente - encontro de Lu. intermedia e Lu. neivai ocorrendo em simpatria nos municípios de Machado e Conceição da Aparecida. O segundo aspecto de relevância, também a ser discutido posteriormente, foi o encontro, pela primeira vez, de Lu. longipalpis no Sul de Minas Gerais, em Conceição da Aparecida e Jacutinga.

Destaca-se ainda a ocorrência de Pi. monticola, Mi. migonei e Ev. Jenti, em todos os três municipios pesquisados, apresentando uma grande associação com peri-domicílio e com o domicilio. 
Tabela 02 - Flebotomíneos capturados nos municípios de Conceição da Aparecida, Jacutinga e Machado, por tipo de armadilha, no período de maio de 2001 a novembro de 2002.

\begin{tabular}{lccc}
\hline Localidade/Armadilhas & CDC & SHANNON & TOTAL \\
Conceição da Aparecida & 951 & 493 & 1444 \\
Jacutinga & 57 & 115 & 172 \\
Machado & 252 & 81 & 333 \\
TOTAL & & & \\
\hline
\end{tabular}

Tabela 03 - Espécies de flebotomíneos capturados nos municípios de Conceição da Aparecida, Jacutinga e Machado, no período de maio de 2001 a novembro de 2002.

\section{Categoria Taxonômica}

Nyssomyia whitmani

Nyssomyia intermedia

Nyssomyia neivai

Pintomyia monticola

Pintomyia fischeri

Pintomyia bianchigalatiae

Pintomyia misionensis

Psathyromyia brasiliensis

Psathyromyia aragaoi

Migonemyia migonei

Evandromyia lenti

Evandromyia sallesi

Evandromyia termitophila

Psychodopygus lloydi

Psychodopygus davisi

Lutzomyja longipalpis

Brumptomyia brumpti

Brumptomyia cardosoi

Brumptomyia nitzulescui

Brumptomyia sp.

TOTAL

\section{Conceição \\ da Aparecida}

Jacutinga Machado TOTAL

$\mathbf{x}$

$\mathbf{x}$

$x$

x

$\mathbf{x}$

$\mathbf{x}$

$\mathbf{x}$

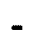

$\mathbf{x}$

$\mathbf{x}$

$\mathbf{x}$

$x$

X

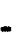

$x$

$-$

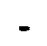

-

$-$

13 $x$

$x$

03

02

03

03

02

02

02

01

01

03

03

02

02

02

01

02

01

01

01

02
10

16 


\subsection{Composição das espécies capturadas, por armadilhas e por} sexo.

No município de Jacutinga pode-se observar, de acordo com os dados apresentados na tabela 04 , que as espécies que predominaram foram, em primeiro lugar a Pi. monticola $(44,8 \%)$, em segundo a $N y$. neivai $(39,6 \%)$ e em terceiro a Ny. whitmani $(5,2 \%)$. Todas estas, com significativa presença no peridomicílio, comprovada pelo sucesso de captura da armadilha de Shannon, armada neste ambiente. Ressalta-se ainda a presença de Lu. longipalpis.

Tabela 04 - Espécies de flebotomíneos capturados no município de Jacutinga/MG, por tipo de armadilhas e por sexo, no periodo de maio de 2001 a outubro de 2002.

\begin{tabular}{|c|c|c|c|c|c|c|c|c|c|c|}
\hline \multirow{2}{*}{$\begin{array}{l}\text { Categoria } \\
\text { taxonốmica }\end{array}$} & \multicolumn{2}{|c|}{ CDC } & \multicolumn{2}{|c|}{ SHANNON } & \multicolumn{2}{|c|}{ Subtotal } & \multicolumn{2}{|c|}{$\%$} & \multirow{2}{*}{ TOTAL } & \multirow[t]{2}{*}{$\%$} \\
\hline & $f$ & $m$ & $f$ & $m$ & $\bar{f}$ & $\mathbf{m}$ & $\bar{f}$ & $\bar{m}$ & & \\
\hline Nyssomyia whitmani & 03 & 01 & 02 & 03 & 05 & 04 & 55,6 & 44,4 & 09 & 5,2 \\
\hline Nyssomyia neivai & 20 & 01 & 35 & 12 & 55 & 13 & 80,9 & 19,1 & 68 & 39,6 \\
\hline Pintomyia monticola & 19 & 01 & 48 & 09 & 67 & 10 & 85,1 & 14,9 & 77 & 44,8 \\
\hline Pintomyia fischeri & - & - & 01 & 02 & 01 & 02 & 33,3 & 66,7 & 03 & 1,7 \\
\hline Psathyromyia aragaoi & 01 & - & - & - & 01 & - & 100,0 & - & 01 & 0,6 \\
\hline Migonemyia migonei & 01 & 02 & - & - & 01 & 02 & 33,3 & 66,7 & 03 & 1,7 \\
\hline Evandromyia lenti & 01 & 01 & 01 & 00 & 02 & 01 & 66,7 & 33,3 & 03 & 1,7 \\
\hline Psychodopygus davisi & - & - & - & 01 & - & 01 & - & 100,0 & 01 & 0,6 \\
\hline Lutzomyia longipalpis & 01 & - & - & - & 01 & - & 100,0 & - & 01 & 0,6 \\
\hline Brumptomyia brumpti & 03 & 01 & - & - & 03 & 01 & 75,0 & 25,0 & 04 & 2,3 \\
\hline Brumptomyia sp. & 01 & - & - & 01 & 01 & 01 & 50,0 & 50,0 & 02 & 1,2 \\
\hline Subtotal & 50 & 07 & 87 & 28 & 137 & 35 & & & & \\
\hline$\%$ & 87,7 & 12,3 & 75,6 & 24,4 & 69,3 & 30,7 & & & & \\
\hline TOTAL & & & & & & & & & 172 & \\
\hline$\%$ & & & & & & & & & & 100,0 \\
\hline
\end{tabular}


Neste municipio as capturas foram mais eficiente com a armadilha de Shannon, responsável por $66,9 \%$ dos insetos encontrados. Pode-se ainda observar na tabela 04, que o predominio, em ambas as armadilhas, foi de fêmeas, $87,7 \%$ na CDC e $75,6 \%$ na Shannon. Das 20 espécies encontradas no estudo neste municipio foram capturadas 11 delas.

Diferentemente do que foi observado em Jacutinga, nos municipios de Machado e Conceição da Aparecida onde as armadilhas automáticas luminosas tipo CDC tiveram as maiores freqüências nas capturas, $75,7 \%$ e $76,5 \%$, respectivamente (tabelas 05 e 06). Entretanto, a predominância de fêmeas sobre os machos também foi observada nestes dois municípios, com 70,0\% em Machado e 62,1\% em Conceição da Aparecida. Predominância esta também em ambas as armadilhas.

Em Machado a espécie mais capturada foi $N y$. Whitmani $(57,4 \%)$, seguida por Mi. migonei (18,9\%). A diferença no percentual de captura de Pi. fischeri com $7,5 \%$ e de Pi. monticola com $7,2 \%$ foi muito pequena. Ali foram capturadas 16 espécies, das 20 relatadas na pesquisa como um todo (tabela 05).

Na tabela 06 observa-se que em Conceição da Aparecida a espécie $\mathrm{Ny}$. whitmani também foi a mais capturada, com freqüência elevada $62,7 \%$, seguida pela Mi. migonei, com $21,4 \%$ do total de Flebotomíneos capturados neste município. Destaca-se ainda a presença de Lu. longipalpis neste município, bem como a ausência de espécies do gênero Brumptomyia. Treze espécies foram encontradas em Conceição da Aparecida, dentre às 20 capturadas na pesquisa. 
Tabela 05 - Espécies de flebotomineos capturados no município de Machado/MG, por tipo de armadilhas e por sexo, no período de maio de 2001 a outubro de 2002.

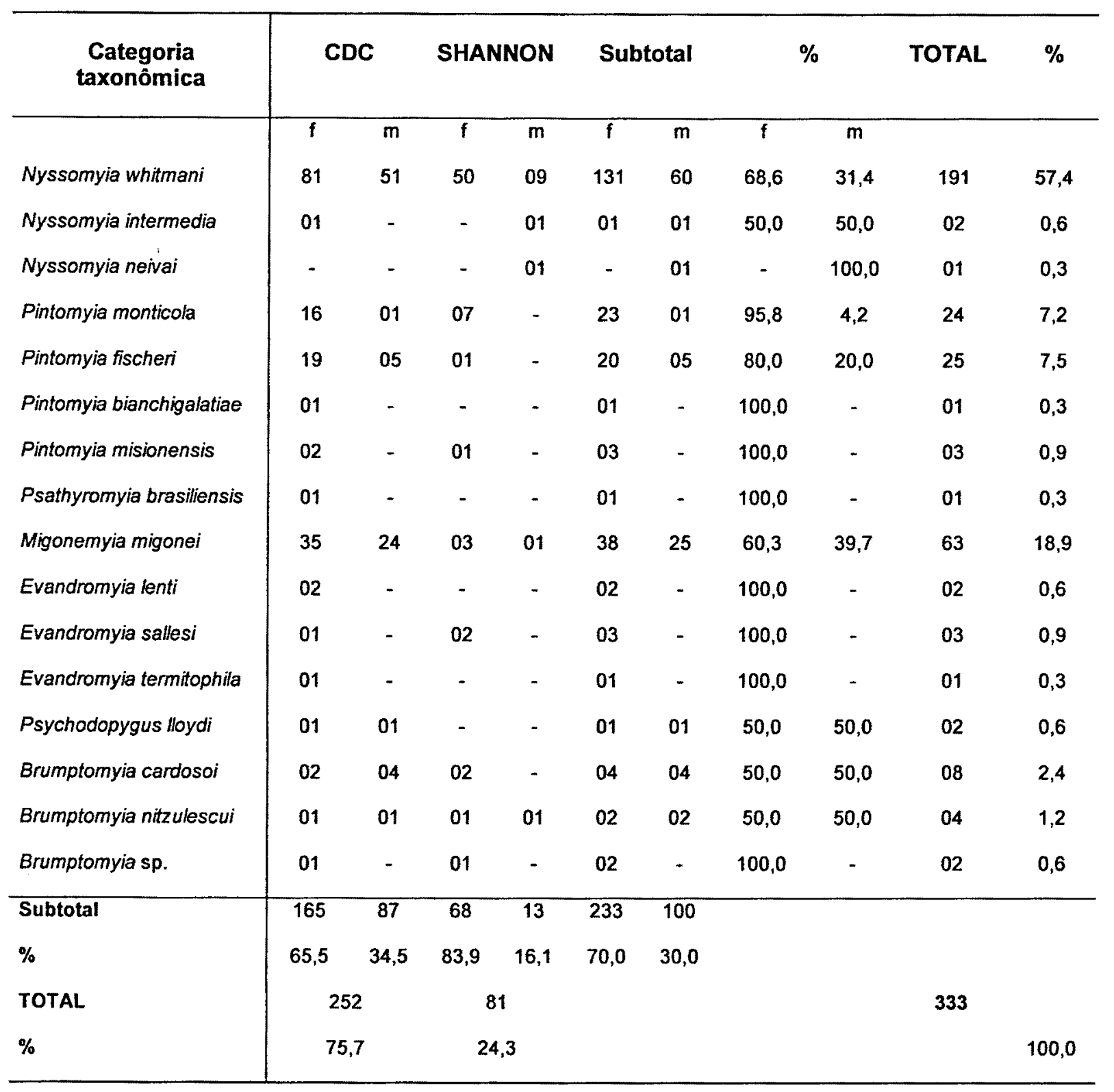


Tabela 06 - Espécies de flebotomíneos capturados no município de Conceição da Aparecida/MG, por tipo de armadilhas e por sexo, no periodo de maio de 2001 a outubro de 2002.

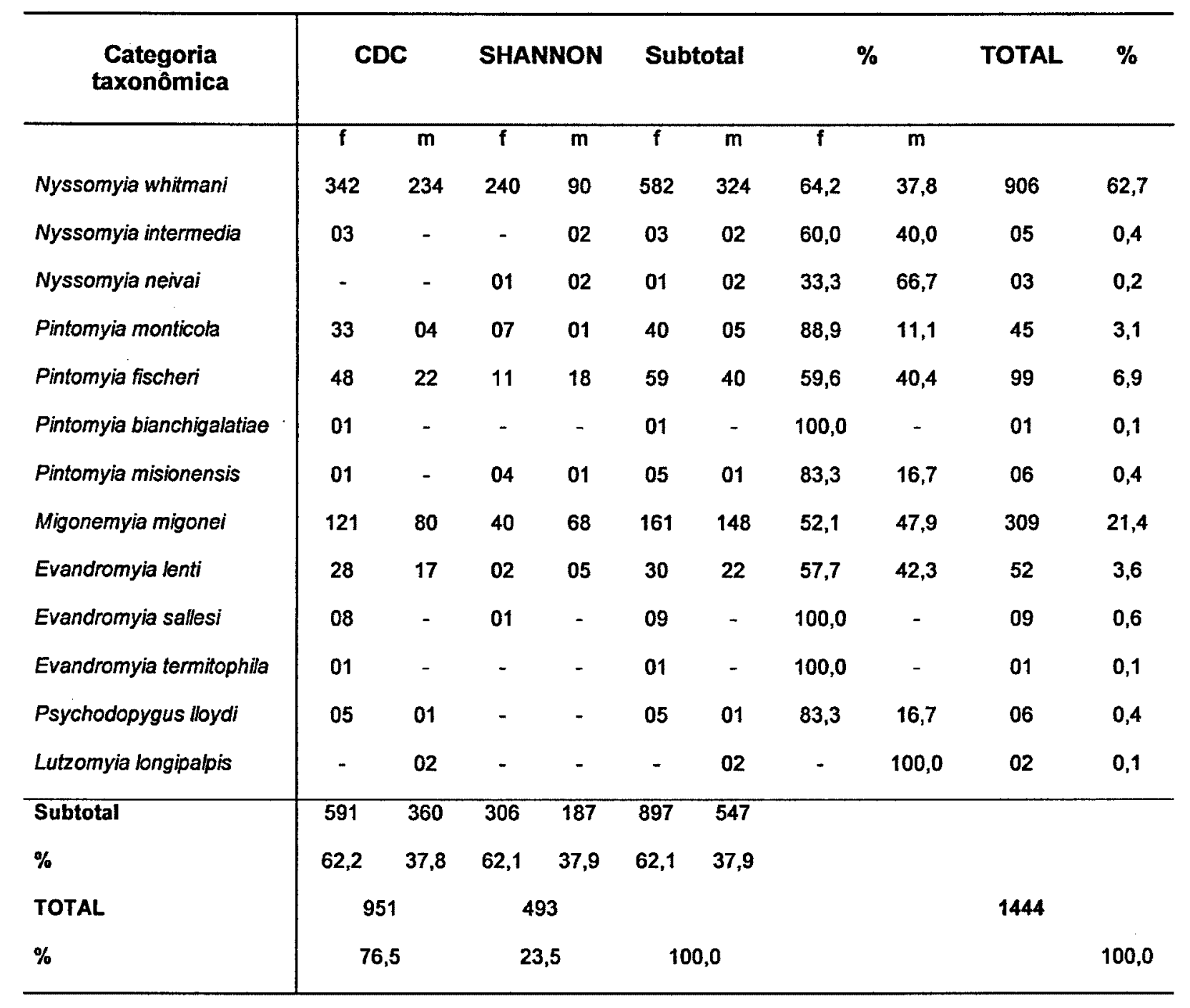




\subsection{Composição das espécies capturadas com a armadilha automática luminosa, tipo CDC, por ecótopos e por sexo}

Os resultados a seguir se referem às capturas realizadas somente com as armadilhas automáticas luminosas do tipo $C D C$, as quais foram distribuidas por diferentes ecótopos, nos três municípios nos quais foram capturados flebotomineos.

Portanto, na tabela 07 são apresentados os resultados obtidos nas capturas em Jacutinga em quatro ecótopos diferentes: no domicílio, com três armadilhas; na mata, a 100 metros do domicílio, três armadilhas; uma no bosque dos aposentados, em área central da cidade; e uma na área verde de um hotel, próximo ao parque das águas.

Em $87,8 \%$ da pesquisa entomológica foram capturados flebotomíneos na mata residual, onde também foram realizadas as capturas com a armadilha de Shannon. Destaca-se ainda a predominância de $N y$. neivai $(36,8 \%)$ em todos os ecótopos, inclusive no domicilio, onde foi comprovada, por notificação e investigação epidemiológica, conduzidas pela Secretaria Municipal de Saúde, a transmissão intra-domiciliar de um caso de LTA. Caso este referente à paciente AS, de 57 anos (figura 04).

Capturou-se também em Jacutinga, com freqüência relativamente elevada, a Pi. monticola $(29,8 \%)$. Ressalta-se ainda o predomínio de fêmeas de todas as espécies encontradas, em todos os ecótopos.

Na tabela 08 são apresentados os resultados das capturas em Machado, onde houve um destaque para as espécies $N y$. whitmani $(52,4 \%)$ e Mi. migonei 
(23,4\%), com ampla distribuição entre os ecótopos pesquisados. Dos espécimes, $32,9 \%$ foram encontrados no domicílio e todos pertencentes a estas duas espécies, com predominância de machos $(62,7 \%)$.

Deve-se destacar ainda, os $27,0 \%$ de insetos capturados nas lavouras de café e banana, ecótopos do peri-domicilio muito presentes na região do Sul de Minas Gerais. Neste ponto de capturas, diferentemente do domicilio, houve um predominio de insetos fêmeas $(85,3 \%)$.

No galinheiro, desta localidade, as aves não eram confinadas, sendo comum várias galinhas dormirem na amoreira (outro ecótopo pesquisado), onde também permaneciam alguns cães, o que pode explicar os $26,2 \%$ dos flebotomineos neste ecótopo.

Em Conceição da Aparecida, tabela 09, destacam-se as espécies $N y$. whitmani $(60,6 \%)$ e Mi. migonei $(21,1 \%)$, seguidas por Pi. fischeri $(7.4 \%)$, Ev. lenti $(4,7 \%)$, Pi. monticola (3,9\%).

O galinheiro se apresenta como o ecótopo mais rico em espécimes capturados, ou seja, com $37,3 \%$ seguido pelo domicílio $(22,2 \%)$, pela mata $(15,6 \%)$, pela lavoura $(9,8 \%)$, pela goiabeira $(9,6 \%)$ e pelo lago $(5,6 \%)$. Estes três últimos ecótopos se apresentam mais homogêneos sob o ponto de vista quantitativo, entretanto estes aspectos serão mais bem apresentados através do cálculo de similaridade, que vai avalia-los qualitativamente.

Uma grande variedade de espécies foram encontradas no domicilio, sete das doze encontradas neste local. 
Tabela 07 - Espécies de flebotomíneos capturados no municipio de Jacutinga/MG, nas armadilhas tipo CDC, por ecótopos e por sexo, no período de maio de 2001 a outubro de 2002.

\begin{tabular}{|c|c|c|c|c|c|c|c|c|c|c|c|c|c|c|}
\hline \multirow{2}{*}{$\begin{array}{l}\text { Categoria } \\
\text { taxonórnica }\end{array}$} & \multicolumn{2}{|l|}{ Domicilio } & \multicolumn{2}{|c|}{ Bosque } & \multicolumn{2}{|c|}{ Hotel } & \multicolumn{2}{|c|}{ Mata } & \multicolumn{2}{|c|}{ SubtotalL } & \multicolumn{2}{|c|}{$\%$} & \multirow[t]{2}{*}{ TOTAL } & \multirow[t]{2}{*}{$\%$} \\
\hline & $f$ & m & $f$ & m & $\mathbf{f}$ & m & $f$ & $\mathrm{~m}$ & $f$ & $\mathbf{m}$ & $f$ & m & & \\
\hline Nyssomyia whitmani & - & - & - & - & - & - & 03 & 01 & 03 & 01 & 75,0 & 25,0 & 04 & 7,0 \\
\hline Nyssomyia neivai & 01 & - & - & - & 05 & - & 13 & 02 & 19 & 02 & 90,5 & 9,5 & 21 & 36,8 \\
\hline Pintomyia monticola & - & - & - & - & - & - & 17 & - & 17 & - & 100,0 & - & 17 & 29,8 \\
\hline Psathyromyia aragaoi & - & - & - & - & - & - & 01 & - & 01 & - & 100,0 & - & 01 & 1,8 \\
\hline Migonemyia migonei & - & - & - & - & - & - & 01 & 02 & 01 & 02 & 33,3 & 66,7 & 03 & 5,3 \\
\hline Lutzomyia longipalpis & - & - & - & - & - & - & 01 & - & 01 & - & 100,0 & - & 01 & 1,8 \\
\hline Evandromyia lenti & - & - & 01 & - & - & - & - & 01 & 01 & 01 & 50,0 & 50,0 & 02 & 3,5 \\
\hline Brumptomyia brumpti & - & - & - & - & - & - & 03 & 01 & 03 & 01 & 75,0 & 25,0 & 04 & 7.0 \\
\hline Brumptomyia sp. & - & - & - & - & - & - & 03 & 01 & 03 & 01 & 75,0 & 25,0 & 04 & 7.0 \\
\hline Subtotal & 01 & - & 01 & - & 05 & - & 42 & 08 & 49 & 08 & & & & \\
\hline$\%$ & 100,0 & - & 100,0 & - & 100,0 & - & 84,0 & 16,0 & 86,0 & 14,0 & & & & \\
\hline TOTAL & 01 & & & & & & & & & & & & 57 & \\
\hline$\%$ & 1,7 & & & & & & & & & & & & & 100,0 \\
\hline
\end{tabular}

Quantidade de armadilhas por ponto de captura:

Hotel $=01 ;$ Domicilio $=03 ;$ Mata $=03$ Bosque $=01$

Total de armadilhas por campanha de campo $=08$

Tabela 08 - Espécies de flebotomineos capturados no município de Machado, nas armadilhas tipo CDC, por ecótopos e por sexo, no período de maio de 2001 a outubro de 2002.

\begin{tabular}{|c|c|c|c|c|c|c|c|c|c|c|c|c|c|c|c|c|}
\hline \multirow[t]{2}{*}{ Categoria taxonómica } & \multicolumn{2}{|c|}{ Domicilio } & \multicolumn{2}{|c|}{ Amoreira } & \multicolumn{2}{|c|}{ Galinheiro } & \multicolumn{2}{|c|}{ Lavoura } & \multicolumn{2}{|c|}{ Mata } & \multicolumn{2}{|c|}{ Subtotal } & \multicolumn{2}{|c|}{$\%$} & \multirow[t]{2}{*}{ TOTAL } & \multirow[t]{2}{*}{$\%$} \\
\hline & $\mathbf{f}$ & m & $f$ & m & $f$ & m & $f$ & m & $f$ & $\mathbf{m}$ & $f$ & m & $\mathbf{f}$ & $\begin{array}{c}\mathbf{f} \\
\mathbf{m} 8\end{array}$ & & \\
\hline Nyssomyia whitmani & $\$ 1$. & 30 & 28 & 15 & 03 & 01 & 27 & 03 & 12 & 02 & 81 & 51 & 61,4 & 6 & 132 & 52,4 \\
\hline Nyssomyia intermedia & - & - & - & - & 01 & - & - & - & $=$ & - & 01 & - & 100,0 & - & 01 & 0,4 \\
\hline Pintomyia monticola & - & - & 06 & 01 & 01 & - & $\infty 6$ & - & 03 & - & 16 & 01 & 94,1 & 5,9 & 17 & 6,7 \\
\hline Pintomyia fischeri & - & - & 05 & 01 & - & - & 13 & 04 & 01 & - & 19 & 05 & 79,2 & 20,8 & 24 & 9,5 \\
\hline Pintomyja bianchigalatiae & - & - & - & - & - & - & - & - & 01 & - & 01 & - & 100,0 & 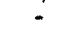 & 01 & 0,4 \\
\hline Pintomyia misionensis & - & - & - & - & - & - & 02 & - & - & - & 02 & - & 100,0 & - & 02 & 0,8 \\
\hline Psathyromyia brasiliensis & - & - & - & - & - & - & - & - & 01 & - & 01 & - & 100,0 & - & 01 & 0,4 \\
\hline Migonemyia migonei & 20 & 22 & 06 & 02 & 01 & - & 06 & - & 02 & - & 35 & 24 & 44,3 & 55,7 & 59 & 23,4 \\
\hline Evandromyia lenti & - & - & - & 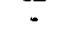 & 01 & - & - & - & 01 & - & 02 & - & 100,0 & - & 02 & 0,8 \\
\hline Evandromyia sallesi & - & - & - & - & - & - & 01 & - & - & - & 01 & - & 100,0 & - & 01 & 0,4 \\
\hline Evandromyia termitophila & - & - & - & - & - & - & 01 & - & - & - & 01 & - & 100,0 & - & 01 & 0,4 \\
\hline Psychodopygus lloydi & $=$ & - & 01 & - & - & - & - & - & - & 01 & 01 & 01 & 50,0 & 50,0 & 02 & 0,8 \\
\hline Brumptomyia nitzulescui & - & - & 01 & - & - & - & - & 01 & - & - & 01 & 01 & 50,0 & 50,0 & 02 & 0,8 \\
\hline Brumptomyia cardosoi & - & - & - & - & - & - & 01 & 02 & 01 & 02 & 02 & 04 & 33,3 & 66,7 & 06 & 2,4 \\
\hline Bnumptomyia sp. & - & - & - & - & - & - & 01 & - & - & - & 01 & - & 100,0 & - & 01 & 0,4 \\
\hline Subtotal & 31 & 52 & 47 & 19 & 07 & 01 & 58 & 10 & 22 & 05 & 165 & 87 & & & & \\
\hline$\%$ & 37,3 & 62,7 & 71,2 & 28,8 & 87,5 & 12,5 & 85,3 & 14,7 & 81,5 & 18,5 & 65,5 & 34,5 & & & & \\
\hline TOTAL & \multicolumn{2}{|c|}{83} & \multicolumn{2}{|c|}{66} & \multicolumn{2}{|c|}{08} & \multicolumn{2}{|c|}{68} & \multicolumn{2}{|c|}{27} & & & & \multicolumn{3}{|c|}{252} \\
\hline$\%$ & \multicolumn{2}{|c|}{32,9} & \multicolumn{2}{|c|}{26,2} & \multicolumn{2}{|c|}{3,2} & \multicolumn{2}{|c|}{27,0} & \multicolumn{2}{|c|}{10,7} & & & & & & 100,0 \\
\hline
\end{tabular}

Quantidade de armadilhas por ponto de captura:

Amoreira $=01 \quad$ Lavoura $=03 \quad$ Domicilio $=02$

Total de armadilhas por campanha de campo $=09$

Galinheiro $=01 \quad$ Mata $=02$ 
Tabela 09 - Espécies de flebotomineos capturados no município Conceição da Aparecida, nas armadilhas tipo CDC, por ecótopos e por sexo, no período de maio de 2001 a outubro de 2002.

\begin{tabular}{|c|c|c|c|c|c|c|c|c|c|c|c|c|c|c|c|c|c|c|}
\hline \multirow[t]{2}{*}{ Categoria taxonómica } & \multicolumn{2}{|c|}{ Domicilio } & \multicolumn{2}{|c|}{ Goiabeira } & \multicolumn{2}{|c|}{ Galinheiro } & \multicolumn{2}{|c|}{ Lago } & \multicolumn{2}{|c|}{ Lavoura } & \multicolumn{2}{|c|}{ Mata } & \multicolumn{2}{|c|}{ Subtotal } & \multicolumn{2}{|c|}{$\%$} & \multirow[t]{2}{*}{ TOTAL } & \multirow[t]{2}{*}{$\%$} \\
\hline & $f$ & m & $f$ & $\mathbf{m}$ & $f$ & $m$ & $f$ & m & $f$ & m & $f$ & $\mathrm{~m}$ & $\mathbf{f}$ & m & $f$ & m & & \\
\hline Nyssomyia whitmani & 64 & 111 & 32 & 29 & 129 & 49 & 13 & 12 & 49 & 15 & 55 & 18 & 342 & 234 & 59,4 & 40,6 & 576 & 60,6 \\
\hline Nyssomyia intermedia & 01 & - & - & - & 01 & - & - & - & 01 & - & - & - & 03 & - & 100,0 & - & 03 & 0.3 \\
\hline Pintomyia monticola & 03 & - & - & - & 03 & - & 04 & 01 & 03 & & 20 & 03 & 33 & 04 & 89,2 & 10,8 & 37 & 3,9 \\
\hline Pintomyia fischen & 03 & 01 & 02 & 04 & 23 & 06 & 03 & - & - & 01 & 17 & 10 & 48 & 22 & 68,6 & 31,4 & 70 & 7,4 \\
\hline Pintomyia bianchigalatiae & - & - & - & - & - & - & - & - & - & - & 01 & - & 01 & - & 100,0 & - & 01 & 0,1 \\
\hline Pintomyia misionensis & - & - & 01 & - & - & - & - & - & - & - & - & - & 01 & - & 100,0 & - & 01 & 0,1 \\
\hline Migonemyia migonei & 16 & 04 & 06 & 15 & 69 & 52 & 10 & 05 & 09 & 01 & 11 & 03 & 121 & 80 & 60,2 & 39,2 & 201 & 21,1 \\
\hline Evandromyia lenti &, 03 & 04 & - & 02 & 12 & 08 & 04 & 01 & 05 & 02 & 04 & - & 28 & 17 & 62,2 & 37,8 & 45 & 4,7 \\
\hline Evandromyia sallesi & 01 & - & - & - & 01 & - & - & - & $\infty 6$ & - & - & - & $O B$ & - & 100,0 & - & 08 & 0,9 \\
\hline Evandromyia termitophila & - & - & - & - & - & - & - & - & 01 & - & - & - & 01 & - & 100,0 & - & 01 & 0,1 \\
\hline Lutzomyia longipalois & - & - & - & - & - & 02 & - & - & - & - & - & - & - & 02 & - & 100,0 & 02 & 0,2 \\
\hline Psychodopygus Iloydi & - & - & - & - & - & - & - & - & - & - & 05 & 01 & 05 & 01 & 83,3 & 16,7 & 06 & 0,6 \\
\hline Subtotal & 91 & 120 & 41 & 50 & 238 & 117 & 34 & 19 & 74 & 19 & 113 & 35 & 591 & 360 & & & & \\
\hline$\%$ & 43,1 & 56,9 & 45,0 & 55,0 & 67,0 & 33,0 & 64,2 & 35,8 & 79,6 & 20,4 & 76,4 & 23,6 & 62,2 & 37,8 & & & & \\
\hline TOTAL & \multicolumn{2}{|c|}{211} & \multicolumn{2}{|c|}{91} & \multicolumn{2}{|c|}{355} & \multicolumn{2}{|c|}{53} & \multicolumn{2}{|c|}{93} & \multicolumn{2}{|c|}{148} & & & & \multicolumn{3}{|c|}{951} \\
\hline$\%$ & \multicolumn{2}{|c|}{22,2} & \multicolumn{2}{|c|}{9,6} & \multicolumn{2}{|c|}{37,3} & \multicolumn{2}{|c|}{5,6} & \multicolumn{2}{|c|}{9,8} & \multicolumn{2}{|c|}{15,6} & & & & & & 100,0 \\
\hline
\end{tabular}

Quantidade de armadilhas por ponto de captura:

Mata = 02; Galinheiro = 01; Domicilio = 02; Lavoura $=03 ;$ Lago $=01 ;$ Goiabeira $=01$

Total de armadilhas por campanha de campo $=10$ 


\subsection{Distribuição sazonal de flebotomíneos capturados e os dados climatológicos}

A tabela 10 e a figura 14 demonstram a distribuição dos flebotomíneos capturados com a armadilhas CDC e Shannon, no municipio de Jacutinga. Ressalta-se que os resultados computados para a caracterização sazonal referem-se ao periodo compreendido entre novembro de 2001 e outubro de 2002, periodo no qual está compreendido um ciclo climatológico completo.

O mesmo resultado será apresentado pelas tabelas 11 e 12 e figuras 15 e 16, para os municípios de Machado e Conceição da Aparecida.

Tabela 10 - Flebotomíneos capturados no municipio de Jacutinga/MG, por tipo de armadilha, no periodo de maio de 2001 a novembro de 2002.

\begin{tabular}{lccc}
\hline \multicolumn{1}{c}{ Mês/Armadilhas } & CDC & SHANNON & TOTAL \\
Maio/2001 & - & - & - \\
Junho/2001 & - & - & - \\
Julho/2001 & 01 & - & 01 \\
Agosto/2001L & 03 & - & 03 \\
Setembro/2001 & - & - & - \\
Outubro/2001 & - & - & - \\
Novembro/2001 & 08 & - & 08 \\
Dezembro/2001 & - & - & - \\
Janeiro/2002 & 08 & - & 08 \\
Fevereiro/2002 & 02 & 17 & 19 \\
Março/2002 & 08 & - & 08 \\
Abril/2002 & 13 & 26 & 39 \\
Maio/2002 & - & 07 & 07 \\
Junho/2002 & 06 & 06 & 12 \\
Julho/2002 & - & - & - \\
Agosto/2002 & 01 & 08 & 09 \\
Setembro/2002 & 07 & 51 & 58 \\
Outubro/2002 & - & - & - \\
TOTAL & 57 & 115 & 172 \\
\hline
\end{tabular}




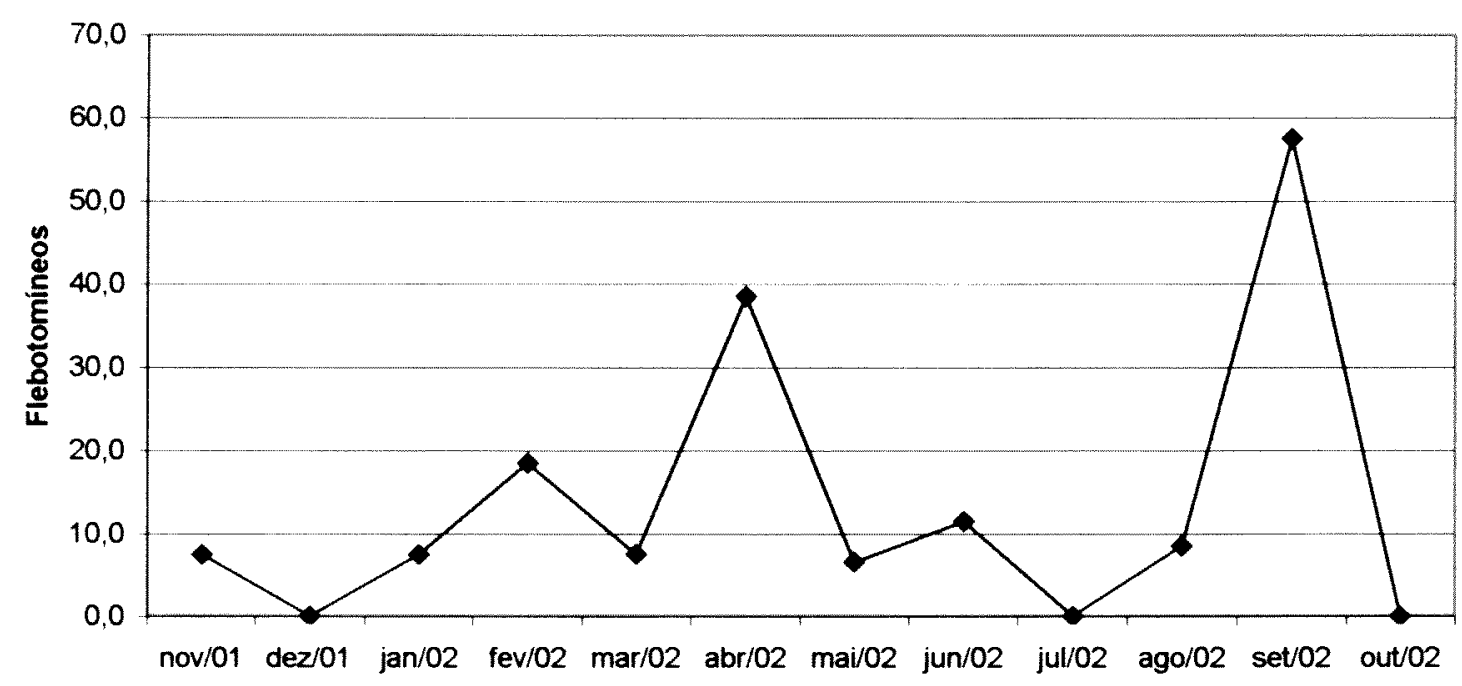

Figura 14 - Distribuição sazonal de flebotomíneos capturados no município de Jacutinga/MG, nas armadilhas de CDC e Shannon, no período de novembro de 2001 a outubro de 2002.

Tabela 11 - Flebotomíneos capturados no município de Machado/MG, por tipo de armadilha, no periodo de maio de 2001 a novembro de 2002.

\begin{tabular}{lccc}
\hline Localidade/Armadilhas & CDC & SHANNON & TOTAL \\
Maio/2001 & 09 & - & 09 \\
Junho/2001 & 03 & 03 & 06 \\
Julho/2001 & - & 17 & 17 \\
Agosto/2001L & 20 & - & 20 \\
Setembro/2001 & 02 & - & 02 \\
Outubro/2001 & 02 & 01 & 03 \\
Novembro/2001 & - & 01 & 01 \\
Dezembro/2001 & 02 & 06 & 08 \\
Janeiro/2002 & 75 & 03 & 78 \\
Fevereiro/2002 & - & - & - \\
Março/2002 & 03 & 05 & 08 \\
Abril/2002 & 22 & 20 & 42 \\
Maio/2002 & 26 & 19 & 45 \\
Junho/2002 & 05 & 04 & 09 \\
Julho/2002 & 07 & - & 07 \\
Agosto/2002 & 12 & 01 & 13 \\
Setembro/2002 & 64 & 01 & 65 \\
Outubro/2002 & - & - & - \\
TOTAL & 252 & 81 & 333 \\
\hline
\end{tabular}




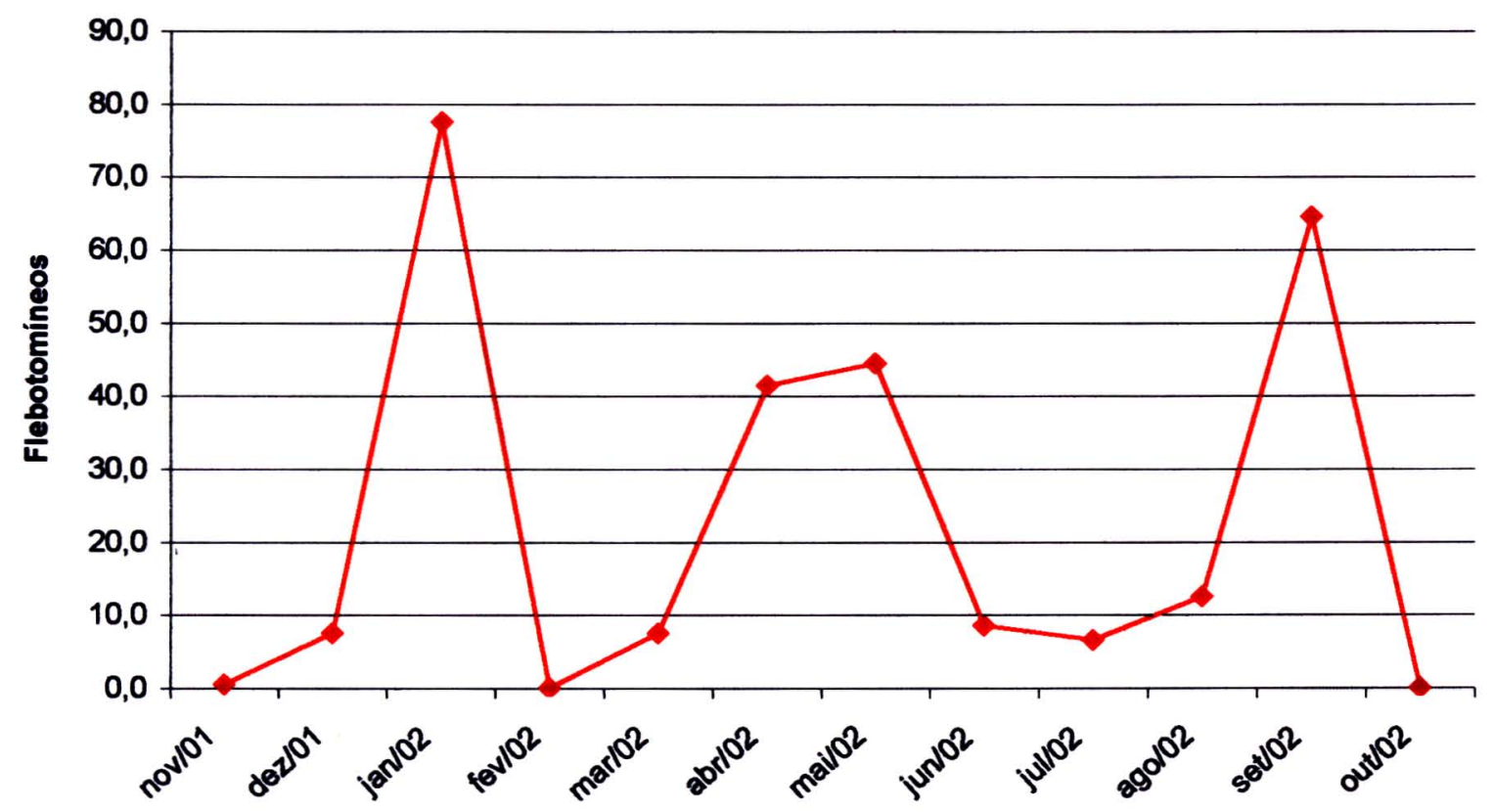

Figura 15 - Distribuição sazonal de flebotomíneos capturados no município de Machado/MG, nas armadilhas de CDC e Shannon, no período de novembro de 2001 a outubro de 2002.

Tabela 12 - Flebotomíneos capturados no município de Conceição da Aparecida/MG, por tipo de armadilha, no período de maio de 2001 a novembro de 2002.

\begin{tabular}{lccc}
\hline Localidade/Armadilhas & CDC & SHANNON & TOTAL \\
Maio/2001 & 34 & 33 & 67 \\
Junho/2001 & 13 & 01 & 14 \\
Julho/2001 & 05 & - & 05 \\
Agosto/2001L & 11 & - & 11 \\
Setembro/2001 & 103 & - & 103 \\
Outubro/2001 & 06 & - & 06 \\
Novembro/2001 & 49 & 23 & 72 \\
Dezembro/2001 & - & - & - \\
Janeiro/2002 & 216 & 264 & 480 \\
Fevereiro/2002 & 61 & 04 & 65 \\
Março/2002 & 62 & 24 & 86 \\
Abril/2002 & 201 & 127 & 329 \\
Maio/2002 & 16 & 06 & 22 \\
Junho/2002 & 07 & 09 & 16 \\
Julho/2002 & 119 & - & 119 \\
Agosto/2002 & 19 & 02 & 21 \\
Setembro/2002 & 24 & - & 24 \\
Outubro/2002 & 05 & - & 05 \\
TOTAL & & 493 & 1444 \\
\hline
\end{tabular}




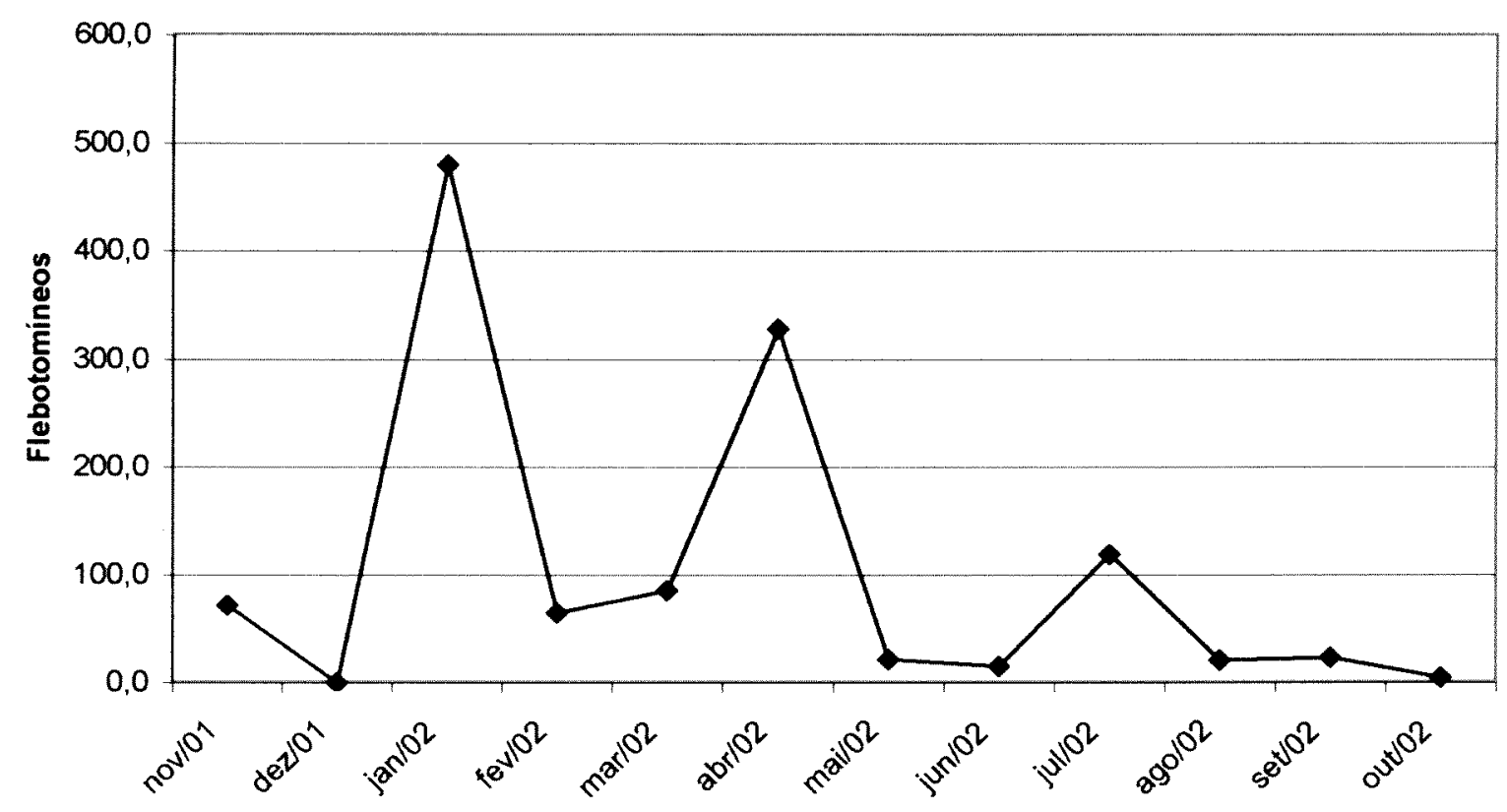

Figura 16 - Distribuição sazonal de flebotomineos capturados no município de Conceição da Aparecida/MG, nas armadilhas de CDC e Shannon, no período de novembro de 2001 a outubro de 2002.

O gráfico da figura 14 mostra claramente dois picos de distribuição de flebotomineos, nos meses de abril de 2001 e setembro de 2002, em Jacutinga. No municipio de Machado ocorreram três picos, em janeiro de 2002 , maio de 2002 e setembro de 2002, um pouco semelhante à distribuição sazonal em Conceição da Aparecida. Neste último, o terceiro pico ocorreu, com menor intensidade, no mês de julho de 2002.

As figuras 17 e 18 apresentam os dados de temperaturas e pluviosidade usados como referencial para o municipio de Conceição da Aparecida e coletados junto à Estação Climatológica da CEMIG em Passos/MG.

Os dados climatológicos referentes aos municípios de Machado e Jacutinga estão apresentados nas figuras 19 e 20. Estes foram obtidos junto à Estação Climatológica da CEMIG em Botelhos/MG. 
Deve-se ressaltar que a ausência de dados de temperaturas nos meses de setembro e outubro de 2002, na estação climatológica de Passos/MG se deveu a problemas técnicos do sistema deixando estas medidas sem ser computadas durante este periodo. 


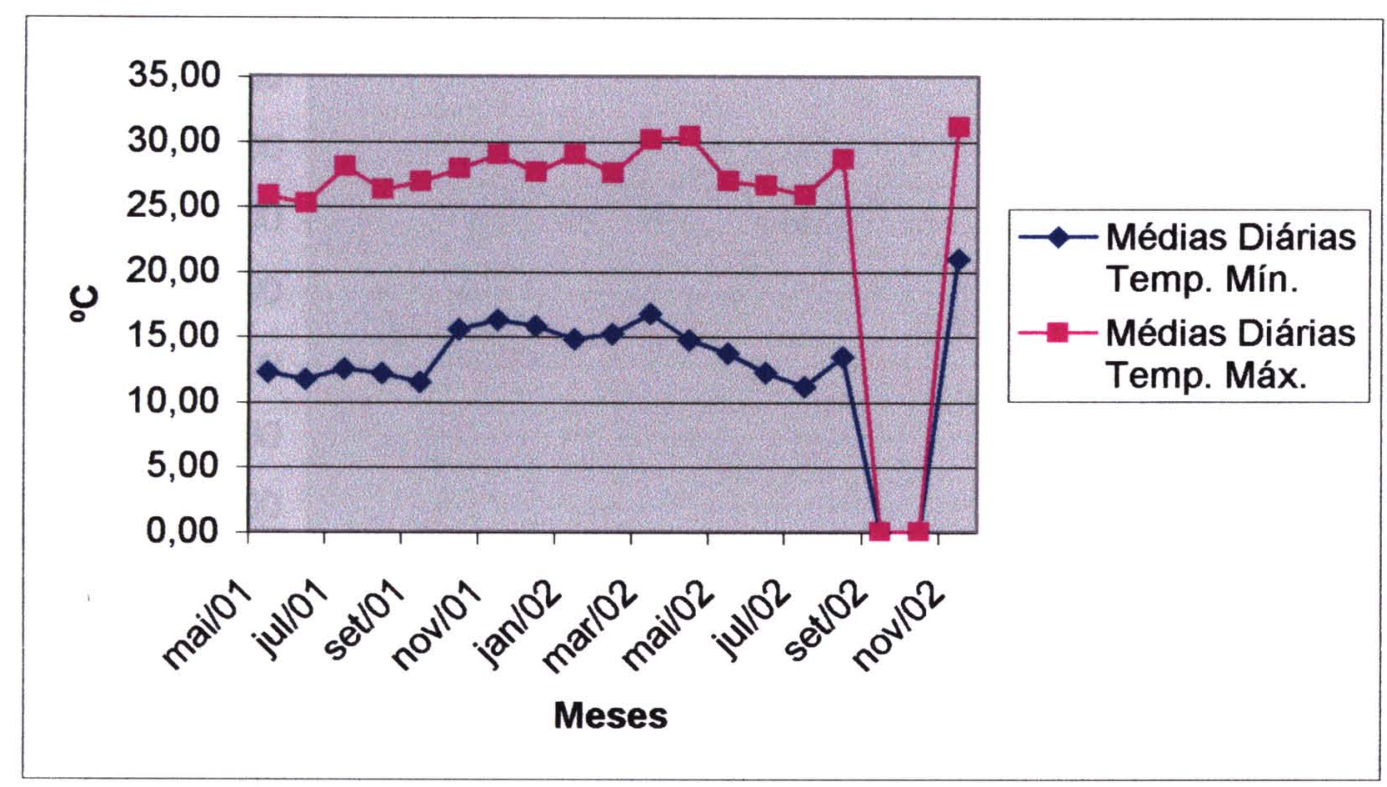

Figura 17 - Médias mensais de temperaturas máximas e mínimas diárias da estação climatológica da Companhia Energética de Minas Gerais - CEMIG, em Passos/MG, referente ao município de Conceição da Aparecida/MG, no período de maio de 2001 a outubro de 2002.

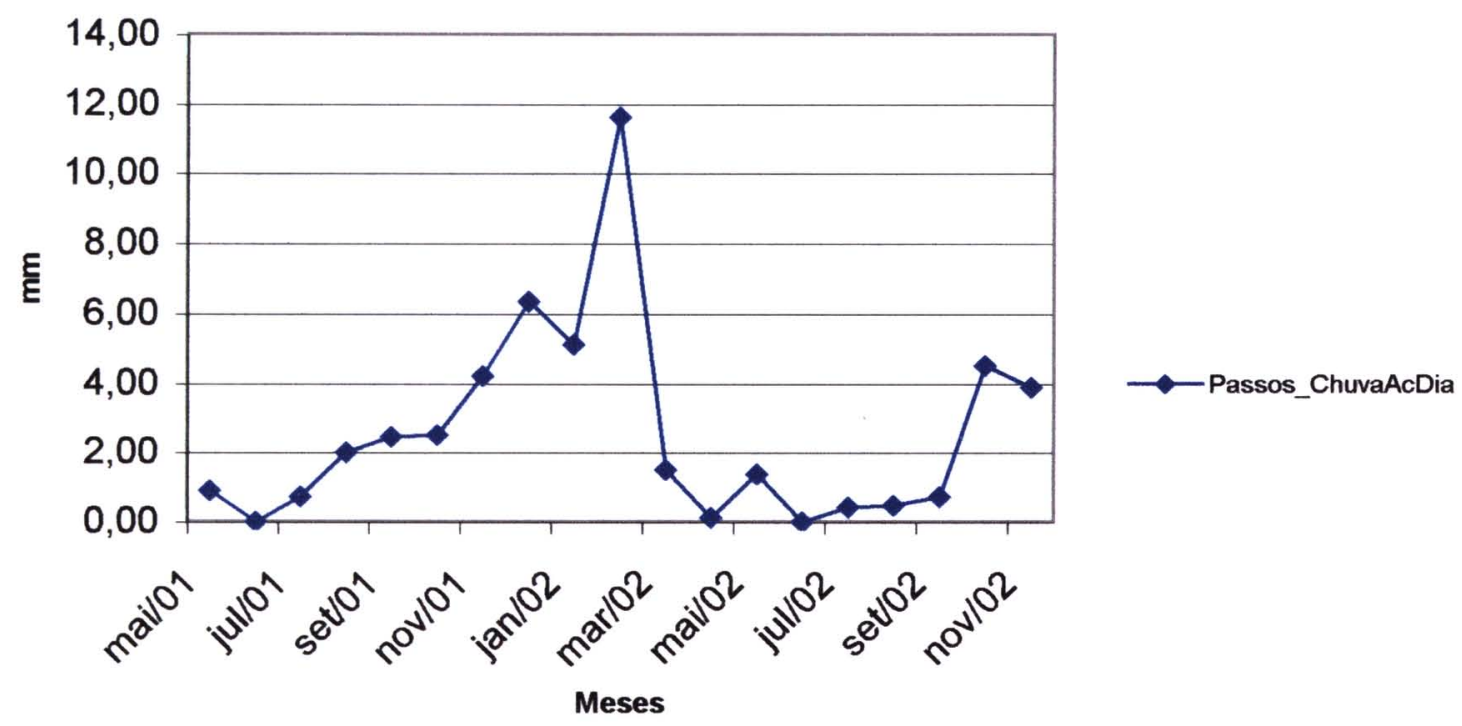

Figura 18 - Médias diárias mensais de pluviosidade da estação climatológica da Companhia Energética de Minas Gerais - CEMIG, em Passos/MG, referente ao município de Conceição da Aparecida/MG, no período de maio de 2001 a outubro de 2002. 


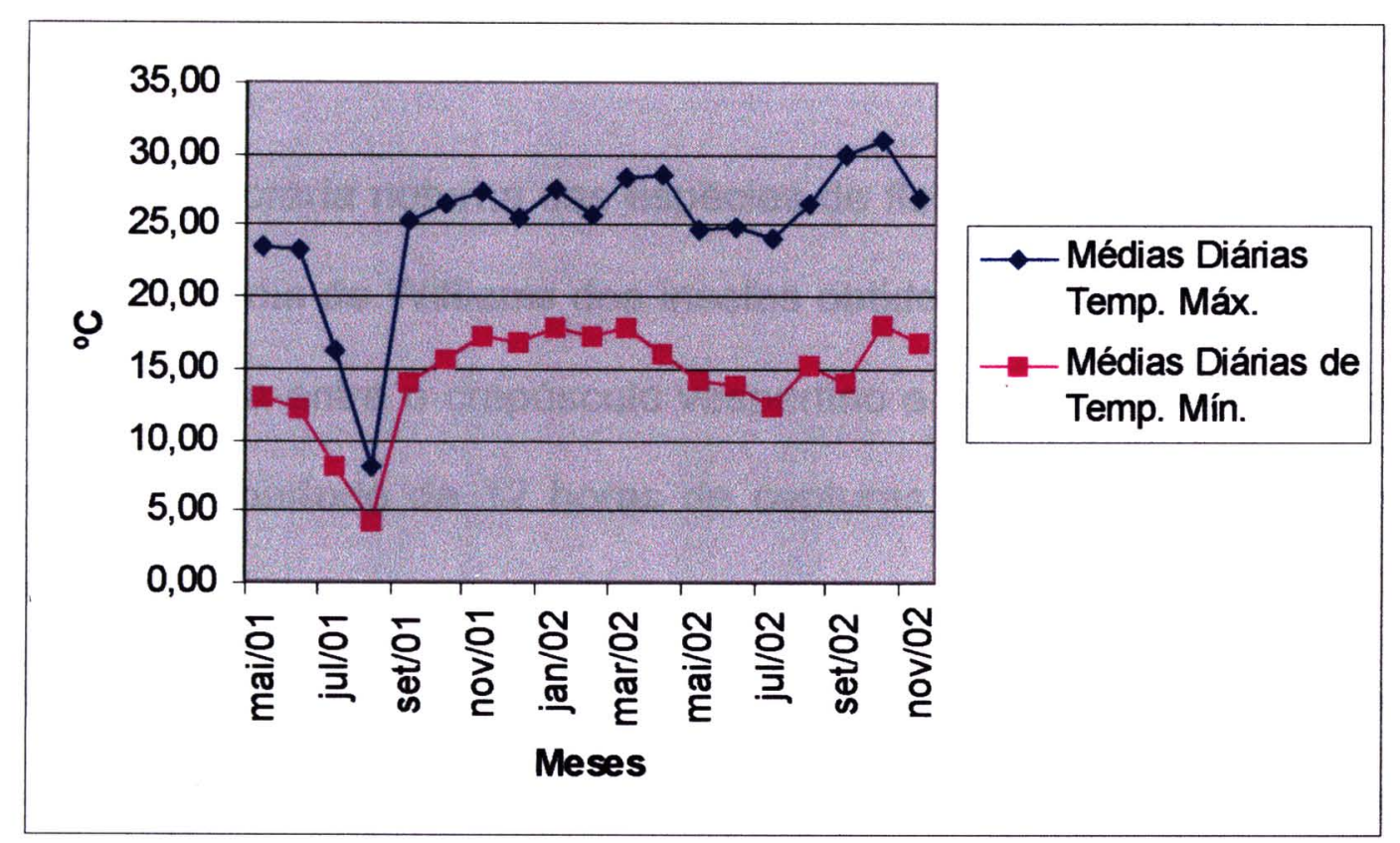

Figura 19 - Médias mensais de temperaturas máximas e mínimas diárias da estação climatológica da Companhia Energética de Minas Gerais - CEMIG, em Botelhos/MG, referente aos municípios de Machado e Jacutinga, no período de maio de 2001 a outubro de 2002.

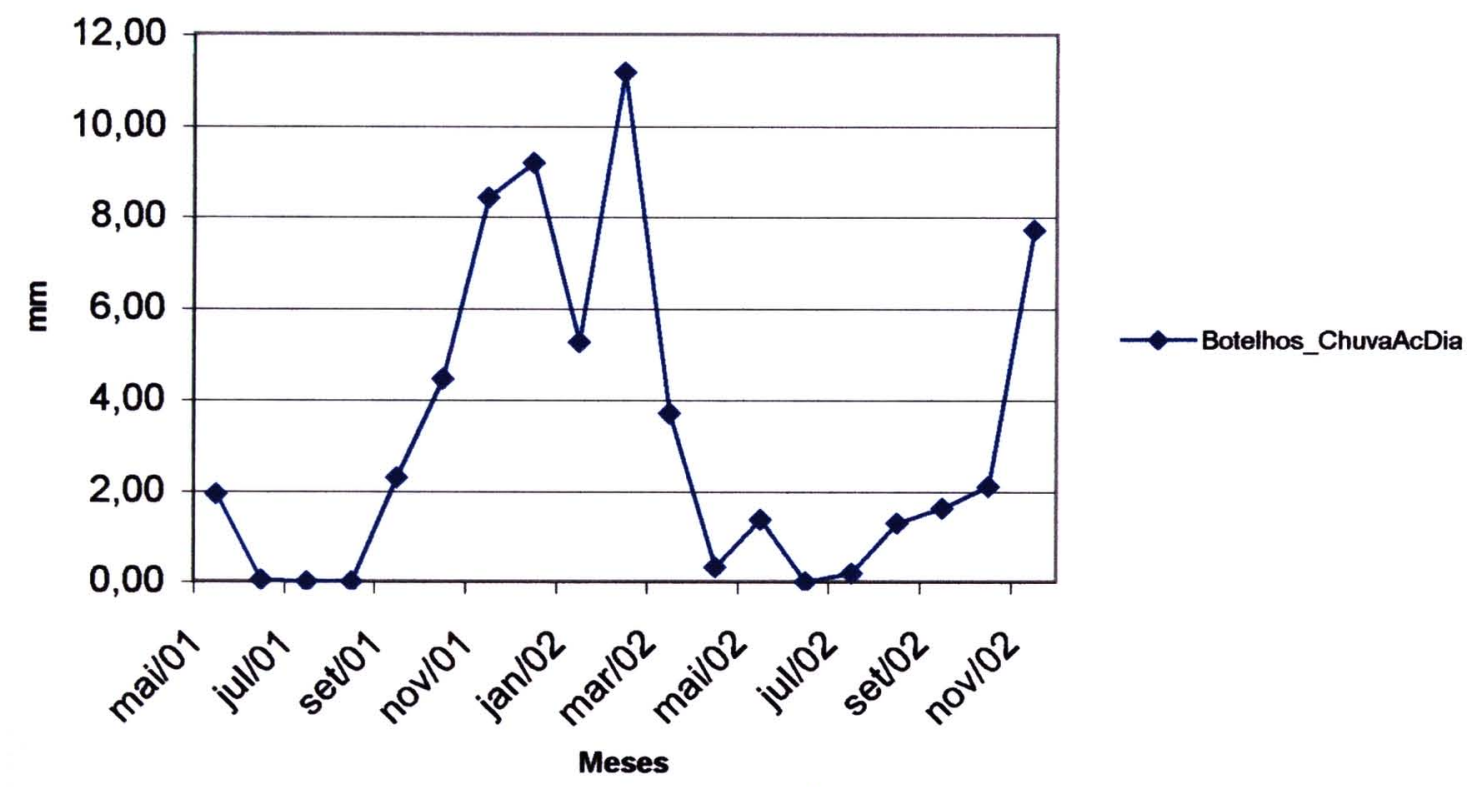

Figura 20 - Médias diárias mensais de pluviosidade da estação climatológica da Companhia Energética de Minas Gerais - CEMIG, em Botelhos/MG, referente aos municípios de Machado e Jacutinga, no periodo de maio de 2001 a outubro de 2002. 


\subsection{Freqüência horária noturna das espécies de Flebotomíneos}

A freqüência horária noturna das espécies de flebotomíneos capturadas foi calculada pela Média de Williams dos insetos obtidos através da armadilha de Shannon, realizada entre o crepúsculo vespertino e o crepúsculo matutino, compreendendo um período de 12 horas de capturas uma vez por mês, em cada município pesquisado.

Sendo assim, estes resultados serão apresentados a seguir em forma de gráficos, para melhor ilustrar a distribuição horária das espécies capturadas através desta metodologia. Serão destacadas também as espécies mais abundantes em cada um dos municípios.

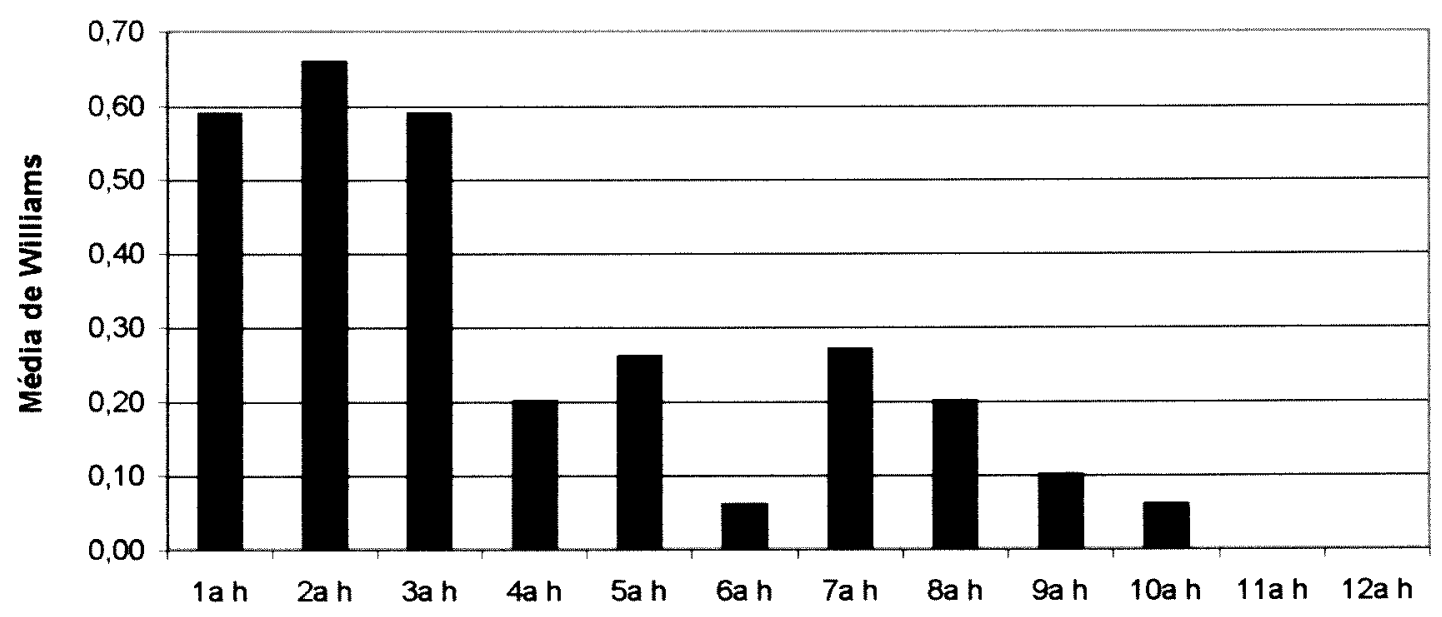

Figura 21 - Distribuição horária das espécies de flebotomíneos capturados no municipio de Jacutinga/MG, na armadilha de Shannon, no período de novembro de 2001 a outubro de 2002.

Nesta figura 21 percebe-se uma maior concentração dos flebotomíneos nas primeiras horas do crepúsculo vespertino, mas a atividade se prolonga de uma maneira homogenia durante toda a noite. 


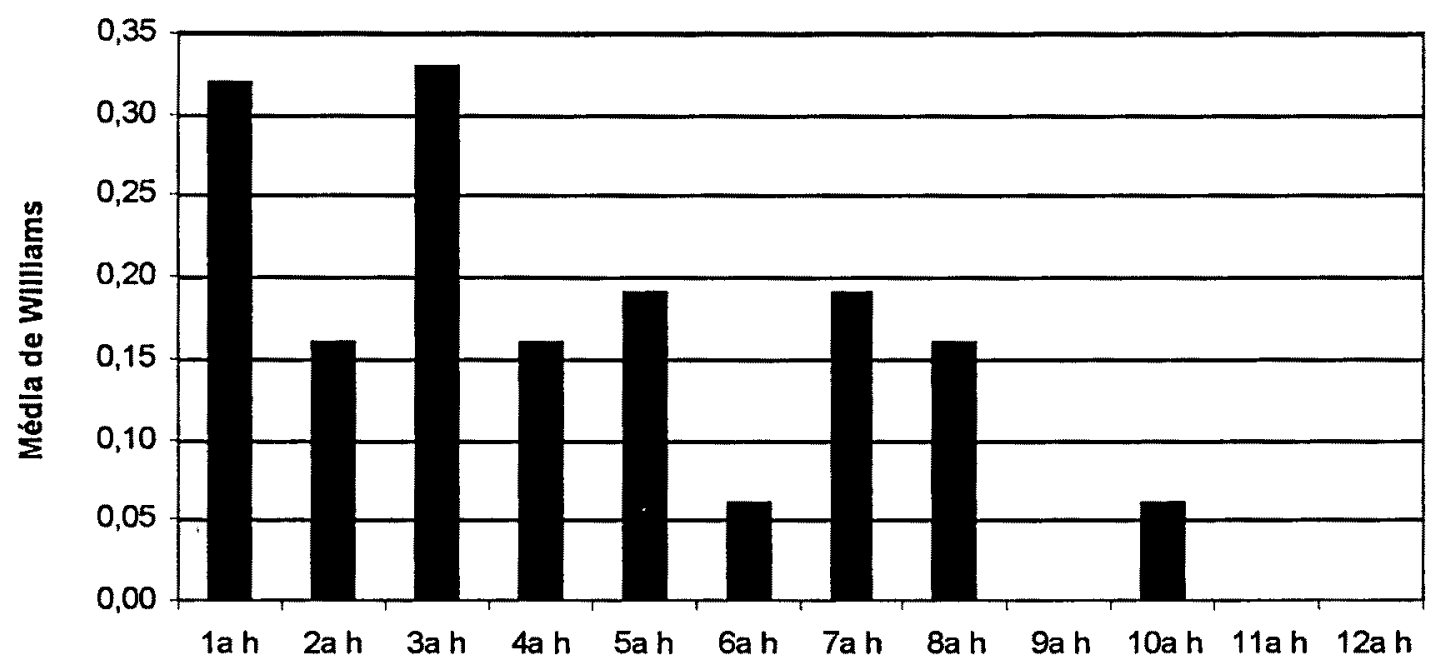

Figura 22 - Distribuição horária da espécie Nyssomyia neivai capturada no município de Jacutinga/MG, na armadilha de Shannon, no periodo de novembro de 2001 a outubro de 2002.

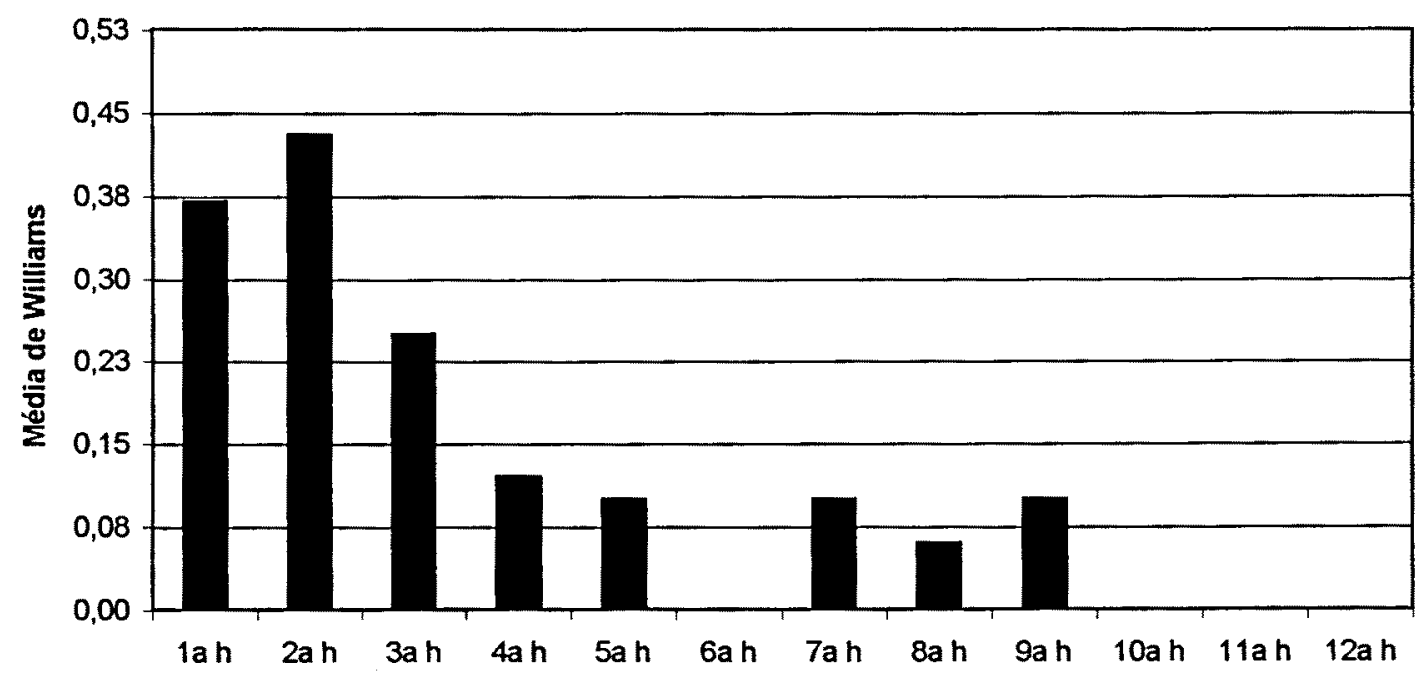

Figura 23 - Distribuição horária da espécie Pintomyia monticola capturada no município de Jacutinga/MG, na armadilha de Shannon, no período de novembro de 2001 a outubro de 2002.

Nas figuras 22 e 23 são apresentadas as espécies $N y$. neivai, a mais abundante nesta localidade, e a Pi. monticola, segunda mais capturada. Observa-se uma atividade durante praticamente toda à noite para a primeira, com maiores concentrações no início do periodo. Já a Pi. monticola se concentra mais nas primeiras horas. 


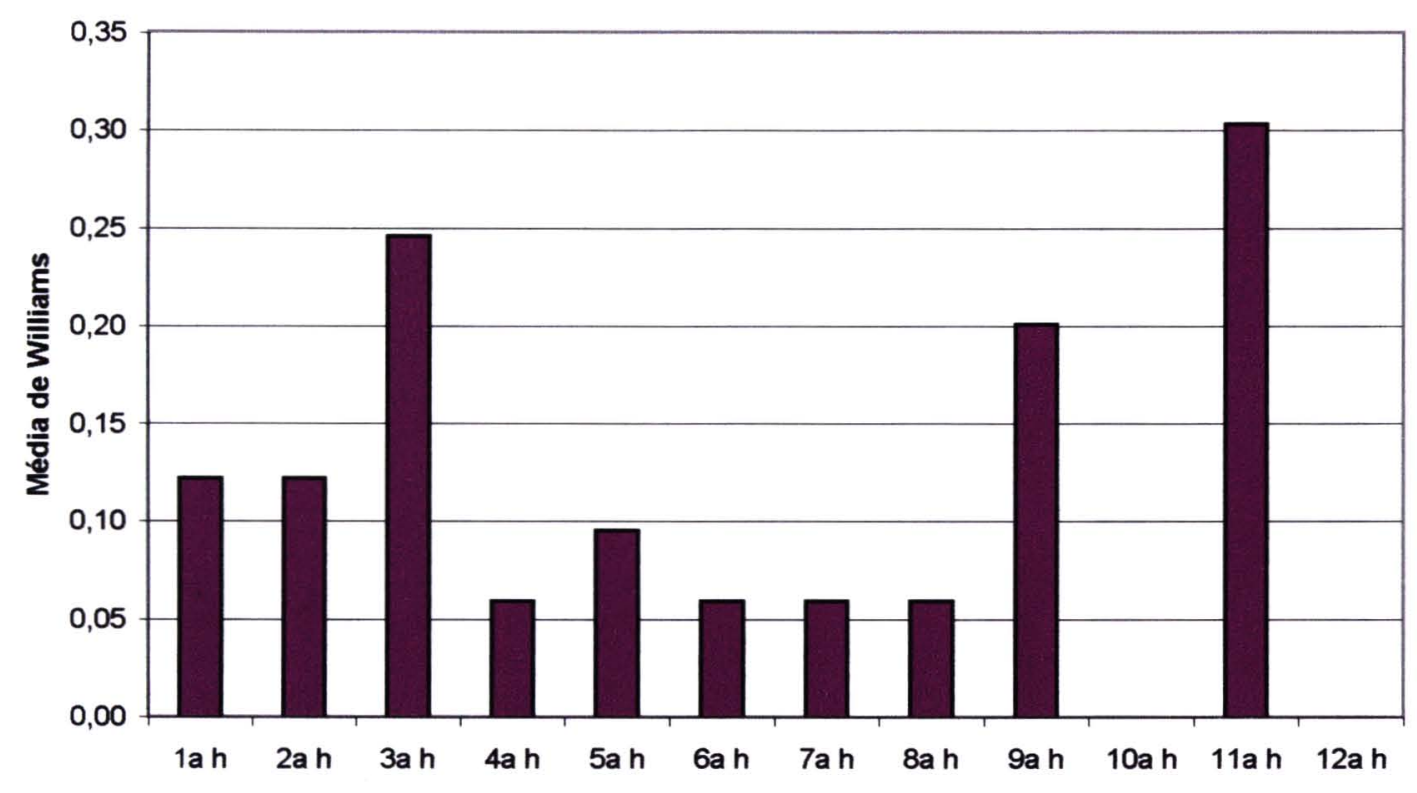

Figura 24 - Distribuição horária das espécies de flebotomíneos capturados no município de Machado/MG, na armadilha de Shannon, no período de novembro de 2001 a outubro de 2002.

Esta figura 24 mostra, no municipio de Machado/MG, uma distribuição horária das espécies capturadas com atividades durante toda a noite e com picos na terceira hora e no crepúsculo matutino na $11^{\mathrm{a}}$ primeira hora.

A espécie mais abundante em Machado, na armadilha de Shannon, foi a Ny. whitmani. O seu respectivo gráfico, na figura 25 , apresenta a distribuição horária desta espécie, a qual parece ser a responsável pelos picos de distribuiçăo. Pois no gráfico geral, da figura 24, são, praticamente, reproduzidos os picos de atividade da Ny. whitmani.

A figura 26 mostra a distribuição horária das espécies capturadas no município de Conceição da Aparecida, onde percebe-se uma distribuição maior das espécies durante toda a noite, assemelhando-se à distribuição horária em Jacutinga, mas com maior concentração nas primeira metade da noite. 


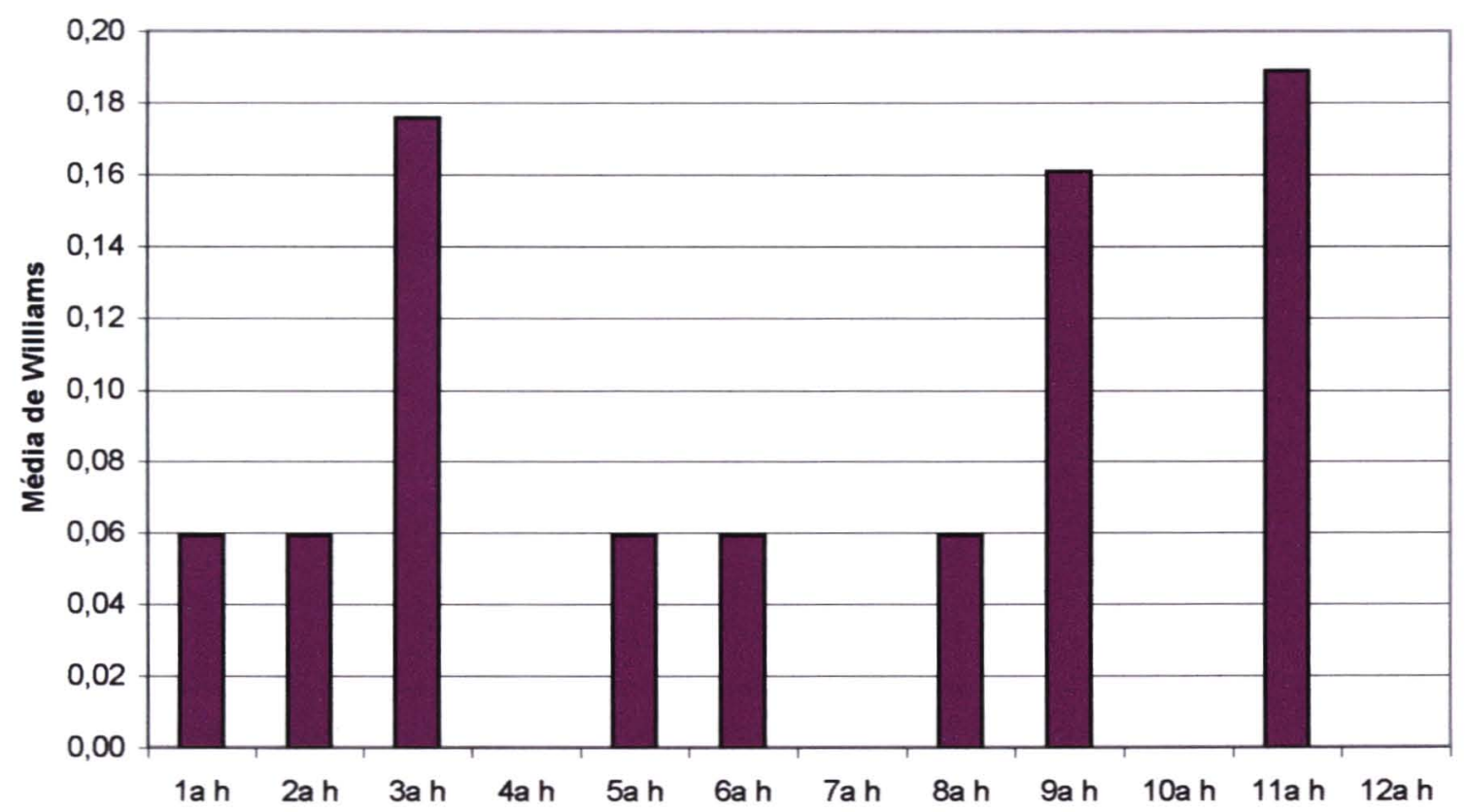

Figura 25 - Distribuição horária da espécie Nyssomyia whitmani capturada no município de Machado/MG, na armadilha de Shannon, no período de novembro de 2001 a outubro de 2002.

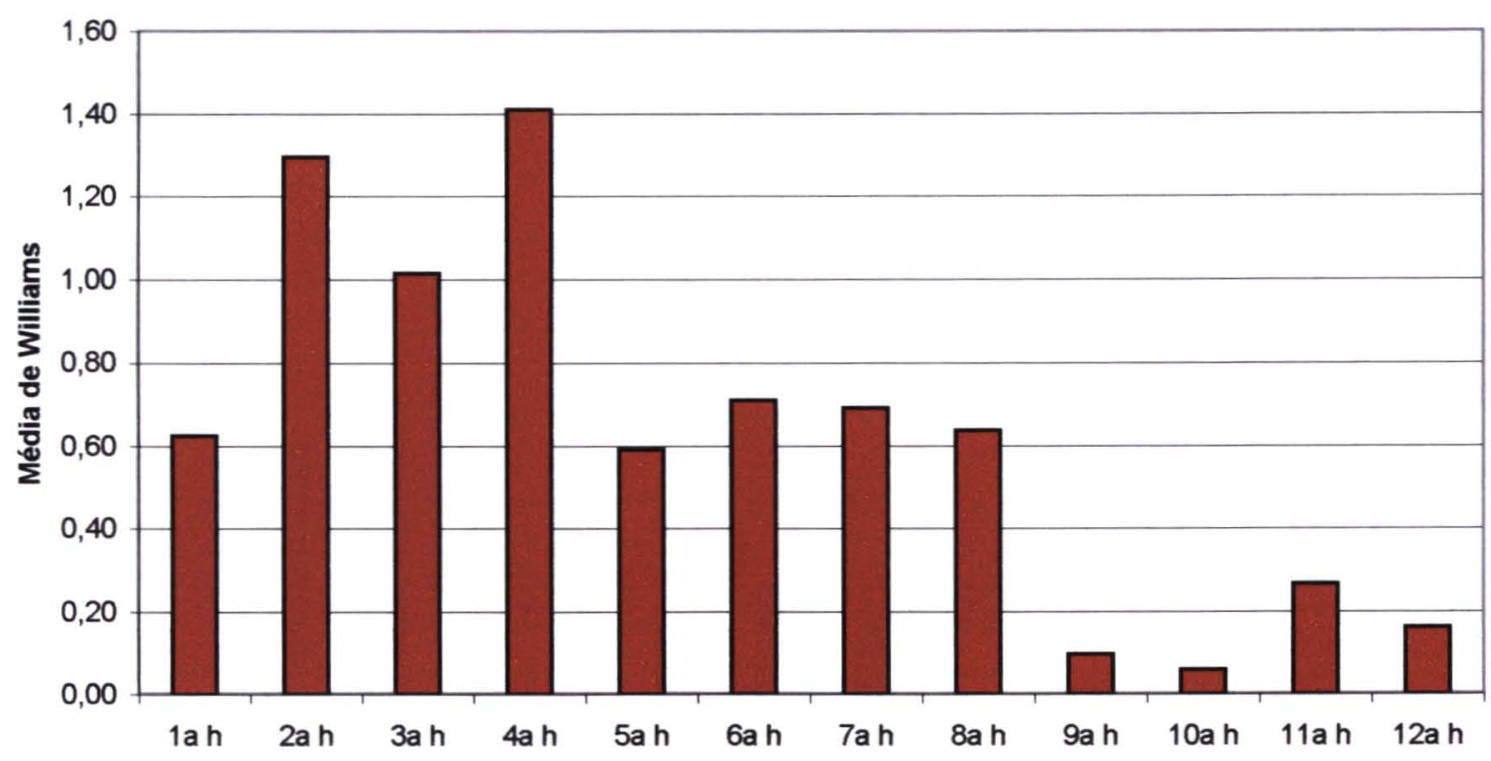

Figura 26 - Distribuição horária das espécies de flebotomíneos capturados no município de Conceição da Aparecida/MG, na armadilha de Shannon, no período de novembro de 2001 a outubro de 2002. 
As espécies mais abundantes em Conceição da Aparecida foram, $\mathrm{Ny}$. whitmani e Mi. migonei, das quais são apresentas as freqüências horárias nos gráficos das figuras 27 e 28 . Estas espécies possivelmente são as responsáveis pelo delineamento da freqüência horária dos flebotomíneos neste município.

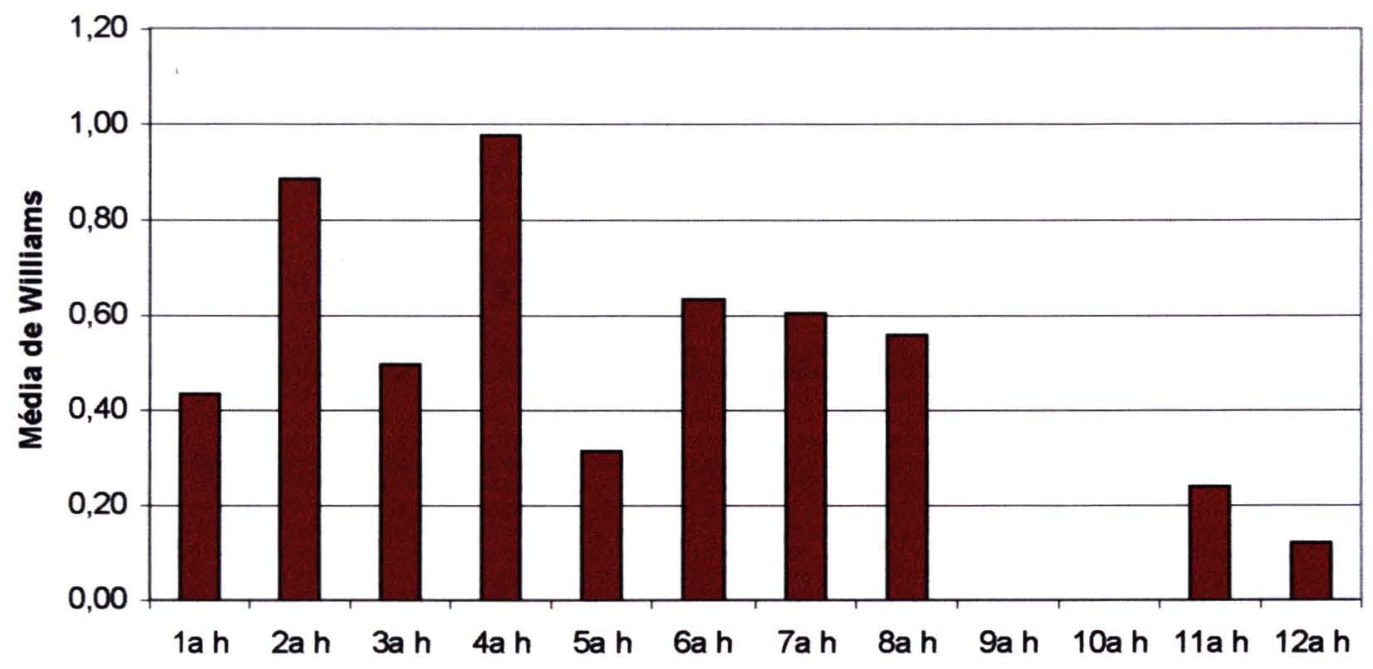

Figura 27 - Distribuição horária da espécie Nyssomyia whitmani capturada no município de Conceição da Aparecida/MG, na armadilha de Shannon, no período de novembro de 2001 a outubro de 2002.

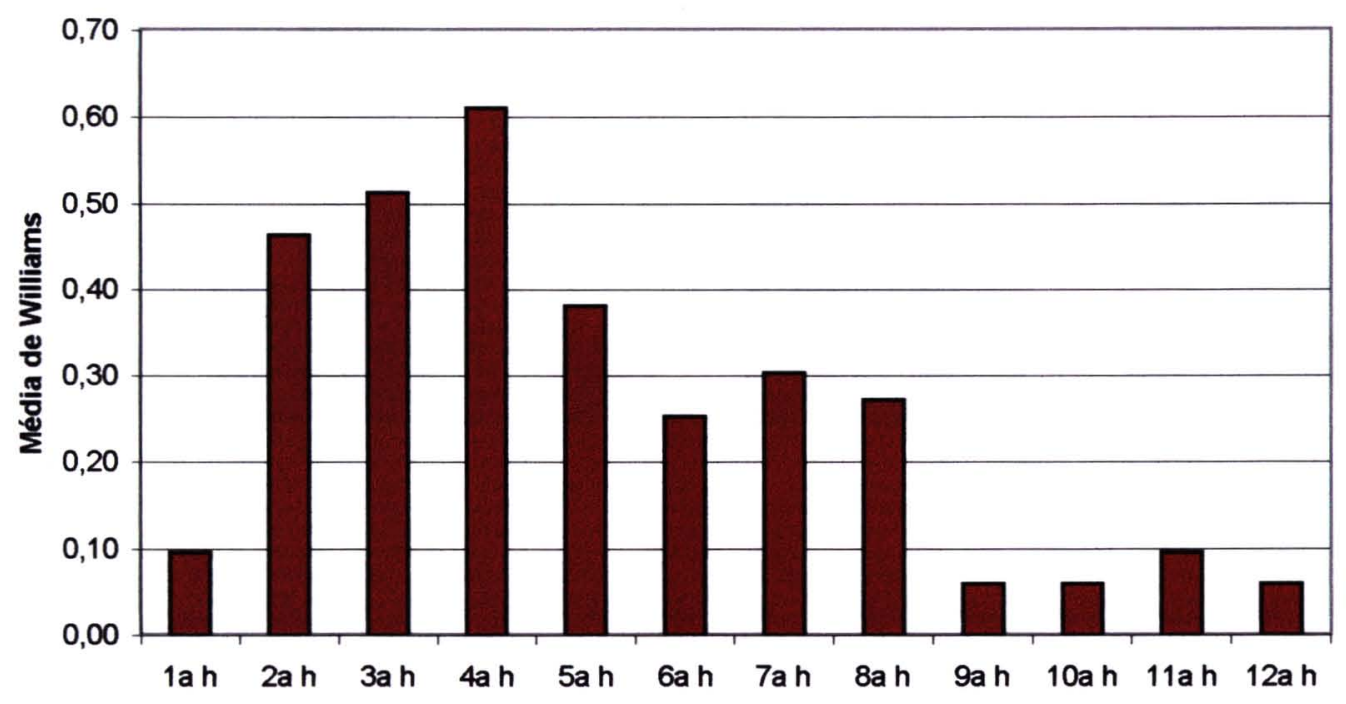

Figura 28 - Distribuição horária da espécie Migonemyia migonei capturada no município de Conceição da Aparecida/MG, na armadilha de Shannon, no período de novembro de 2001 a outubro de 2002. 


\section{7. Índice de abundância de espécies}

O Índice de Abundância de Espécies Padronizado - IAEP, foi calculado sobre as espécies de flebotomíneos capturados nas armadilhas CDC, por ecótopos em cada um dos municípios onde estes insetos forma encontrados, de acordo com a metodologia descrita anteriormente. Portanto, esta análise estará avaliando a abundância de espécies capturadas através das armadilhas automática luminosas tipo $\mathrm{CDC}$, no período de 12 meses, compreendido entre novembro de 2001 a outubro de 2002.

A apresentação do IAEP será em forma de gráficos para cada um dos municípios amostrados.

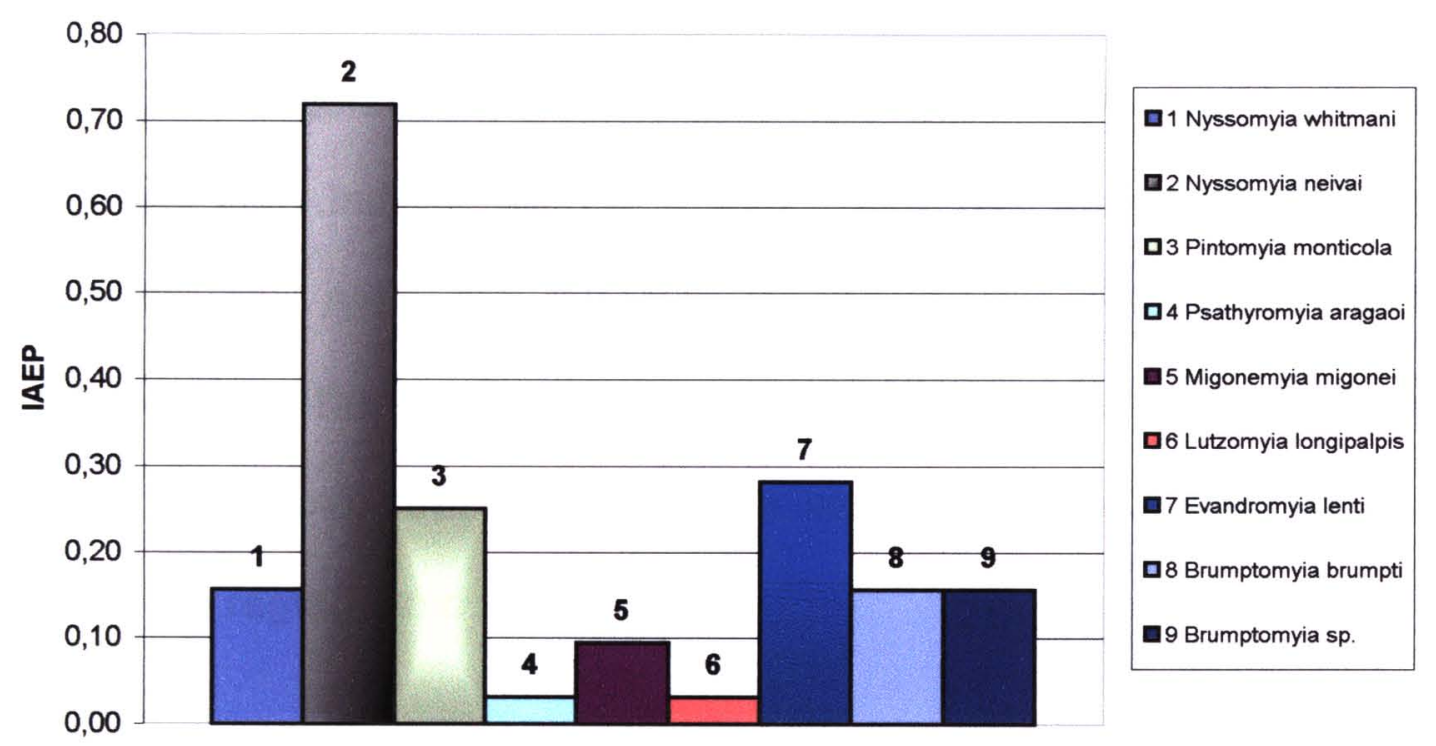

Figura 29 - Índice de Abundância de Espécies Padronizado - IAEP no município de Jacutinga/MG, por armadilha tipo CDC, no período de novembro de 2001 a outubro de 2002. 
A figura 29 apresenta como espécie mais abundante em Jacutinga, a Ni. neivai com um índice de 0,72 , ou seja, é a espécie que apresenta o índice mais próximo de 1. Em seguida aparecem as espécies Ev. lenti, com índice de 0,28 e Pi. monticola, com índice de 0,25 . Sendo assim, como foi mencionado na metodologia deste cálculo, aquelas que apresentam seus indices mais próximos de um (1), são consideradas as mais abundantes e aquelas com índices próximos a zero (0) são as menos abundantes.

No municipio de Machado, de acordo com a figura 30 , as espécies que se apresentaram mais abundantes foram $\mathrm{Ny}$. whitmani e Mi. migonei, com indices de 0,98 e 0,84, respectivamente. Pi. monticola aparece com um índice intermediário de 0,58 , se mostrando com uma abundância média.

Na figura 31, em Conceição da Aparecida, as espécies já apresentam um compartilhamento em termos de abundância aparecendo duas mais abundantes com indices de 1,0 e 0,82, para $\mathrm{Ny}$. whitmani e Mi. migonei, respectivamente. Além das espécies Ev. lenti $(0,61)$, Pi. fischeri $(0,60)$ e Pi. monticola $(0,47)$. Destaca-se ainda, nesta análise a Lu. longipalpis com indice de 0,24 , o que parece bastante relevante, para uma espécie que não havia sido reportada na região até o momento. 


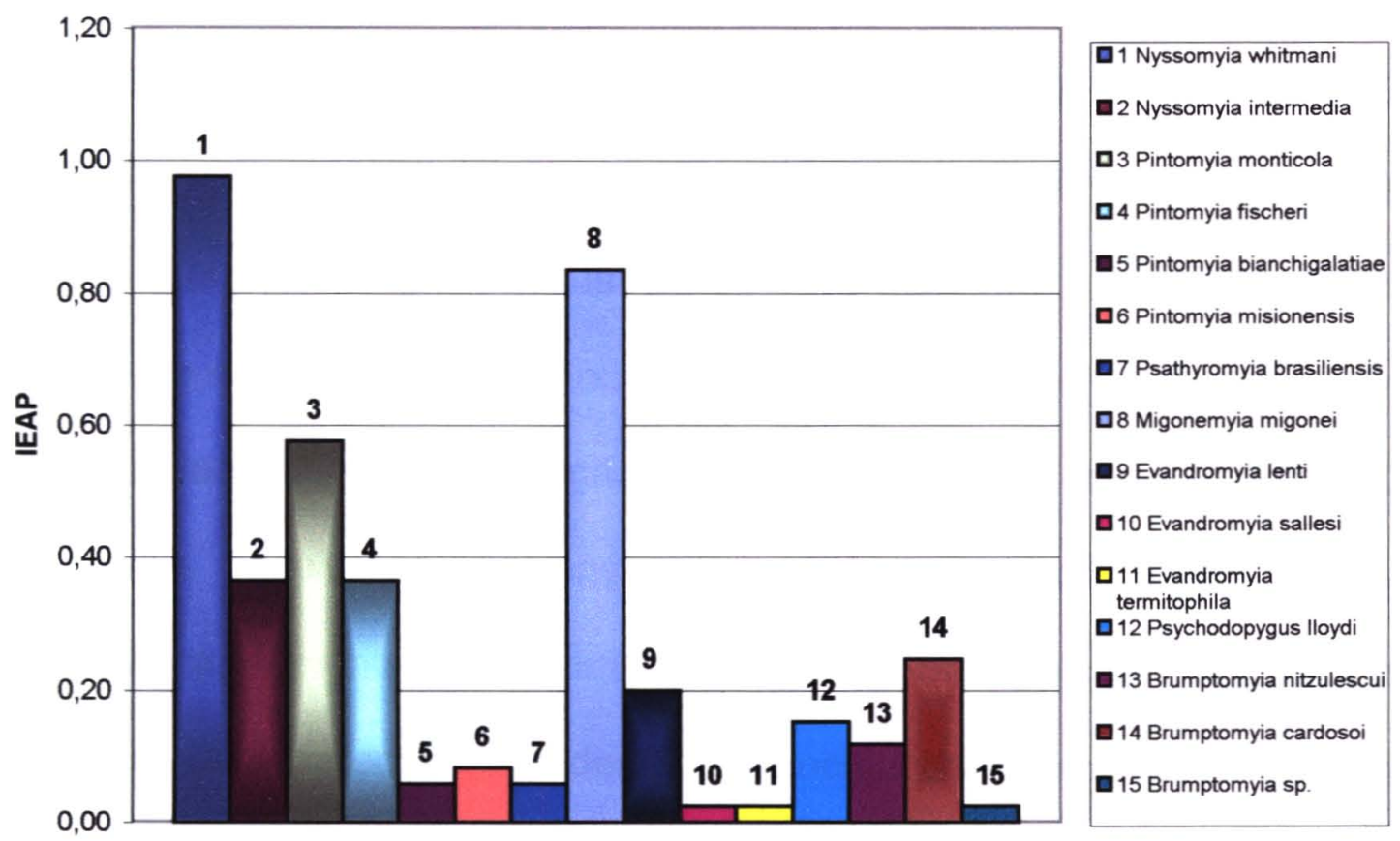

Figura 30 - Índice de Abundância de Espécies Padronizado - IAEP no município de Machado/MG, por armadilha tipo CDC, no período de novembro de 2001 a outubro de 2002.

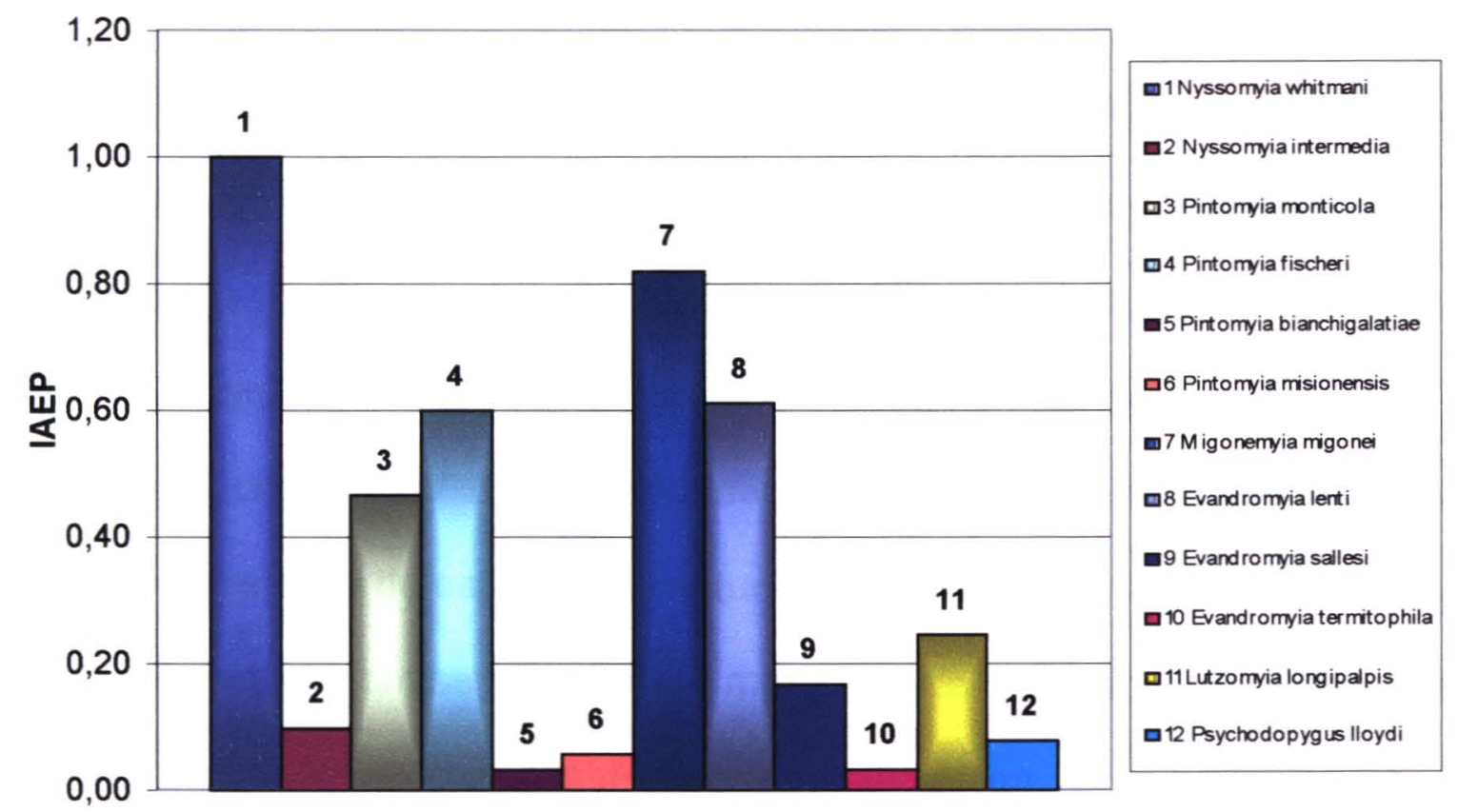

Figura 31 - Índice de Abundância de Espécies Padronizado - IAEP no municipio de Conceição da Aparecida/MG, por armadilha tipo CDC, no período de novembro de 2001 a outubro de 2002. 


\section{8. Índice de Similaridade entre as localidades pesquisadas}

O Índice de Similaridade entre as localidades pesquisadas foi calculado segundo a metodologia descrita, usando-se como bases de dados a tabela 03 Sendo assim, comparando-se Jacutinga com Machado têm-se um índice de similaridade de 0,46, Jacutinga com Conceição da Aparecida têm-se um índice de 0,52 e Machado com Conceição da Aparecida têm-se um índice de 0,83.

Estes resultados demonstram que, perante os dados da fauna flebotomínica, somente existe similaridade entre os municípios de Machado e Conceição da Aparecida. As demais associações demonstram uma menor similaridade entre as faunas encontradas neste estudo.

\subsection{I Índice de Diversidade de espécies capturadas}

O Índice de Diversidade também foi calculado de acordo com a descrição da metodologia, e ele avalia a composição das espécies de um determinado ambiente ou localidade. Deste modo, conforme estes índices estão apresentados na figura 32, percebe-se que no municipio de Machado foi encontrada uma maior diversidade de espécies, em termos de número e abundância relativa de espécimes capturados, segundo o método utilizado para esta análise. Logo em seguida vem o município de Conceição da Aparecida e por fim, com menor diversidade dos três está Jacutinga. 


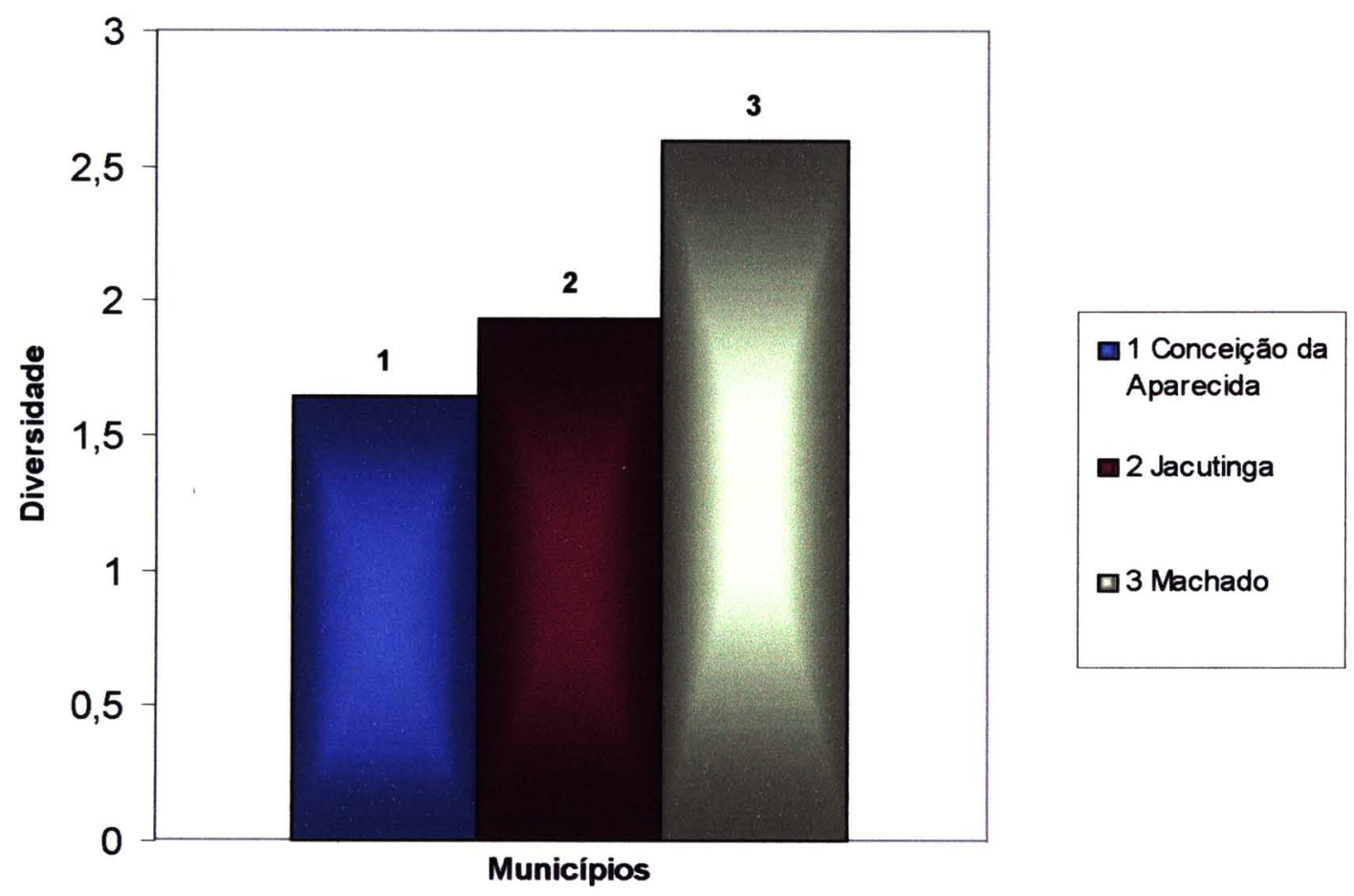

Figura 32 - Índice de Diversidade de Espécies entre os municipios de Jacutinga/MG, Machado/MG e Conceição da Aparecida/MG, frente ao número de espécies encontradas a sua abundância relativa, no período de maio de 2001 a outubro de 2002. 
6. DISCUSSÃO 
Os Coeficientes de Incidência Acumulada da LTA sulmineiros mostram uma semelhança com aqueles das regiões do Estado de São Paulo limítrofes com o sul de Minas Gerais. Foi nessa região de São Paulo onde ocorreu a maior concentração de casos na década de 90 , com os indices variando entre 10,01 a 80,00 casos/100.000 hab. (NEVES 1999). Sendo assim, os Coeficientes (casos/100.000 hab.) de municipios como, Careaçu $(20,05)$, Carvalhópolis $(20,15)$, Conceição da Aparecida $(20,08)$, Machado $(17,99)$, Poço Fundo $(18,07)$, Conceição do Rio Verde $(37,35)$, Ribeirão Vermelho $(19,07)$ demonstram que o sul do Estado Mineiro faz parte da casuística de importância epidemiológica.

Não são notificados com freqüência casos de LVA nestas regiões do Estado de Minas Gerais, mas deve-se destacar o encontro de Lu. longipalpis na presente pesquisa. Destaque este que deve se ressaltar mediante a notificação de um óbito, no ano de 2002, de uma paciente de 22 anos no município de Cabo Verde, vizinho de Conceição da Aparecida, onde foram capturados exemplares desta espécie de importância vetorial. Além disso, é freqüente o trânsito de cães positivos na região, trazidos por universitários e trabalhadores rurais vindos de áreas endêmicas para LVA (BERNIS 1998).

Dentre os municipios enfocados neste estudo, destaca-se o fato do Coeficiente de Incidência da LTA ser nulo em Caldas, e coincidentemente, nesta localidade não ter sido encontrada nenhuma espécie de flebotomíneos. Sendo assim ressalta-se a importância de se investigar com maior profundidade sobre quais os fatores que poderiam estar interferindo negativamente no desenvolvimento da fauna flebotomínica na área do Planalto de Poços de Caldas, especificamente no município de Caldas, onde foram 
realizadas as pesquisas. Sabe-se que a altitude limita a abundância neste grupo de insetos o que afeta diretamente o potencial de transmissão, como visto no trabalho de FERREIRA et al. 2001. Estes autores encontram uma fauna bem diversa de insetos, mesmo em grandes altitudes, o mesmo não pode ser dito para a abundância dos mesmos. Sendo assim, seria possível a existência de fatores ou elementos presentes no solo da localidade pesquisada que possam estar interferindo na biologia e desenvolvimento dos flebotomíneos na área? Possivelmente outros estudos, complementares a este, poderão elucidar e discutir esta hipótese.

Outro fato a ser destacado refere-se à diferença entre o número de casos notificados nos regionais de saúde. Demonstrando uma possivel interferência da Serra da Mantiqueira na potenciação da transmissão. Ou seja, possivelmente a Serra esteja funcionando como uma barreira geográfica na dispersão dos transmissores. Os dados da fauna encontrada na divisa com São Paulo, ao sul da Serra, em Jacutinga, são mais próximos àqueles dados relatados no monitoramento da SUCEN, ilustrados por NEVES et al. 2002, do que nas áreas ao norte da Serra da Mantiqueira. As cinco espécies mais freqüentes em São Paulo são: Ny. intermedia s.l., Mi. migonei, Ny. whitmani, Pi. fischeri e Pi. pessoai (NEVES et al.2002). Das quais, apenas a última não foi encontrada em Jacutinga.

Sobre as espécies encontradas nos municípios pesquisados, cabe discutir principalmente dois aspectos já destacados nos resultados. Primeiramente, o encontro de Lu longipalpis, que é o mais importante vetor de Leishmania chagasi, agente etiológico da LVA no Brasil (GRIMALDI et al. 1989, GRIMALDI e TESH 1993). De acordo com YOUNG \& DUCAN 1994, esta 
espécie se distribui do México até a Argentina e com uma grande distribuição no Brasil. Hoje esta espécie tem sido considerada como um complexo de variedades, com diferenças morfológicas, descritas pela primeira vez por MANGABEIRA em 1969. Desde então, vários pesquisadores têm estudado esta complexidade de formas e variedades de Lu longipalpis (WARD et al. 1985, WARD et al. 1988, LANZARO et al. 1993, MUTEBI et al. 1999) com objetivos de caracterizar alterações no comportamento e biologia destas populações e que possam interferir na transmissibilidade da Le. chagasi para o homem e para outros hospedeiros. A Lu longipalpis tem sido encontrada em grandes cidades, sobretudo em suas periferias e também, nas áreas rurais do Brasil, ocorrendo em diferentes condições geográficas e distribuido-se em diferentes regiōes (AZEVEDO et al. 2000). Portanto, não é novidade a grande valência ecológica desta espécie, mas encontra-la sempre significa um motivo de alerta para a saúde pública, haja vista a sua grande capacidade adaptativa e dispersiva, aliadas à sua potencialidade vetora.

Outro fator importante na caracterização da fauna flebotominica no sul de Minas Gerais é a ocorrência em simpatria, das espécies até pouco tempo consideradas sinonimias, a $N y$. intermedia s.s. e a $N y$. neivai. A distinção entre estas espécies já vem ocupando muitos pesquisadores desde a descrição por Lutz \& Neiva em 1912 (FRANÇA 1920, MACONDES 1996, MACONDES 1997, MARCONDES et al. 1998, MARCONDES \& BORGES 2000). A Ny. intermedia s.l. apresenta alto grau de domiciliação, podendo ser capturada também em áreas urbanas, em abrigos de animais domésticos e, inclusive no intradomicílio (GOMES et al. 1978, MAYRINK et al. 1979, OLIVEIRA et al. 1995, ANDRADE FILHO et al. 1997), o que confirmam os resultados aqui 
apresentados. Ambas as espécies apresentam alto grau de antropofilia, e podem ser encontradas picando o homem (GOMES et al. 1989, ANDRADE FILHO et al. 1994, OLIVEIRA NETO et al. 1998). Entretanto, mesmo diante de muitas evidências, como o encontro de fêmeas de $\mathrm{Ny}$. intermedia s.l. infectadas com flagelados na região Sudeste do Brasil (FORATTINI et al. 1972, RANGEL et al. 1984, CASANOVA et al.1995) e a sua predominância em áreas endêmicas (RANGEL et al. 1990, GOMES et al. 1995, GONTIJO et al. 2002, SALOMÓN et al. 2002) ela ainda é considerada apenas como uma possível espécie vetora (KILLICK-KENDRICK 1990), devido a impossibilidade do isolamento de amostras dos flagelados e a sua comparação com amostras isoladas de casos humanos e/ou caninos.

Um outro aspecto importante a ser discutido a partir dos resultados aqui apresentados, refere-se à associação da fauna flebotomínica com as lavouras da região, principalmente com a lavoura do café. Estudos na Colômbia, que é um grande produtor de café mundial, sobre a associação de casos humanos de LTA, bem como estudos sobre a interação da fauna com este ecótopo, demonstram uma grande interdependência entre estes. Ou seja, muitos casos de LTA na Colômbia estão associados às lavouras de café (ALEXANDER \& USMA 1994, ALEXANDER et al. 1995, ALEXANDER et al. 2001) e o Brasil, segundo ANON 1996, é um dos mais importantes produtores de café no mundo e a região sudoeste de Minas Gerais é responsável pela produção de $50 \%$ do café brasileiro.

Entretanto, como mencionado por ALEXANDER 2002, as informaçōes sobre a transmissão de Leishmania associada às lavouras de café no Brasil são, praticamente, inexistentes. Este mesmo autor relata que, os primeiros 
casos de LTA no sudoeste de Minas Gerais, foram notificado a partir de 1986, além de ressaltar que, no município de Machado, ocorrem $19,6 \%$ dos casos notificados entre os 26 municipios do regional de saúde de Alfenas.

Analisando os resultados das capturas realizadas com as armadilhas tipo CDC, nas lavouras de café, em Machado e Conceição da Aparecida, podese observar no presente estudo que, no primeiro municipio, este ecótopo foi responsável por $27 \%$ de um total de 252 insetos capturados (Tabela 08). Já em Conceição da Aparecida este percentual foi de $9,8 \%$, em um total de 951 flebotomineos capturados (Tabela 09). Avaliando a composição da fauna flebotomínica deste ecótopo, ou seja, na lavoura de café, em Machado, percebe-se que a $N y$. whitmani é a espécie mais freqüente com $44,1 \%$ dos 68 espécimes capturados (Tabela 08). Em Conceição da Aparecida, este percentual foi ainda maior, chegando a $68,8 \%$ dos 93 indivíduos capturados na lavoura de café (Tabela 09).

Analisando-se ainda a composição da fauna nas lavouras de café, no municipio de Machado foram encontradas dez espécies: Ny. whitmani; Pi. monticola; Pi. fischeri; Pi. misionensis; Mi. migonei; Ev. sallesi; Ev. termitophila; Br. cardosoi; Br. nitzulescui, Brumptomyia sp. (Tabela 10). Estes resultados complementam a lista de apenas cinco espécies encontradas por ALEXANDER et al. 2002, neste ecótopo, no municipio em questão. Ressalta-se que, esse autor encontrou a Lu. intermedia no cafezal, fato este que, no estudo atual, não foi observado.

Contudo, diferentemente do que foi discutido por ALEXANDER et al. 2002, na atual pesquisa puderam ser observadas as presenças de $\mathrm{Ny}$. intermedia s.s. e Ny. neivai, em simpatria, em ecótopos do peri-domicílio de 
Machado e Conceição da Aparecida (Tabelas 05 e 06). Todavia, as mesmas não foram encontradas na lavoura de café. No município de Jacutinga, onde as capturas foram realizadas em áreas urbanas, dentre as duas espécies referidas, somente foi encontrada a espécie $N y$. neivai, que por sinal, foi a segunda espécies mais freqüente entre as capturadas neste municipio $(39,6 \%)$ (Tabela 04). Possivelmente, o período de 18 meses de estudo, foi o fator que possibilitou o encontro destas espécies, haja vista que elas corresponderam a somente $0,6 \%$ e $0,3 \%$ do total de insetos capturados em Machado, para $\mathrm{Ny}$. intermedia s.s. e Ny. neivai, respectivamente (Tabela 05). Em Conceição da Aparecida este percentual foi ainda menor, $0,4 \%$ e $0,2 \%$ (Tabela 06). Em ambos os municípios as espécies mais capturadas foram $\mathrm{Ny}$ whitmani e Mi. migonei.

Embora a distribuição sazonal da fauna flebotomínica nos três municípios estudados tenha sido calculada para todas as espécies capturadas (Figuras 14, 15 e 16), aquelas mais abundantes possivelmente determinam as curvas encontradas. Em Jacutinga, de novembro de 2001 a outubro de 2002 houve dois grande picos populacionais de flebotomíneos, no mês de abril de 2002 e o maior deles foi em setembro do mesmo ano.

Estes resultados podem ser comparados aos estudos de GALATI, et al. 1996, em que os autores estudando os flebotomíneos em áreas de LTA no Estado do Mato Grosso do Sul, especificamente no município de Corguinho, apresentam e sugerem a mesma distribuição sazonal para a espécie $N y$. whitmani, ou seja, esta espécie também apresenta individualmente uma maior explosão populacional nos meses mais secos ou após períodos de chuvas com grandes precipitações. 
No que se refere à freqüência horária noturna, houve uma concentração maior das atividades das espécies nas primeiras horas do crepúsculo vespertino, principalmente em Jacutinga, onde $\mathrm{Ny}$. neivai predomina, diferente do observado para $\mathrm{Ny}$. intermedia s.l. (provavelmente $N y$. neivai, face a distribuição dada por MARCONDES et al. 1996) no município de Teodoro Sampaio, na região sudoeste paulista, onde o maior pico de atividade foi registrado entre Oh e 1h. (CONDINO et al. 1998). Em Conceição da Aparecida, onde Ny. whitmani e Mi. migonei também predominam, se verificou maior atividade nas primeiras horas da noite, como observado por MAYO et al. 1998, para estas duas espécies no município de Itupeva na região sudeste paulista.

Ainda para a Ny. whitmani, que se apresenta mais abundante em Machado e Conceição da Aparecida, destaca-se a sua atividade durante toda a noite, mas com picos nas $3^{a}, 9^{a}$ e $11^{a}$ horas (Figuras 27). Dados estes que apresentam um possivel e novo comportamento de $N y$. whitmani, ainda não apresentado em outros estudos (GOMES et al. 1989, GALATI et al. 1996).

Destacam-se ainda, nos resultados sobre a freqüência noturna, as informações sobre o comportamento de $\mathrm{Ny}$. neivai que, pela primeira vez, foi estudada em separado de $N y$. intermedia s.I. Sendo assim, a figura 22 ilustra a homogênea atividade desta espécie até a $8^{\mathrm{a}}$ hora, apresentando dois picos na primeira e na terceira hora, em Jacutinga. Somando-se a ela, para definir a distribuição de freqüência horária geral neste município, está a espécie Pi. monticola (Figura 23).

O cálculo do Índice de Abundância de Espécies Padronizado foi importante para a definição das espécies suspeitas como vetoras nas áreas estudadas. Este Índice considera o número de indivíduos de cada espécie 
capturada, em relação a sua presença ou ausência nos respectivos ecótopos pesquisados. Sendo assim, não são definidas como espécies abundantes aquelas que simplesmente apresentaram o maior número de indivíduos capturados.

Portanto, as espécies mais abundantes foram: Ny. neivai, em Jacutinga, Ny. whitmani e Mi. migonei, em Machado e Conceição da Aparecida. Todas já apresentadas na literatura como possiveis agentes vetoriais na LTA na região Sudeste do Brasil (CASANOVA 2001, GOMES et al. 1982, SILVA \& GOMES 2001, MAYO et al. 1998, DOMINGOS et al. 1998, CANDINO et al. 1998, NEVES et al. 2002).

Além das espécies comprovadas ou suspeitas como vetoras, na região sul de Minas Gerais destaca-se a presença significativa de Pi. monticola, em Jacutinga (Tabela 04 ), onde esta foi a mais freqüente nas capturas $(44,8 \%)$, principalmente na armadilha de Shannon, sugerindo assim a sua antropofilia na área estudada. Fato este que merece melhor investigação, pois a mesma pode atuar na transmissão da LVA, uma vez que apresenta estreita relação filogenética (GALATI, 2003) com Pi. misionensis que foi encontrada infectada com formas de Leishmania (Viannia) sp. no Rio Grande do Sul (SILVA \& GRUNEWALD 1999).

Concomitantemente aos dados de abundância das espécies deve-se observar os valores calculados dos Coeficientes de Incidência Acumulada para os municípios de Jacutinga (6,8 casos/100.000 hab.), Machado $(17,99$ casos/100.000 hab.) e Conceição da Aparecida (20,08 casos/100.000 hab.). Deste modo, associando-se esses Coeficientes, aos dados de abundância das espécies, às informações da sazonalidade e da freqüência horária noturna, 
têm-se bastantes indicativos da participação efetiva destas espécies na transmissão de Leishmania nas áreas estudadas.

Comparando-se ainda os índices de similaridade, obtidos entre os municípios estudados, com os índices de diversidade dos mesmos, pode-se perceber que Jacutinga se difere consideravelmente de Machado e Conceição da Aparecida, tanto pela similaridade quanto pela diversidade. Enquanto Machado e Conceição da Aparecida são mais similares entre si e os mesmos apresentam indices de diversidade da fauna flebotomínica diferentes.

Outro fator relevante na discussão é o comportamento da LTA na região ao sul da Serra da Mantiqueira e a possivel participação de $N y$. neivai, como ocorre nos municipios do Estado de São Paulo limítrofes a Minas Gerais, na transmissão da Leishmania. A LTA, ao norte da Serra, parece se comportar como na maioria das outras regiōes do Estado de Minas Gerais. Sugerindo-se assim, que a Serra da Mantiqueira tem um papel relevante na definição destes comportamentos de transmissão, bem como na composição da fauna flebotomínica e de sua abundância. 
7. CONCLUSÕES 
1. Os municipios dos regionais de saúde de Alfenas/MG e de Pouso Alegre, os quais se localizam ao norte da Serra da Mantiqueira, parecem apresentar uma LTA de comportamento epidemiológico semelhante a outras áreas de transmissão no Estado, mas com índices menores, possivelmente devido às baixas densidade vetoriais encontradas na região;

2. Os municipios do regional de saúde de Varginha e de Pouso Alegre, os quais se localizam ao sul da Serra da Mantiqueira, apresentam índices muito semelhantes aos municípios do Estado de São Paulo, principalmente aqueles que pertencem aos regionais que fazem limite com Minas Gerais, bem como a composição da fauna de espécies possivelmente vetoras na LTA;

3. A baixa ou a ausência de notificação de casos de LVA na região sul de Minas Gerais deve estar correlacionada também com a baixíssima densidade populacional de Lu. longipalpis, encontrada neste estudo;

4. Em Jacutinga a espécie $N y$. neivai, apresentou uma freqüência horária noturna com maior concentração da atividade na primeira e na terceira horas do crepúsculo vespertino, além de estar em atividade durante toda a noite;

5. Em Machado e Conceição da Aparecida destaca-se a abundância de Ny. whitmani que apresenta-se em atividade também durante toda a noite, mas com picos de atividades em horários diferentes. $\mathrm{Na} 3^{\mathrm{a}}, 9^{\mathrm{a}} \mathrm{e}$ $11^{\mathrm{a}}$ horas em Machado e na $2^{\mathrm{a}}$ e $4^{\mathrm{a}}$ horas em Conceição da Aparecida; 
6. Com a ausência de flebotomíneos no município de Caldas/MG, sugerese que possa haver algum elemento ou fator limitante e até excludente, interferindo na dinâmica e na biologia das formas imaturas destes insetos;

7. A presença da espécie Lu. longipalpis, pela primeira vez na área estudada, é um fator relevante para a saúde pública na região, devido aos riscos e ao grande avanço e expansão territorial da LVA no Brasil;

8. A Serra da Mantiqueira sendo um divisor geográfico importante na região, possivelmente pode estar interferindo na dispersão e densidade populacional das espécies flebotomínicas. Podendo assim estar interferindo na distribuição dos casos de LTA; 
8. REFERÊNCIAS BIBLIOGRÁFICAS 
Aguillar CM, Rangel EF, Grimaldi-Filho G, Momen H. Alta freqüência de leishmaniose tegumentar canina em um foco endêmico do Estado do Rio de Janeiro, Brasil. Mem. Inst. Oswaldo Cruz. 1987a; 82(Supl. 1):56.

Aguillar CM, Rangel EF, Grimaldi FOG, Momem H. Human, canine, and equine leishmaniasis caused by Leishmania braziliensis braziliensis in an endemic area in the State of Rio de Janeiro. Mem. Inst. Oswaldo Cruz. 1987b; 82: 82-143.

Alexander B, Usma MC. Potencial sugar sources of Lutzomyia youngi (Diptera: Psychodidae) in a Colombian coffee plantation. Ann. Trop. Med. Parasitol. 1994; 88: 543-549.

Alexander B, Agudelo LA, Navarro F, Ruiz F, Molina J, Aguilera G, Quiñones ML. Phlebotomine sand flies (Diptera: Psychodidae) in Colombian coffee plantation under two systems of cutivation. Med. Vet. Entomol. 2001; 15: 1-11.

Alexander B, Usma MC, Cadena H, Quesada BL, Solarte Y, Roa W, Montoya J, Jaramillo C, Travi BL. Phlebotomine sandflies associated with a focus of cutaneous leishmaniasis in Valle del Cauca, Colombia. Med. Vet. Entomol. 1995; 9: 273-278.

Alexander B, Oliveira EB, Haigh E, Almeida LL. Transmission of Leishmania in coffee plantation of Minas Gerais, Brazil. Mem. Inst. Oswaldo Cruz 2002; 97(5): 627-630.

Andrade Filho JD, Carneiro APS, Lima MLN, Santiago RM, Gama MA, Santos CA, Falcão AL, Brazil RP. Flebotomíneos de Timóteo, Estado de Minas Gerais, Brasil (Diptera: Psychodidae). Cad. Saúde Pública 1997; 13: 767-770.

Andrade Filho JD, Lima MLN, Fonseca LL, Carneiro APS, Falcão AL, Brazil RP. Study of Phlebotominae sandfly fauna in the surrounding of Lapinha Cave, Lagoa Santa, Minas Gerais. Mem. Inst. Oswaldo Cruz 1994; 89 (suppl): 203.

Anon. O café em Minas Gerais. Estado de Minas (Belo Horizonte) 1996; 19 th august.

Ashford RW, Desjeux P, De Raadt. Estimation of population at risk of infection and number of cases of Leishmaniasis. Parasitol. Today 1992; 8:104-5.

Azevedo ACR, Monteiro FA, Cabello PH, Souza NA, Rosa-Freitas MG, Rangel EF. Studies on populations of Lutzomyia longipalpis (Lutz \& Neiva, 1912) (Diptera: Psychodidae: Phlebotominae) in Brazil. Mem. Inst. Oswaldo Cruz 2000; 95(3): 305322.

Badaró R, Jones TC, Carvalho EM, Sampaio D, Reed SG, Barral A, Texeira R, Johnson-Jr WD. (1986). New perspectives on a subclinical form of visceral leishmaniasis. J. Infec. Dis. 1986; 154:1003-11.

Barral A, Sampaio DP, Grimaldi-Jr G, Momen H, Pratte DMM, Jesus AR, Almeida R, Badaró R, Netto MB, Carvalho EM, Johnson-Jr WD. Leishmaniasis in Bahia, Brazil. Evidence that Leishmania amazonensis produces a wide spectrum of clinical diseases. Amer. J. Trop. Med. Hyg. 1991; 44:536-46.

Barretto MP. Observações sobre a biologia, em condições naturais, dos flebótomos do Estado de São Paulo (Diptera, Psychodidae). São Paulo; 1943. [Tese - Faculdade de Medicina da Universidade de São Paulo].

Barros GC, Sessa PA, Mattos EA, Carias VRD, Mayrink W, Alencar JTA, Falqueto A, jesus AC. Foco de Leishmaniose Tegumentar Americana nos municipios de Viana e Cariacica, Estado de Espírito Santo, Brasil. Rev. Saúde Públ., 1985; 19 (2): 146-153.

Bernis VMO. Inquérito soro-epidemiológico de Leishmaniose em cães no município de Alfenas/MG. Alfenas, 1998. [Dissertação - Universidade de Alfenas UNIFENAS1. 
Casanova C, Mayo RC, Rangel O, Mascarini LM, Galati EAB, Gomes AC. Natural Lutzomyia intermedia (Lutz \& Neiva) infection in the Valley of the Mogi Guaçu River, State of São Paulo, Brazil. Bol. Dir. Malariol. Y San. Amb. 1995; 35 (suppl. 1):77-84.

Casanova C. Avaliação de potencial biológico de Lutzomyia intermedia s. I. como vetor da leishmaniose tegumentar americana na zona rural do município de Conchal, Estado de São Paulo. São Paulo, 2001 [Tese de doutorado, Faculdade de Saúde Pública, Universidade de São Paulo].

CENEPI (Centro Nacional de Peidemiologia)/FUNASA (Fundação Nacional de Saúde). Boletim Epidemiológico, Ministério da Saúde. 1996; ano II, No 1.

CENEPI (Centro Nacional de Peidemiologia)/FUNASA (Fundação Nacional de Saúde). Boletim Epidemiológico, Ministério da Saúde. 2002; ano V, No 1.

Cipa Grou: Bermudes H, Dedet JP, Falcão AL, Feliciangeli D, Ferro C, Galati EAB, Gomez EL, Herrero MV, Hervas D, Lebbe J, Morales A, Oguzuku E, Perez E, Rangel $E F$, Sherlock IA, Torres M, Vignes $R$, Wolff $M$. Computer-aided identification of sandflies of America 1999; <http://cipa.snv.jussieu.fr>

Colmenares $M$, Portús $M$, Botet J, Dobaño $C$, Gállego $M$, Wolff $M$, Seguí $G$. Identification of blood meals of Phlebotomus pemiciosus (Diptera: Psychodidae) in Spain by a Competitive Enzyme Linked Immunosorbent Assay Biotin/Avidin Method. J. Med. Ent. 1995; 32(3): 229-33.

Condino MLF, Sampaio SMP, Henriques LF, Galati EAB, Wanderley DMV, Corrêa FMA. Leishmaniose tegumentar Americana: flebotomíneos de area de transmissão no municipio de Teodoro Sampaio, regiāo sudoeste do Estado de São Paulo, Brasil. Rev. Soc. Bras. Méd Trop. 1998; 31(4): 355-360.

Corredor A, Gallego JF, Tesh RB, Morales A, Ferro C, Young DG, Kreutzer RD, Boshell J, Palau MT, Caceres E \& Palaez D. Epidemiology of visceral leishmaniasis in Colômbia. Am. J. Trop. Med. Hyg. 1989; 40: 480-86.

Costa JML, Vale KC, Cecilia IN, Osaki NKM, Netto EM, Tada MS, França F, Barreto MC, Marsden PD. Aspectos psicossociais e estigmatizantes na leishmaniose cutâneomucosa. Rev.Soc.Bras.Med.Trop. 1987; 20:77-82.

Coutinho SG, Nunes MP, Marzochi MCA, Tramontano N. A survey for American cutaneous and visceral leishmaniasis among 1.342 dogs from areas in Rio de Janeiro (Brazil) where the human diseases occur. Mem. Inst. Oswaldo Cruz. 1985; 80 (1): 1722.

Deane LM, Deane MP. 1955. Observaçōes preliminares sobre a importância comparativa do homem, do cão e da raposa (Lycalopex vetulus) como reservatórios de Leishmania donovani em área endêmica de calazar no Ceará. Hospital. 1955; 48:6176.

Dimeir-David L, David C, Muñoz M,Vargas F, Bustillos R, Valda L \& Dedet JP. Epidemiological, clinical and biological features of mucocutaneous leishmaniasis in Bolivia after a 221 patient sample. Bull. Soc. Pathol. Exot. 1993; 86(2): 106-111.

Domingos MF, Carreri-Bruno GC, Ciaravolo RMC, Galati EAB, Wandereley DMV, Corrêa FMA. Leishmaniose Tegumentar Americana: flebotomineos de área de transmissão, no municipio de Pedro de Toledo, região sul do Estado de São Paulo, Brasil. Rev.Soc. Brasil. Med. Trop. 1998; 31 (5): 425-432.

Falqueto A, Coura Jr, Barros GC, Grimaldi G, Sessa PA, Carias VRD, Jesus AC, Alencar JTA. Participação do cão no ciclo de transmissão da Leishmaniose Tegumentar no município de Viana, Estado do Espirito Santo, Brasil. Mem. Inst. Oswaldo Cruz. 1986; 81 (2): 155-163. 
Feliciangeli MD. Ecology of sandflies (Diptera: Psychodidae) in a restricted focus of cutaneaus leishmaniosis in northern Venezuela. I. Description of the study area, catching methods and species composition. Mem. Inst. Oswaldo Cruz.1987; 82 (1):119-124.

Ferreira AL, Sessa PA, Varejão JBM, Falqueto A. Distribuition of sand flies (Diptera: Psychodidae) at different altitudes in na endemic region of american cutaneous leishmaniasis in the State of Espirito Santo, Brazil. Mem. Inst. Oswaldo Cruz. 2001; 96: 1061-1067.

França C. Oservations sur le genre Phlebotomus. II. Plebotomus du Nouveau Monde (Phlébotomes du Bresil et du Paraguay). Bull. Soc. Portug. 1920; 8: 215-236.

Forattini OP. Entomologia Médica. Psychodidae, Phlebotominae, Leishmaniose, Bartonelose. Vol. IV. Ed. Edgard Blucher, São Paulo, 1973, 658 p.

Forattini OP, Pattoli DBG, Rebello EX, Ferreira AO. Infecção natural de flebotomíneos em foco enzoótico de leishmaniose no Estado de São Paulo, Brasil. Rev. Saúde Pública 1972; 6: 431-433.

Forattini OP, Rabello EX, Serra OP, Cotrim MD, Galati EAB \& Barata JMS. Observações sobre a transmissão da Leishmaniose Tegumentar no Estado de São Paulo, Brasil. Ver. Saúde Pública. 1976; 10: 31-43.

Funasa - Série histórica de casos de doenças de notificação compulsória - Brasil, 1980 a 2001. <http://www. funasa.gov.br>

Galati EAB. Sistemática de Phlebotominae (Diptera, Psychodidae) das Américas. São Paulo; 1990. [Tese de Doutorado - Faculdade de Saúde Pública/USP].

Galati EAB; Nunes VL; Dorval MEC; Oshiro ET; Cristaldo G; Espindola MA Rocha HC, Garcia WB. Estudo dos flebotomíneos (Diptera, Psychodidae) em área de leishmaniose tegumentar, no Estado de Mato Grosso do Sul, Brasil. Rev. Saúde Pública. 1996; 30(2): 115-28.

Galati EAB; Nunes VL; Rego-Jr FA; Oshiro ET, Rodrigues M. Estudo de flebotomíneos (Diptera, Psychodidae) em foco de leishmaniose visceral no Estado de Mato Grosso do Sul, Brasil. Rev. Saúde Pública. 1997; 31(4):378-90.

Galati EAB, Nunes VL, Dorval MRC, Boggiani PC, Shaw JJ, Cristaldo J, Rocha HC, Andrade RMG, Oshiro ET, Casanova C, Naufel G. (1999a). Ecological aspects of the phlebotomine fauna from Serra da Bodoquena, Mato Grosso do Sul State, Brazil. Programme \& Abstracts of the $3^{\text {rd }}$ International Symposium on Phlebotomine Sandflies. Montpellier, 1999. P-36.

Galati EAB. Phlebotominae (Diptera, Psychodidae). Biologia, Classificação. Terminologia, Morfologia e Identificação de Adultos. S. Paulo; 2002 [Apostila do Curso de Entomologia Médica, Departamento de Epidemiologia, Faculdade de Saúde Pública/USP], 193 p.

Galati EAB. Galati EAB. Phlebotominae (Diptera, Psychodidae). Biologia, Classificação. Terminologia, Morfologia e Identificação de Adultos. S. Paulo; 2003 [Apostila da Disciplina de Pós-Graduação Bioecologia e Identificação de Phlebotominae, Departamento de Epidemiologia, Faculdade de Saúde Pública/USP], $193 \mathrm{p}$.

Gomes AC, Rabello EX, Galati EAB. Flebotomíneos encontrados em galinheiros experimentais nos Estados de São Paulo e Minas Gerais (Brasil) e algumas observaçōes ecológicas. Rev. Saúde Pública 1978; 12: 403-407.

Gomes AC, Rabello EX, Santos JLF, Galati EAB. Aspectos ecológicos da leishmanioses tegumentar americana: 2. Ecótopos artificiais como abrigo de 
Psychodopygus intermedia e observações sobre alimentação e reprodução sob influência de fatores físicos naturais. Rev. Saúde Pública 1982; 16: 149-159.

Gomes AC. American leishmaniasis epidemiology in Brazil. Insect. Sci. Appl. 1986; 7 (2): 161-169.

Gomes AC, Barata JMS, Rocha e Silva EO \& Galati EAB. Aspectos ecológicos da leishmaniose tegumentar americana. 6 - Fauna flebotomínica antropófila de matas residuais situadas na região centro-nordeste do Estado de São Paulo, Brasil. Rev. Inst. Méd. Trop. São Paulo. 1989a; 31(1): 32-9.

Gomes AC \& Galati EAB. Aspectos ecológicos da leishmaniose tegumentar americana. 7 - Capacidade vetorial flebotomínea em ambiente florestal primário do sistema Serra do Mar, Região do Vale do Ribeira, Estado de São Paulo, Brasil. Rev. Saúde Pública. 1989b; 23(2): 36-42.

Gomes AC. Perfil epidemiológico da Leishmaniose Tegumentar no Brasil. An. Bras. Dermatol.1992; 67 (2): 55-60.

Gomes AC. Sand fly vectorial ecology in the State of São Paulo. Mem.Inst. Oswaldo Cruz. 1994; 89 (3): 457-460.

Gomes, AC, Galati EAB, Casanova C, Domingos MF, Marques GRAM, Neves VLF. Analysis of the geographical distribution of leishmaniasis vestors in the state of São Paulo, Brazil. Bol. Dir. Malariol. San. Amb. 1995; 35 (suppl. 1): 143-146.

Gontijo CMF, Coelho MV, Falcão AR, Falcão AL (1987). The fiding of one male specimen of Lutzomyia renei (Martins, Falcão \& Silva, 1957) experimentally infected by Leishmania. Mem. Instituto Oswaldo Cruz. 1987; 82(3):445.

Gontijo CMF, Silva ES, Fuccio MB, Souza MCA, Pacheco RS, Dias ES, Andrade Filho JD, Brazil RP, Melo MN. Epidemiolgical studies of na outbreak of cutaneous leishmaniasis in the Rio Jequitinhonha Valley, Minas Gerais, Brazil. Ac. Trop. 2002; 81: 143-150.

Grimaldi Jr G, Tesh RB, Pratt DM. A review of the geografic distribution and epidemiology of the New World. Amer. J. Trop. Med. Hyg. 1989; 41: 687-725.

Grimaldi Jr G, Tesh RB. Leishmaniasis os New World: current concepts and implications for future research. Clin. Microbol. Rev. 1993; 6: 230-250.

Haddow AJ. Studies on the biting-habits of African mosquitos. An. appraisal of methods employed with special reference to the twenty-four catch. Bull. Ent. Res. 1954; 45:199-242.

Haddow AJ. 1960. Studies on the biting-habits and medical importance of East African mosquitos in the genus Aedes. I. Subgenera Aedimorphus, Banksinella and Nunnius. Bul Ent. Res. 1960; 50:759-779.

Hennig W. Insektenfossilien aus der unteren Kreide. IV. Psychodidae (Phlebotominae), mit einer kritischen Übersicht uber das phylogenetische System der Familie und die bisher beschhriebenen Fossilien (Diptera). Stutt. Beitr. Naturkunde. 1972; 241: 1-69.

IBGE - Instituto Brasileiro de Geografia e Estatítica (1985). Contagem da população residente, por sexo e população cedida, segundo o código e o nome dos municipios. 1985.

IBGE - Instituto Brasileiro de Geografia e Estatítica. Contagem da população residente, por sexo e população cedida, segundo o código e o nome dos municípios. 2000.

IBGE - Instituto Brasileiro de Geografia e Estatítica. Contagem da população residente, por sexo e população cedida, segundo o código e o nome dos municípios. 2003. 
International Commission on Zoological Nomeclature. International Code of Zoological Nomeclature. (Ed. Ride WDL, Cogger HG, Dupuis C, Kraus O, Minelli A, Thompson FC, Tubbs PK) 1999; 306 p.

Killick-Kendrick R. Biology of Leishmania in Phlebotomine sandflies. In : LUMSDEN WHR; EVANS DA (eds), Biology of the Kinetoplastida. London:1979; Academic Press.

Killick-Kendrick R. 1990. Phlebotomine vectors of the leishmaniasis: a review. Med. Vet. Ent. 1990; 4:1-24.

Lainson R \& Shaw JJ. Epidemiological considerations of the leishmaniasis, with particular reference to the New World. In: Fallis AM (eds), Ecology and Physiology of Parasites. Canadá: 1971; University of Toronto Press.

Lainson R \& Shaw JJ. Evolution, classification and geographical distribution. In : Peters,W \& Killick-Kendrick R (eds), The Leishmaniasis in Biology and Medicine. London:1987; Academic Press, v.1, p. 1-120.

Lanzarao GC, Ostrovska K, Herrero MV, Lawyer PG, Warburg A. Lutzomyia longipalpis is a species complex: genetic divergence and interspecific hybrid sterility among theree populations. Am. J. Trop. Med Hyg. 1993; 48: 839-847.

Magurran AE. Ecological diversity and its measurement. 1988, Cambridge: University Press.

Mangabeira Filho O. Sobre a sistemática e biologia dos Phlebotumus do Ceará. Ver. Brás. Malariol. Doenc. Trop. 1969; 21: 3-26.

Marcondes CB. A redescription of Lutzomyia (Nyssomyia) intermedia (Lutz \& Neiva, 1912) and ressurection of $L$. neivai (Pinto, 1926) (Diptera, Psychodidade, Phlebotominae). Mem. Inst. Oswaldo Cruz 1996; 91: 457-462.

Marcondes CB. Morfometria e DNA mitocondrial de populaces sul americanas de Lutzomyia (Nyssomyia) intermedia (Lutz \& Neiva, 1912) (Diptera, Psychodidae, Phlebotominae). Curitiba; 1997. [Tese de Doutorado - Departamento de Ciências Biológicas, Universidade Federal do Paraná].

Marcondes CB. An improved technique for the dissection of female genitalia of phlebotomine sandflies (Diptera: Psychodidae), with an improvement in the hadling of insects. Mem. Inst. Oswaldo Cruz 1998; 93: 109.

Marcondes CB, Borges PSS. Distinction of male of the Lutzomyia intermedia (Lutz \& Neiva, 1912) species complex by ration between dimensions and by an artificial neural network (Diptera, Psychodidade, Phlebotominae). Mem. Insti. Oswaldo Cruz 2000; 95: 685-688.

Martins AV, Morales-Farias EN. Sobre a distribuição geográfica dos flebotomíneos americanos (Diptera, Psychodidae, Phlebotominae). Rev. Brasil. Biol. 1972; 32: 361371.

Martins AV, Williams P, Falcão AL. American Sand Flies (Diptera: Psychodidae: Phlebotominae) 1978. Acd. Brasil. Ciências, Rio de Janeiro,1978; 195 p.

Marzochi MCA. 1992. Leishmanioses no Brasil. As leishmanioses tegumentares. JBM. $1992 ; 63(5 / 6): 82-104$.

Marzochi MCA \& Marzochi KBF. Leishmanioses em áreas urbanas. Rev. Soc. Brasil. Med. Trop._1997; 30 (Suplemento 1) 162-164.

Mayo RC, Casanova C, Mascarini LM, Pignatti MG, Rangel O, Galati EAB, Wanderley DMV, Corrêa FMA. Flebotomíneos (Diptera, Psychodidae) de area de transmissão de 
leishmaniose tegumentar americana, no municipio de Itupeva, região sudeste do Estado de São Paulo, Brasil. Rev. Soc. Bras. Méd. Trop. 1998; 31(4): 339-345.

Mayrink W, Williams P, Coelho MV, Dias M, Martins AV, Magalhães PA, Costa CA, Falcão AR, Melo MN, Falcão AL. Epidemiology of dermal leishmaniasis inthe Rio Doce Valley, State of Minas Gerais, Brazil. Ann. Trop. Med. Parasitol. 1979; 73: 123-137.

Mello DA, Rego-JrFA, Oshiro E, Nunes VL. (1988). Cerdocyon thous (L.) (Carnivora, Canidae) naturally infected with Leishmania donovani chagasi (Cunha \& Chagas, 1937) in Corumbá (Mato Grosso do Sul State, Brazil). Mem. Inst. Oswaldo Cruz. 1988; 83(2):259.

Memmott J. Sandfly distribution and abundance in a tropical rain forest. Med. Vet. Entomol. 1991; 5: 403-411.

Miles MA, Arias JR, Valente SAS, Naiff RD, Souza AA, Povoa MM, Lima JAN, Cedillos RA. Vertebrate hosts and vectors of Trypanosoma rangeli in the Amazon basin of Brazil. Am.J.Trop.Med.Hyg. 1983; 32: 1251-1259.

Momen H, Grimaldi Jr G, Deane LM. Leishmania infantum, the aethiological agente of the American Visceral Leishmaniasis (AVL). Mem. Inst. Oswaldo Cruz. 1987; 82: 447448.

Morrison AC, Ferro C, Morales A, Tesh RB, Wilson ML. Dispersal of the sand fly Lutzomyia longipalpis (Diptera: Psychodidae) at an endemic focus of visceral leishmaniasis in Colombia. J. Med. Entomol. 1993; 30 (2): 427-435.

Mutebi JP, Alexander B, Sherlock I, Wellington J, Souza AA, Shaw, J, Rangel EF, Lanzaro GC. Breesing struture of sand fly Lutzomyia longipalpis (Lutz and Neiva) in Brazil. Am. J. Trop. Med. Hyg. 1999; 61: 149-157.

Muzón J, Spinelli GR, Salomón OD, Rossi GC. A first record of phlebotomine from Argentinean Patagonia (Diptera: Psychodidae: Phlebotominae). Mem. Inst. Oswaldo Cruz. 2002; 97(6): 797-798.

Naiff RD, Barrett TV, Freitas RA. Isolation of Trypanosoma freitasi (Kinetoplastida: Trypanosomatidae) from Psychodopygus claustrei (Diptera: Psychodidae). Mem. Inst.Oswaldo Cruz. 1989; 84: 273-275.

Natal D, Marucci D, Reis IM, Galati EAB. Modificação da armadilha CDC com testes para coletas de flebotomíneos (Diptera). Revta. bras. Ent. 1991; 35(4):697-700.

Neves VLFC. Caracteristicas da transmissão da leishmaniose tegumentar americana no Estado de São Paulo, Brasil. São Paulo. 1999. [Dissertação. Faculdade de Saúde Pública/USP].

Neves VLFC. Correlação da presença de espécies de flebotomíneos (Diptera: Psychodidae) com registros de casos da leishmaniose tegumentar americana no Estado de São Paulo, Brasil. Ver. Soc. Brasil. Méd. Trop. 2002; 35(4): 299-306.

Ngumbi PM, Lawyer PG, Johnson RN, Kiilu G, Asiago C. Identification of phlebotomine sandfly bloodmeals from Baringo district, Kenya, by direct enzime-linked immunosorbent assay (ELISA). Med. Vet. Ent. 1992; 6:385-8.

Ogusuku E, Perez JE, Paz L, Nieto E, Monje J \& Guerra H. Identification of bloodmeal sources of Lutzomyia spp. in Peru. Ann. Trop. Med. Parasit. 1994; 88(3):329-35.

Oliveira SMP, Afonso RCH, Dias CMG, Brazil RP. Estudo da fauna de flebotomineos(Diptera: Psychodidade) em Santa Cruz, município do Rio de Janeiro, Brasil. Rev. Brasil. Entomol. 1995; 39: 547-551.

Oliveira Neto MP, Pirmey C, Rangel EF, Schubach A, Grimald G. An outbreak americancutaneous leishmaniasis (Leishmania braziliensis braziliensis) in a periurban 
area of Rio de Janeiro City, Brazil: clical and epidemiological studies. Mem. Inst. Oswaldo Cruz 1998; 83: 427-435.

Passos VMA, Falcão AL, Marzochi MCA, Gontijo CMF, Dias ES, Barbosa-Santos EGO, Guerra HL, Katz . Epidemiological aspects of American cutaneous leishmaniasis in a periurban area of the metropolitan region of Belo Horizonte, Minas Gerais, Brazil. Mem. Inst. Oswaldo Cruz. 1993; 88 (1): 103-110.

Pessôa SB, Barretto MP. Leishmaniose tegumentar americana. Imprensa Nacional, Rio de Janeiro. 1948.

Pirmez C Coutinho SG, Marzochi MCA, Nunes MP, Grimaldi-JR G. Canine American cutaneous leishmaniasis: a clinical and imunnological study in dogs naturally infected with Leishmania braziliensis braziliensis in an endemic area of Rio de Janeiro, Brazil. Amer. J. trop. Med. Hyg. 1988; 38(1):52-8.

Rangel EF, Souza NA, Wermelinger ED, Barbosa AF. Infecção natural de Lutzomyia intermedia Lutz \& Neiva, 1912 em área endêmica de leishmaniose tegumentar no estado do Rio de Janeiro. Mem. Inst. Oswaldo Cruz 1984; 79: 395-396.

Rangel EF, Azevedo ACR, Andrade CA, Souza NA, Wermelinger ED. Studies on sandfly fauna (Diptera: Psychodidae) in focus of cutaneous leishmaniasis in Mesquita, Rio de Janeiro State, Braszil. Mem. Inst. Oswaldo Cruz 1990; 85: 39-45.

Rebêlo JMM, Mendes WA, Costa JML, Cavaleiro N. Lista preliminar das espécies do gênero Lutzomyia, França, 1924 (Psychodidae, Phlebotominae) do Estado do Maranhão, Brasil. Cad. Saúde Públ. 1996; 12 (4): 545-549.

Roberts DR, Hsi BP. An index of species abundance for use mosquito surveillance data. Environ Entomol. 1979; 8: 1007-1013.

Salomon OD, Zaidenberg M, Burgos R, Heredina VI, Caropresi SL. American cutaneous leishmaniasis outbreak, Tartagal city, province of Salta, Argentina. Rev. Inst. Med. Trop. S. Paulo 2002; 43: 105-108.

Shannon RC. Methods for collecting and feeding mosquitoes in jungle yellow fever studies. Am. J. Trop. Med. Hyg. 1939; 19: 131-148

Santos SO, Arias JÁ, Ribeiro AA, Hoffmann MP, Freitas RA, Malacco. Incrimination of Lutzomyia cruzi as a vector of American Visceral Leishmaniasis. Med. Vet. Entomol. 1998; 12:315-317.

Secretaria Estadual de Saúde de Minas Gerais - SES/MG. Relatórios anuais dos casos de Leishmaniose Tegumentar Americana notificados junto à SES/MG e FNS/MG. 2003; Belo Horizonte.

Service MW. Mosquito ecology: field sampling methods. $19932^{\text {a }}$ ed. London: Applied Scince Publication.

Sherlock IA, Miranda JC, Sadigursky M, Grimaldi-JR. Natural infection of the opossum Didelphis albiventris (Marsupialia, Didelphidae) with Leishmania donovani, in Brazil. Mem. Inst. Oswaldo Cruz 1984; 79(4):511.

Sherlock IA. Ecological interactions of Visceral Leishmaniasis in the State of Bahia, Brazil. Mem. Inst. Oswaldo Cruz1996; 97 (6): 671-683.

Silva AC, Gomes AC. Estudo da competência vetorial de Lutzomyia intermedia (Lutz \& Neiva, 1912) para Leishmania (Viannia) braziliensis, Vianna, 1911. Rev. Soc. Bras. Med. Trop. 2001; 34: 187-191.

Silva OS, Grünewald J. Natural haematophagy of male Lutzomyia sandflies (Diptera: Psychodidae). Med. Vet. Ent. 1999; 13(4):465-6. 
Silva OS, Grünewald J. Contribution to the sanfly fauna (Diptera: Phlebotominae) of Rio Grande do Sul, Brazil and Leishmania (Viannia) infections. Mem. Inst. Oswaldo Cruz. 1999; 94:579-582.

Silveira FT, Ishikawa EAY, Souza AAA, Lainson R. An outbreak of cutaneous leishmaniasis among soldiers in Belém, Pará State, Brazil, caused by Leishmania (Viannia) lindengergi $\mathrm{n}$. sp. a new leishmanial parasite of man in the Amazon region. Parasite. 2002; 9:43-50.

Sorensen T. A method of establishing groups of equal amplitude in plant sociology based on similarity of species content and its application to analyses of the vegetation on Danish commons. Biol. Skr. 1948; 5: 1-34.

Souza MB de, Marzochi MCA, Carvalho RW, Conceição NF, Ponte, C.S. Flebotomíneos em áreas de ocorrência de leishmaniose tegumentar no município de São José do Vale do Rio Preto, Rio de Janeiro. Parasitol. al Dia. 1995;19: 97-103.

Szlok M (1993). Métodos Epidemiológicos - Medidas de Risco. In: Apostila do Curso de extensão universitária da Faculdade de Saúde Pública da USP, São Paulo, 1993: p.5.

Tesh RB, Chaniotis BN, Carrera BR, Johnson KM. (1972). Further studies on the natural host preferences of panamanian sandflies. Amer. J. Epidem. 95(1):88-93.

Teodoro U, Salvia FILHO V, Lima EM de, Spinosa R.P, Barbosa OC, Ferreira MEMC, Silveira TGV. Flebotomíneos em área de transmissão de Leishmaniose Tegumentar na região norte do Estado do Paraná, Brasil: variação sazonal e atividade noturna. Rev. Saúde Públ. 1993; 27 (3): 190-194.

Tolezano JE, Luvizotto MCR, Uliana SRB, Araújo MFL, Taniguchl HH, Barbosa JAR; Pinto PLS, Floeter-Winter LM, Shaw JJ. Leishmaniose visceral americana (LVA) em Araçatuba, região oeste do Estado de São Paulo. Investigações laboratoriais e diagnóstico etiológico de uma doença emergente em terras paulistas. Rev. Soc. Brasil. Med. Trop. 1999; 32 (Suplemento I): 218.

Ward RD, Ribeiro AL, Ryan L, Falcão AL, Rangel EF. The distribution of two morphological forms of Lutzomyia longipalpis (Lutz and Neiva) (Diptera: Psychodidae). Mem. Inst. Oswaldo Cruz 1985; 80: 145-148.

Ward RD, Phillips A, Burnet B, Marcondes CB. The Lutzomyia longipalpis complex: reproduction and distribution. In: MW Service, Biosystematics of Haematophagus Insects. Oxford University Press, Oxford 1988; p. 257-269.

WHO. Lutte contre les leishmanioses. Rapport d'un Comité OMS d'Experts. 1990.

Yaghoobi-Ershadi MR, Javadian E, Kannani A. Host preference pattern of phlebotomine sandflies of Borkhar rural district, Isfahan province. Iran. Acta Tropica. 1995; 60: 155-158.

Yoshida ELA, Correa FMA, Marques AS, Solf HLO, Dillon NL, Momen H, Grimaldi-JR G. Human canine and equine (Equus caballus) leishmaniasis due to Leishmania braziliensiss ( $=$ L. braziliensis braziliensis) in the south-west region of São Paulo State, Brazil. Mem. Inst. Oswaldo Cruz. 1990; 85(1):133-4.

Young DG, Duncan MA. Guide to the identification and geographic distribution of Lutzomyia sand flies in Mexico, the West Indies, Central and South America (Diptera: Psychodidae). Mem. Am. Entomol. Inst. 1994; 54: 1-881. 
8. ANEXOS 

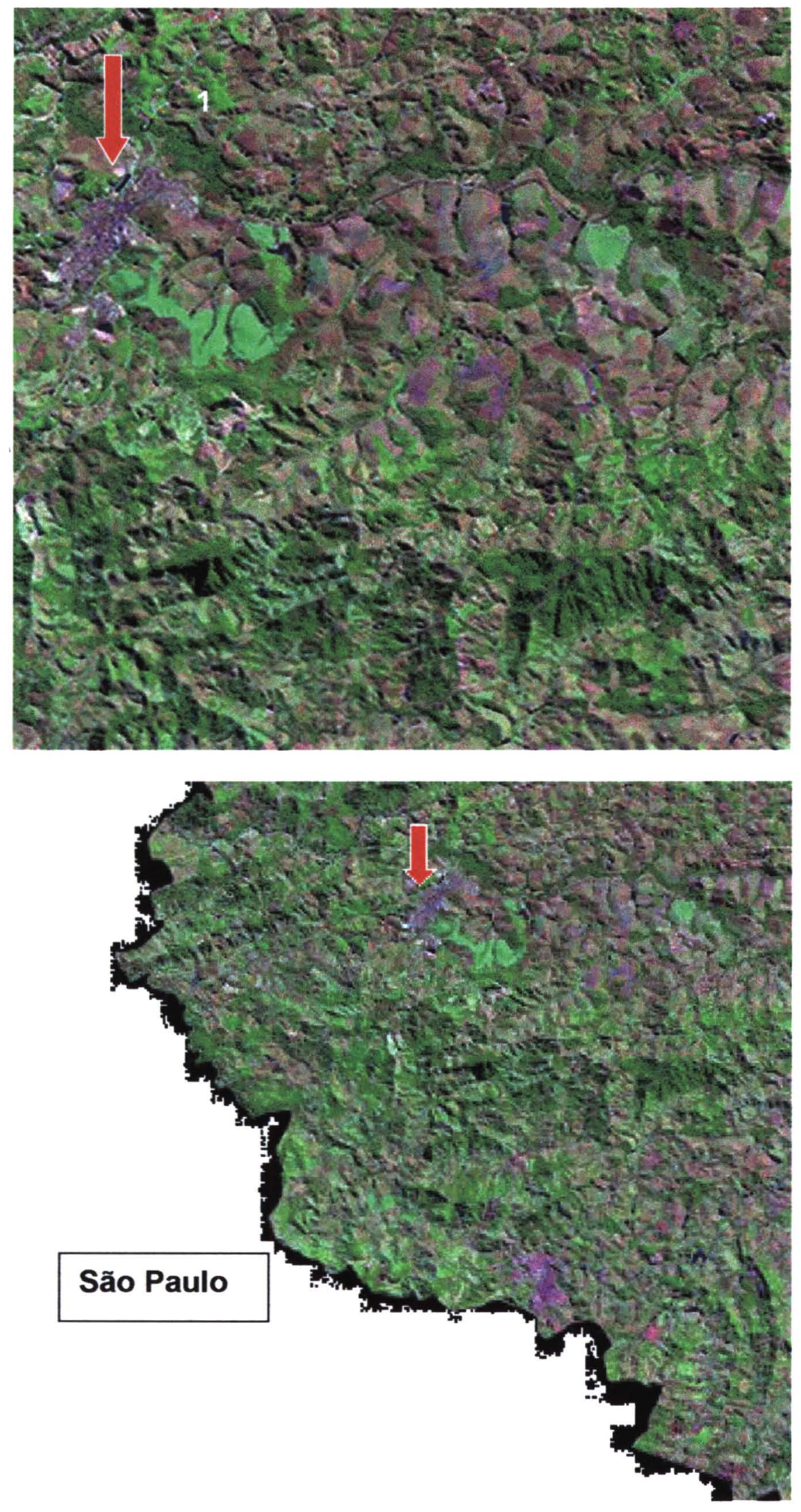

Fonte:Embrapa monitoramento por satélite 2000-2003

Anexo 01 - Fotos de satélite localizando a sede do município de Jacutinga (setas em vermelho), onde também foi realizada a pesquisa entomológica. 

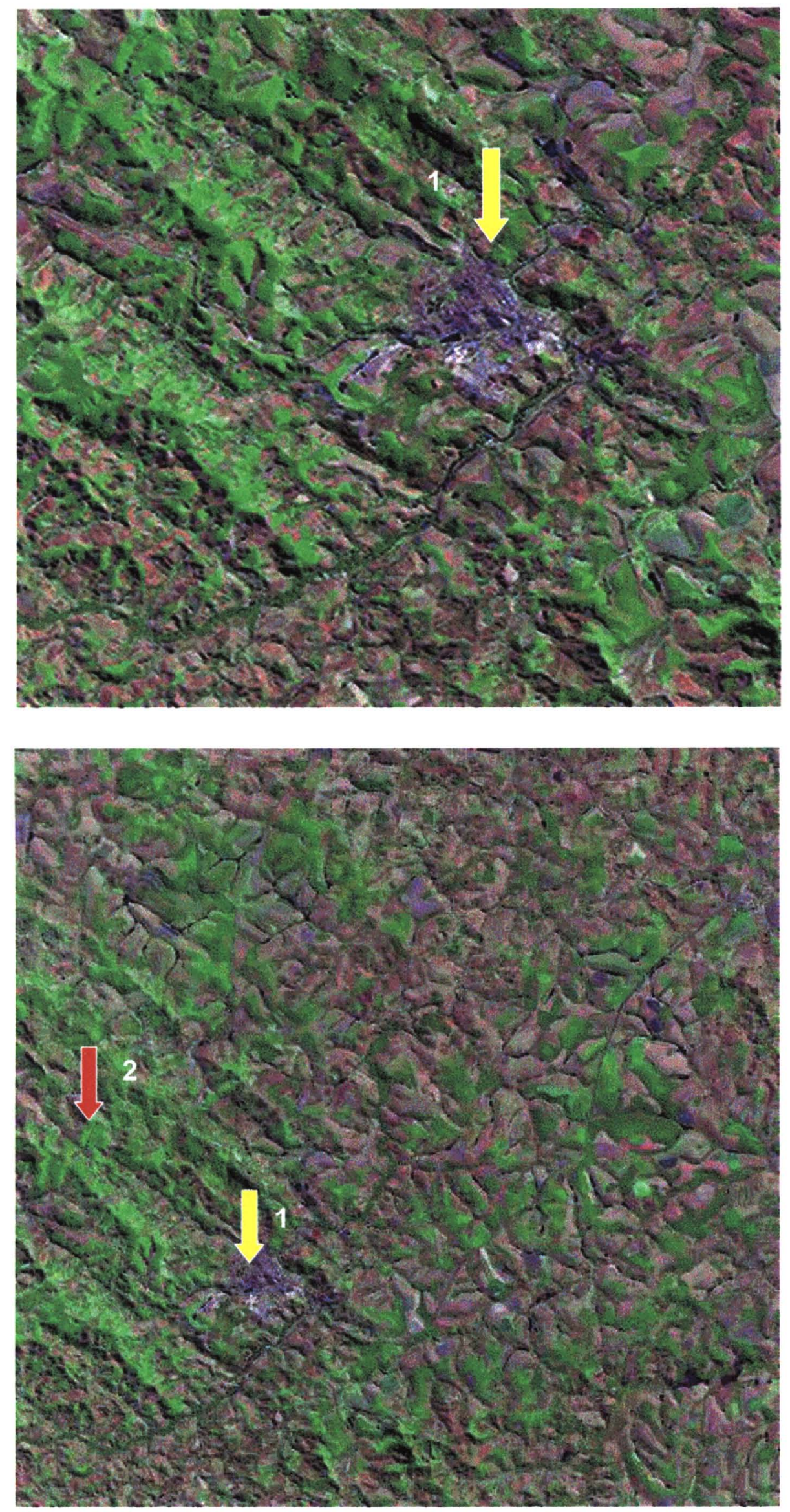

Fonte:Embrapa monitoramento por satélite 2000-2003

Anexo 02 - Foto de satélite localizando a sede do município de Machado (setas 1, em amarelo) e o local de capturas (seta 2, em vermelho). 

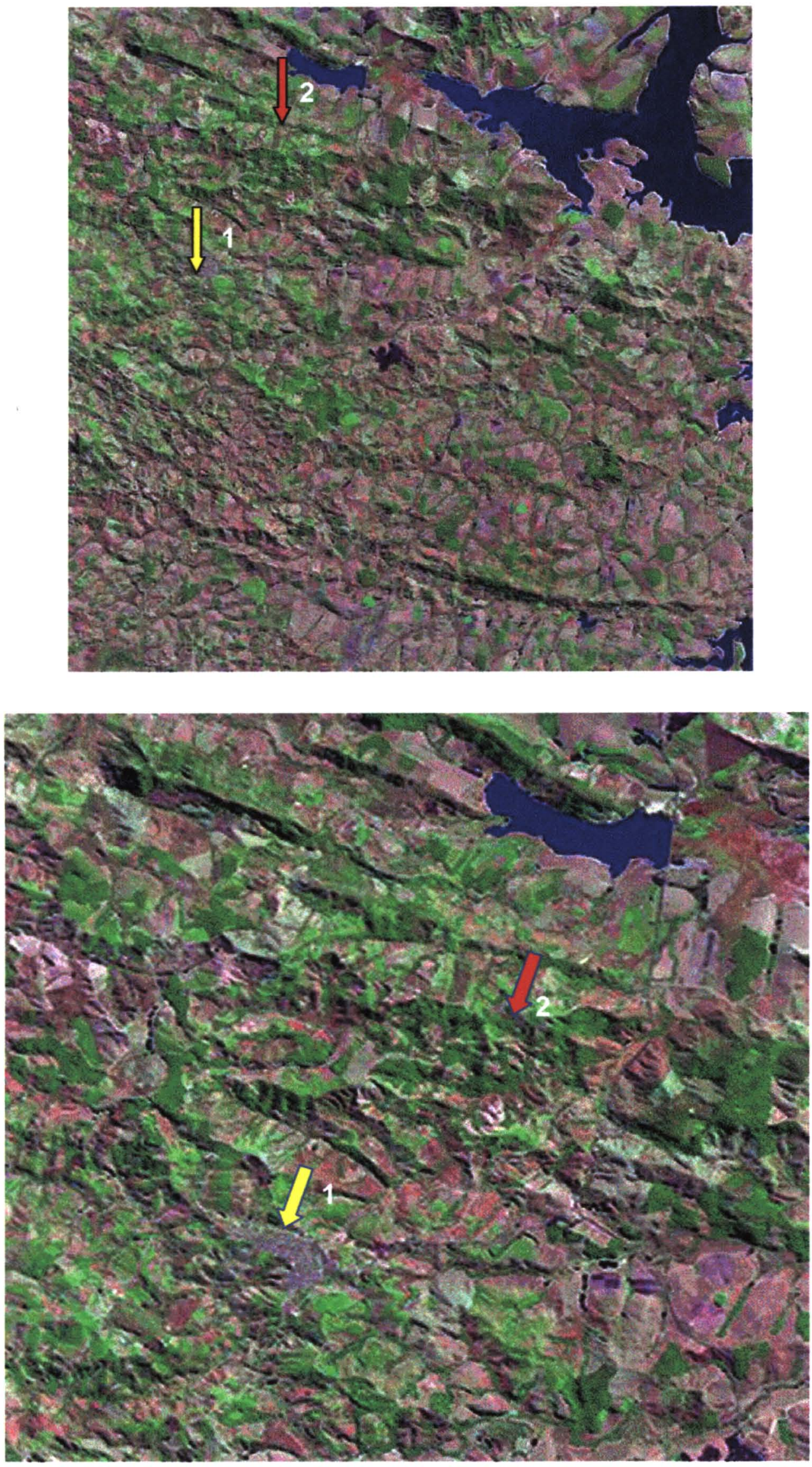

Fonte:Embrapa monitoramento por satelite 2000-2003

Anexo 03 - Foto de satélite localizando a sede do município de Conceição da Aparecida (setas 1, em amarelo) e o local de capturas (seta 2, em vermelho). 


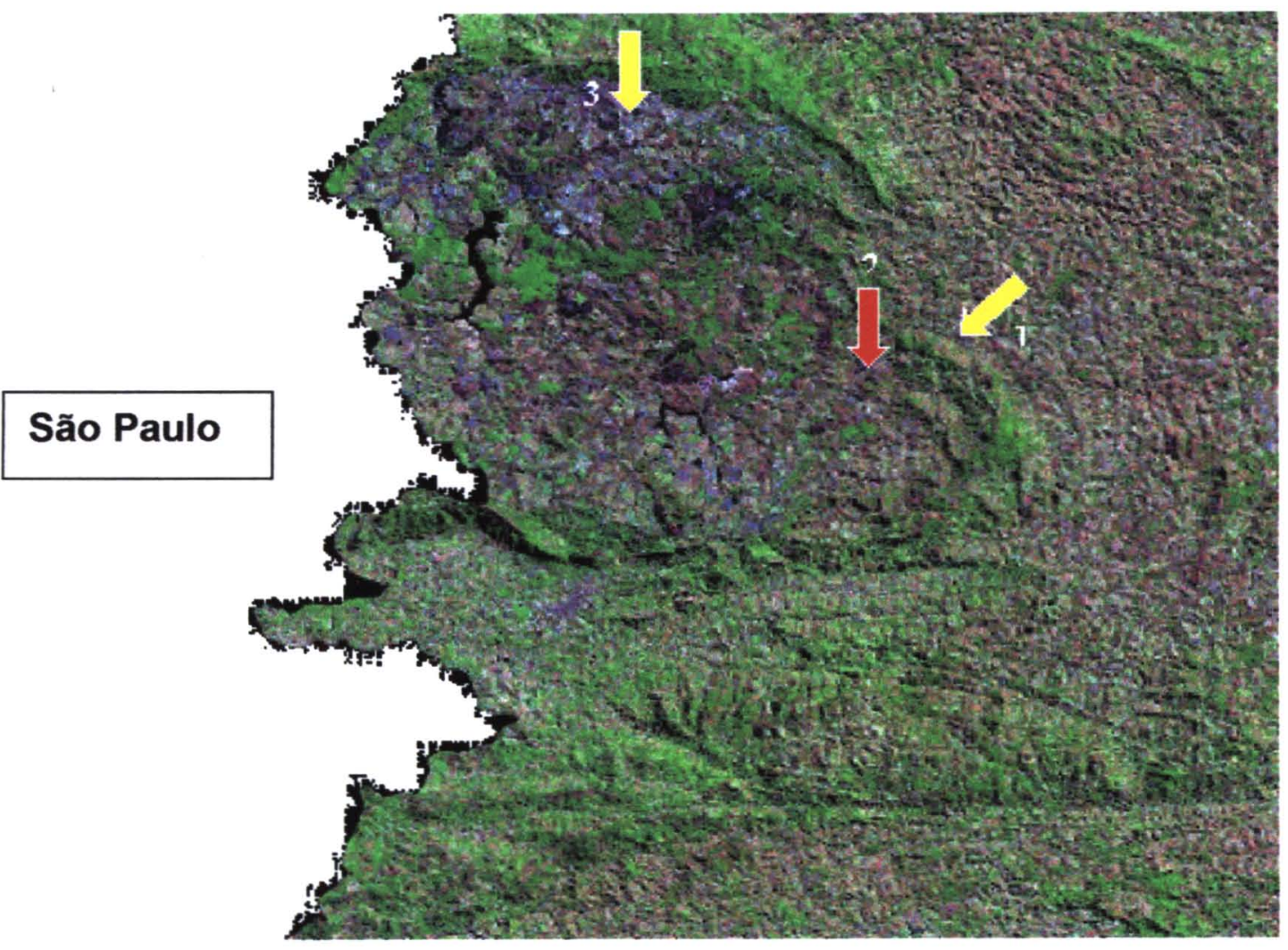

Fonte:Embrapa monitoramento por satélite 2000-2003

Anexo 04- Foto de satélite localizando a sede do município de Caldas (seta 1 , em amarelo), o local de capturas (seta 2 , em vermelho) e a sede do município de Poços de Caldas (seta 3, em amarelo). 


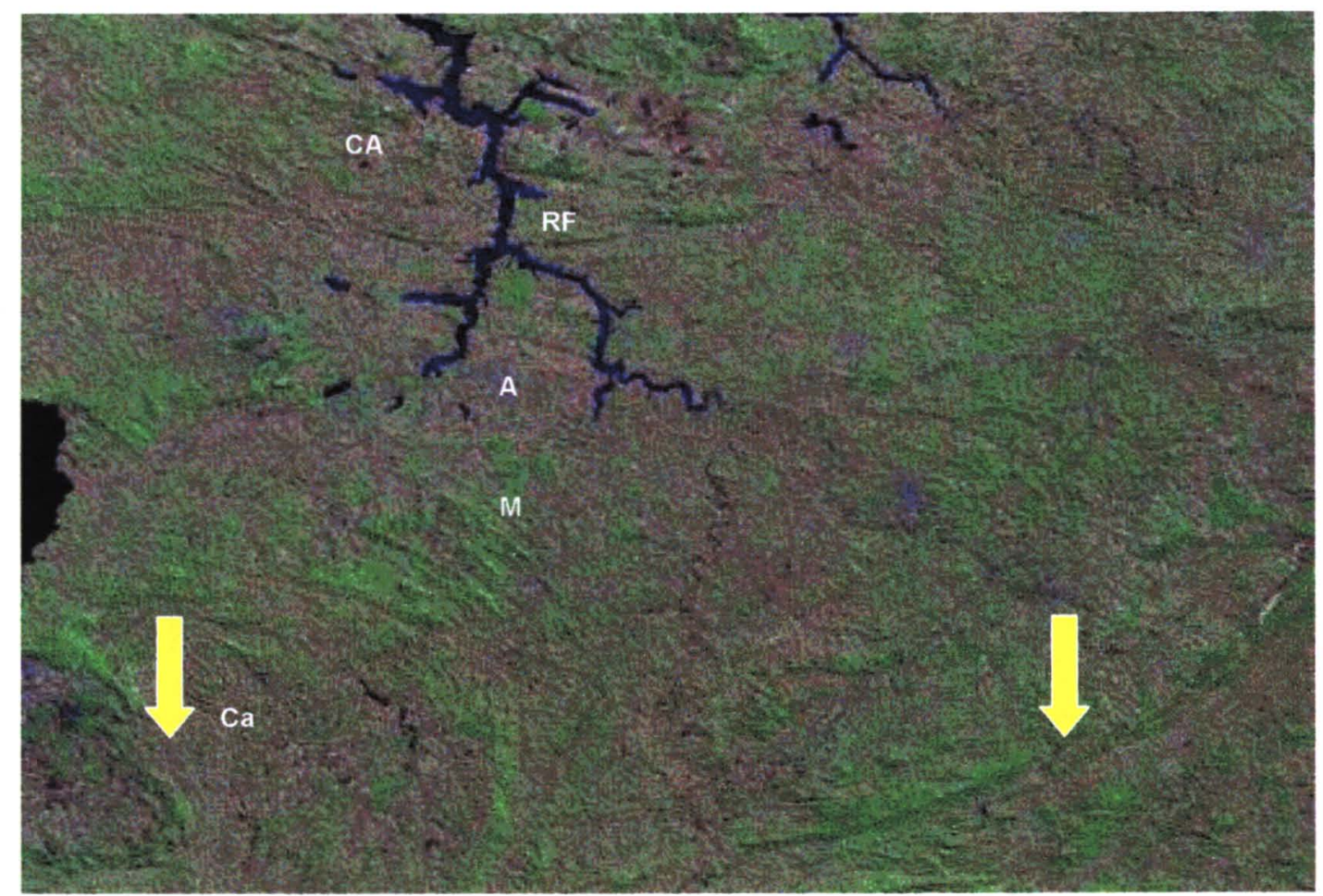

Fonte:Embrapa monitoramento por satelite 2000-2003

Anexo 05 - Foto de satélite localizando a Serra da Mantiqueira (setas em amarelo).

CA - Conceição da Aparecida; RF - Reservatório de Furnas;

A - Alfenas; $\mathrm{M}$ - Machado, $\mathrm{Ca}$ - Caldas. 

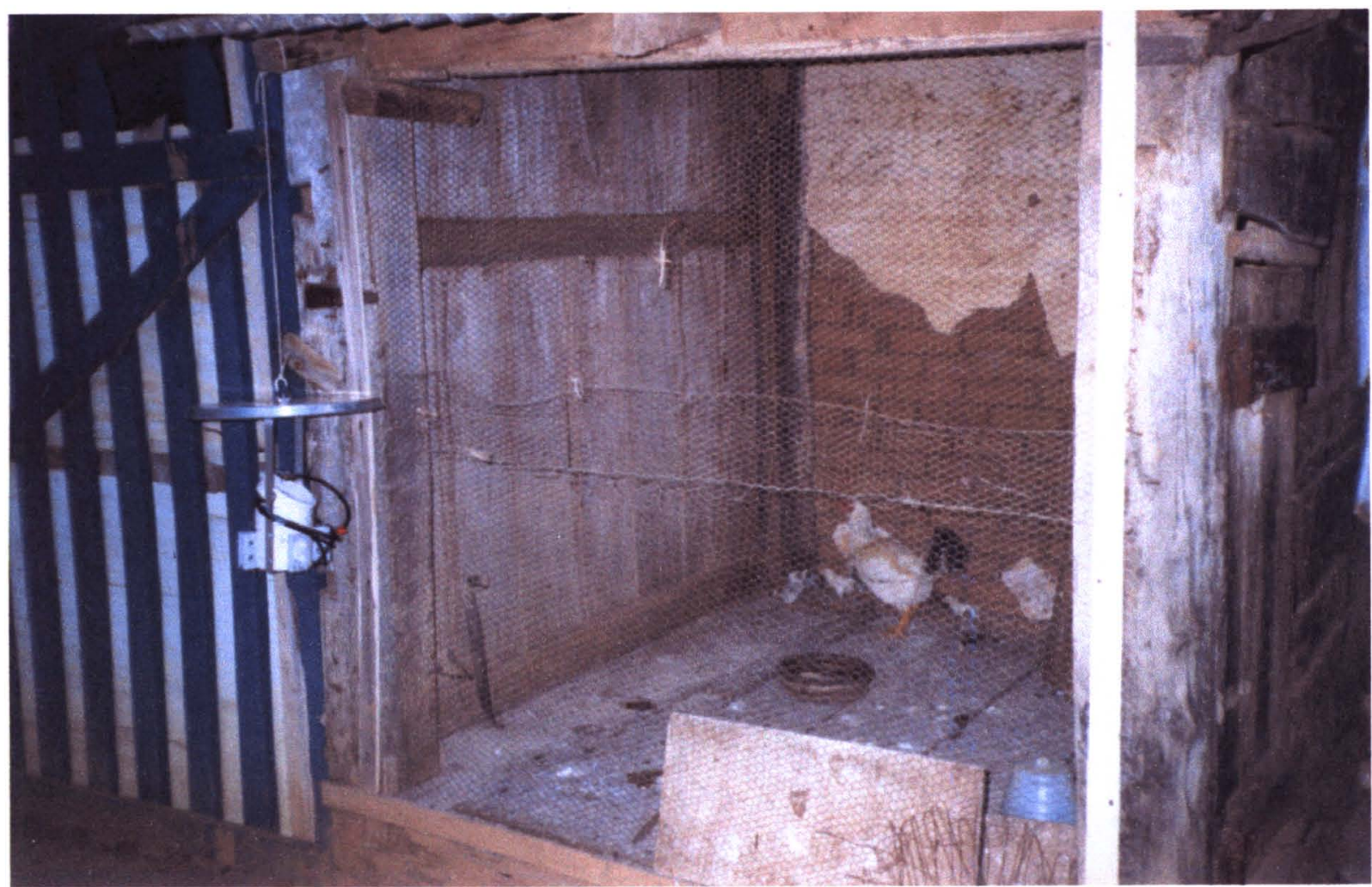

Autor: Carlos Frederico Loiola

Anexo 06 - Foto da armadilha automática luminosa tipo CDC.

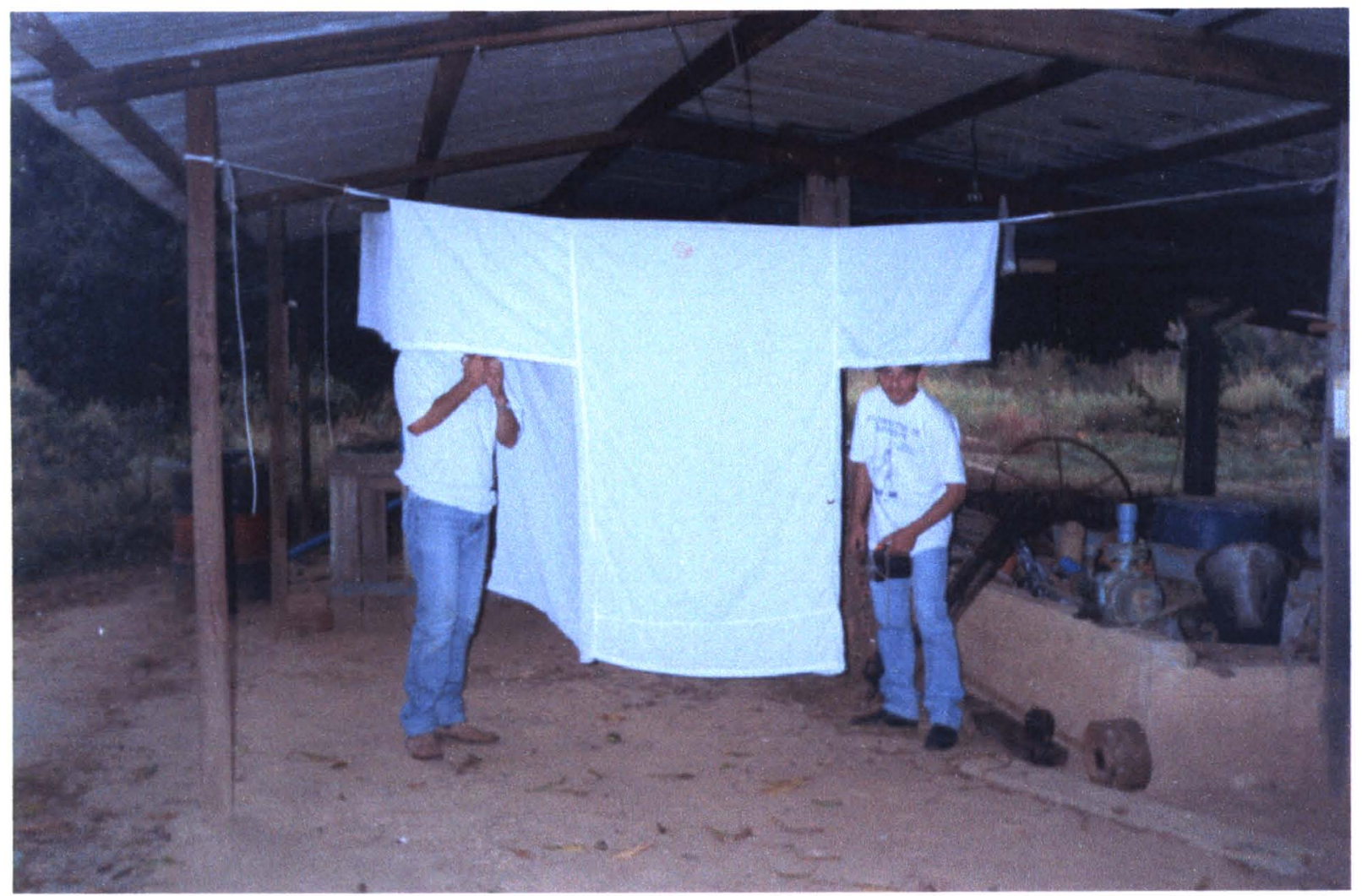

Autor: Carlos Frederico Loiola

Anexo 07 - Foto da Armadilha de Shannon 